\title{
Metabolic Syndrome Risk in Young Adults Attending West Virginia University
}

Amanda M. Dent

West Virginia University

Follow this and additional works at: https://researchrepository.wvu.edu/etd

\section{Recommended Citation}

Dent, Amanda M., "Metabolic Syndrome Risk in Young Adults Attending West Virginia University" (2012). Graduate Theses, Dissertations, and Problem Reports. 4846.

https://researchrepository.wvu.edu/etd/4846

This Thesis is protected by copyright and/or related rights. It has been brought to you by the The Research Repository @ WVU with permission from the rights-holder(s). You are free to use this Thesis in any way that is permitted by the copyright and related rights legislation that applies to your use. For other uses you must obtain permission from the rights-holder(s) directly, unless additional rights are indicated by a Creative Commons license in the record and/ or on the work itself. This Thesis has been accepted for inclusion in WVU Graduate Theses, Dissertations, and Problem Reports collection by an authorized administrator of The Research Repository @ WVU. For more information, please contact researchrepository@mail.wvu.edu. 
Metabolic Syndrome Risk in Young Adults Attending West Virginia University

Amanda M. Dent

Thesis submitted to the

Davis College of Agriculture, Natural Resources \& Design

at West Virginia University

in partial fulfillment of the requirements

for the degree of

Master of Science
in
Animal and Nutritional Sciences
Melissa Olfert, DrPH, MS, RD, LD, Chair
Kristen Matak, PhD
Colleen Harshbarger, MS
Department of Animal and Nutritional Sciences

Morgantown, West Virginia

2012

Keywords: Metabolic Syndrome; Young Adults; Appalachia; C - reactive protein Copyright 2012 Amanda M. Dent 


\section{ABSTRACT}

\section{Metabolic Syndrome Risk in Young Adults Attending West Virginia University Amanda M. Dent}

The prevalence of Metabolic Syndrome (MetS) is increasing throughout the United States across age groups. The purpose of this study was to collect descriptive baseline anthropometric and biochemical data to determine MetS prevalence in 18 to 24 year olds and to assess change in MetS risk after a 10 week web-based intervention. MetS was defined using the National Cholesterol Education Program's Third Adult Treatment Panel (NCEP ATP III) definition. Blood pressure, anthropometric and biochemical measures were obtained at baseline, post-intervention and 15 months. The overall prevalence of MetS at baseline was $15.1 \%(n=14)$. The prevalence of one or two components of MetS was $33.1 \%$ and $23.7 \%$, respectively. Significant differences between male and females subjects were observed for elevated waist circumference $(p=0.0055)$, elevated blood pressure $(p=0.0075)$ and impaired fasting blood glucose measures $(p=0.0345)$. Of all MetS components, fasting blood glucose ( $p$ $=0.0318$ ) measures exhibited the most notable decrease from baseline to post-intervention between the intervention and control group. Additional downward trends moving toward improvement were observed for several of the subjects in the intervention group exhibiting MetS risk from baseline to post-intervention, but this trend was not sustained at the 15 month followup. Due to the large percentage of individuals moving toward the onset of MetS, a more aggressive and specific behavior tailored intervention may have yielded better outcomes in this high risk population of subjects. Identification of MetS early in life is needed in order to reduce the onset of chronic disease. Therefore, implementing a screening process to identify at-risk young adults will help tailor more effective behavioral interventions. 


\section{ACKNOWLEDGEMENTS}

First and foremost, I would like to thank Dr. Melissa Olfert, for providing me with the opportunity to work as a graduate research assistant for the multi-state group project, titled Young Adults Eating \& Active for Health (YEAH). I would also like to thank her for her time, encouragement and expertise throughout the past two years.

Next, I would like to thank my additional committee members Dr. Kristen Matak and Ms. Colleen Harshbarger for their continued support and flexibility. I would also like to extend my appreciation to Dr. Matthew Gurka for his statistical advice and expertise. Lastly, I would like to thank Dr. Diana Vinh and Dr. Travis White for providing the Health Education Lab to complete our blood pressure, anthropometric and biochemical measures and their continued support of the YEAH Project.

I would also like to thank the students who participated as YEAH Project research team members during the 2011 and 2012 spring semesters. Your dedication, support and willingness to help contributed to the success of the YEAH Project. In closing, I would like to thank my family and close friends for their continued support and encouragement throughout the completion of my Master's Program. 


\section{TABLE OF CONTENTS}

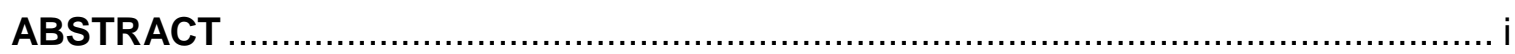

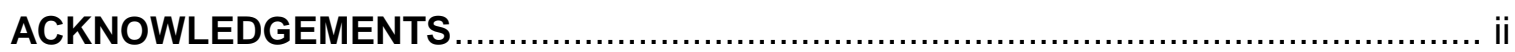

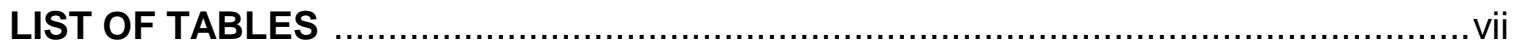

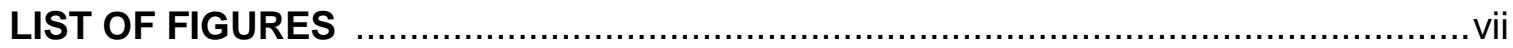

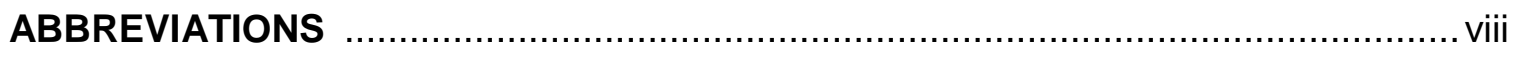

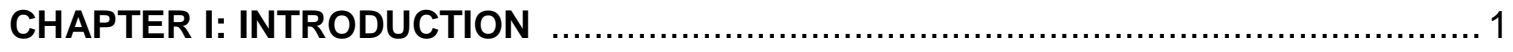

Scope of the Obesity Epidemic in Young Adults ………............................... 1

Metabolic Syndrome (MetS) ………........................................................ 1

Target Population Selection ………………………........................... 3

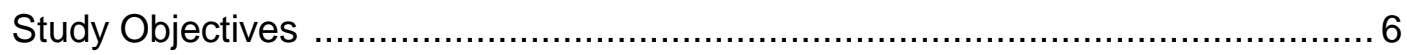

CHAPTER II: REVIEW OF LITERATURE

Transition of Adolescence into Young Adulthood ............................................. 7

Potential Health Risks in Young Adults .................................................... 8

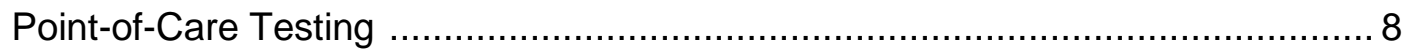

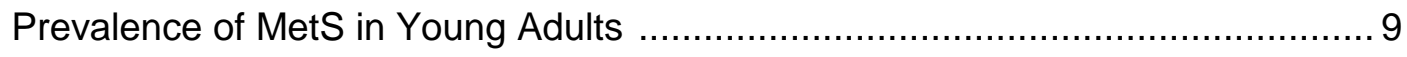

Inflammation and Risk of Chronic Disease ............................................... 13

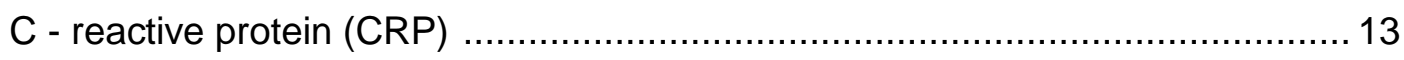

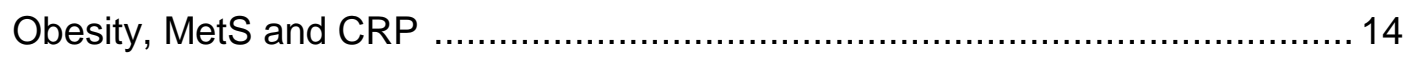

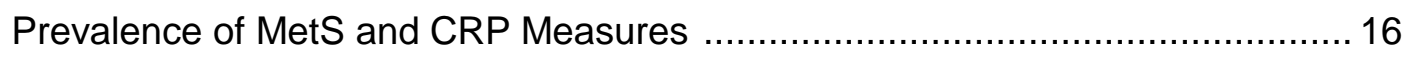

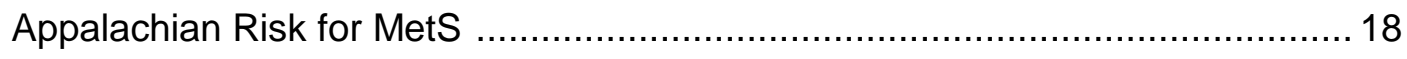

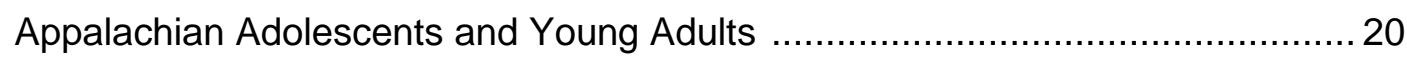

Web-based Interventions to Change Behavior ...............................................22

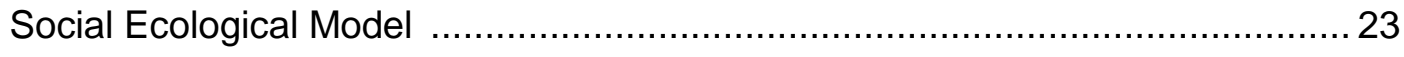

Community Based Participatory Research (CBPR) ………............................ 23

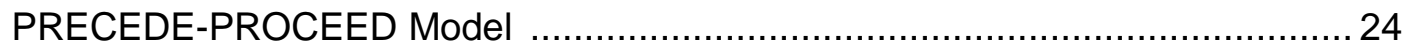




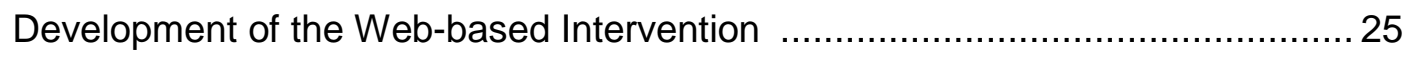

Web-Based Intervention Description ......................................................... 27

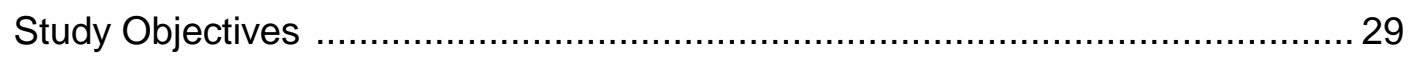

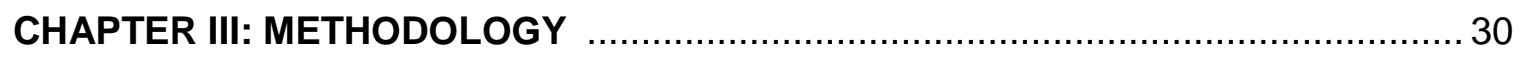

Community Based Steering Partnership …………..................................... 30

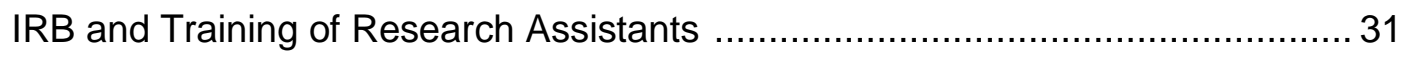

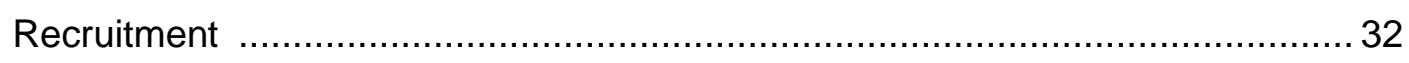

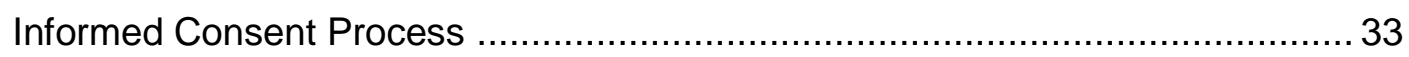

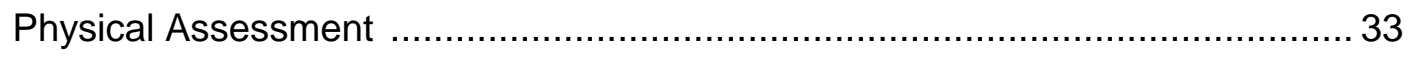

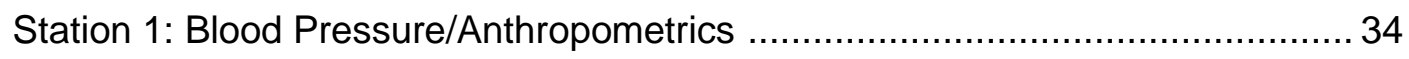

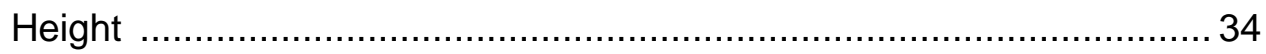

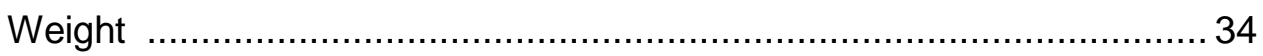

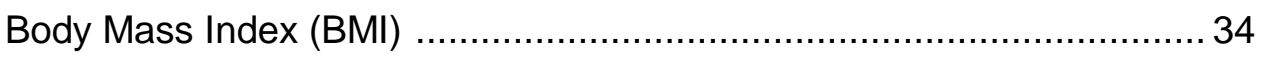

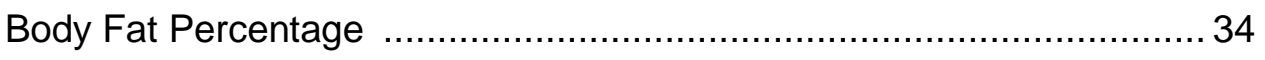

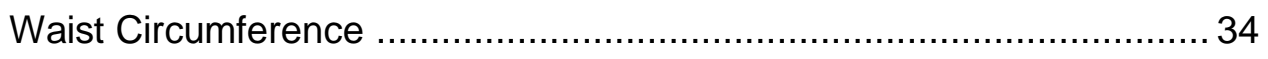

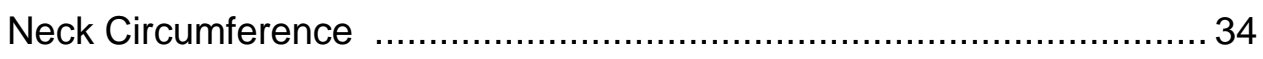

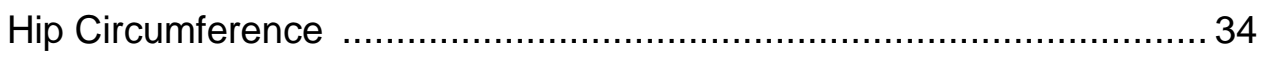

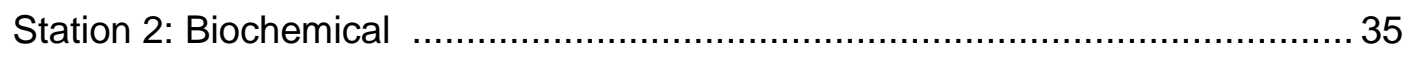

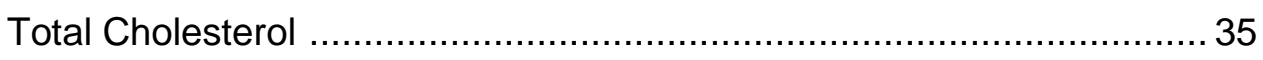

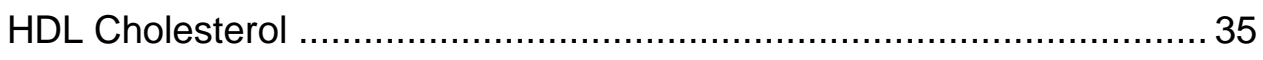

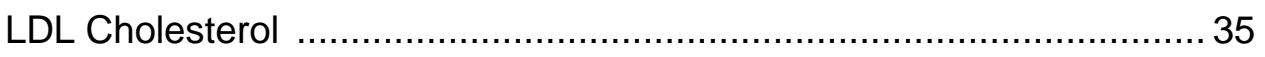

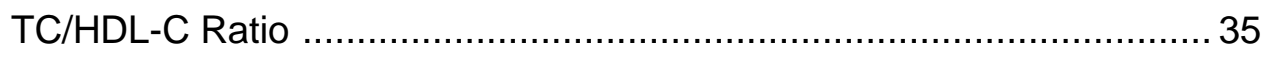

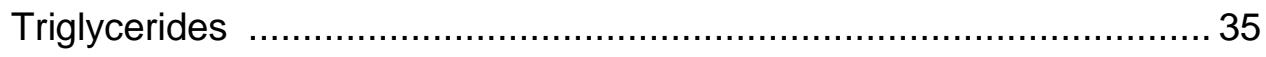

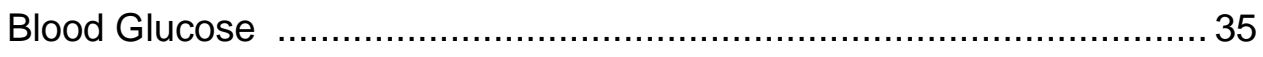

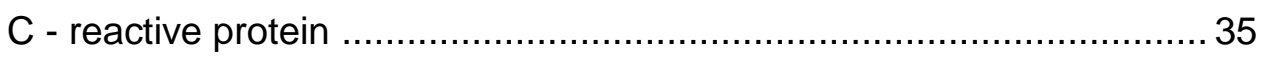

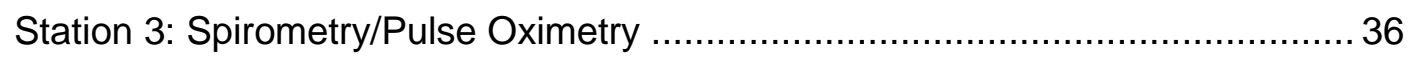




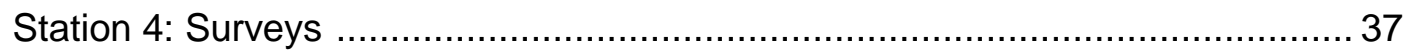

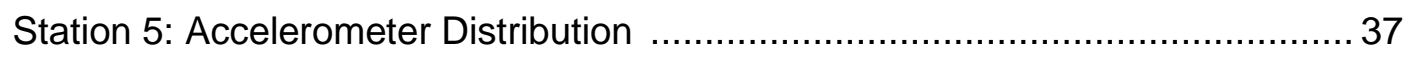

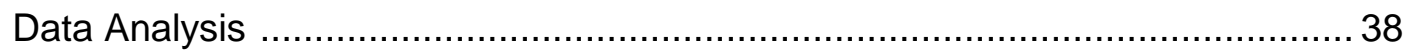

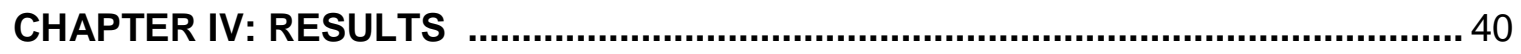

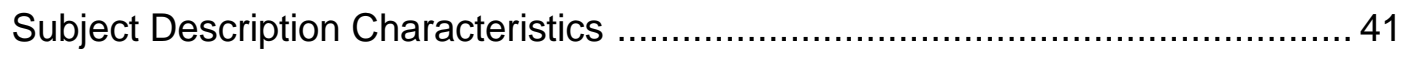

Baseline Anthropometric Measures by Sex ................................................ 41

Baseline Biochemical Measures by Sex ........................................................ 41

Biochemical and Anthropometric Measures by Region .................................. 42

Correlations for BMI, CRP and MetS Components ......................................... 43

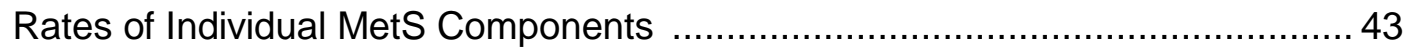

Frequency of MetS and Number of MetS Components …................................ 44

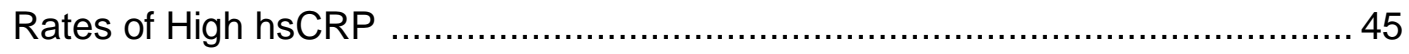

Anthropometric and Biochemical Changes from Baseline …............................ 47

Metabolic Risk at Baseline, Post-Intervention and Follow-Up ............................. 48

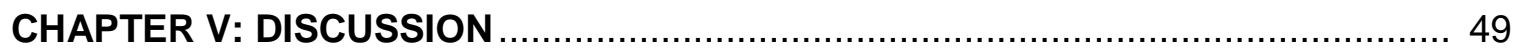

Prevalence of MetS and Risk Components .................................................... 49

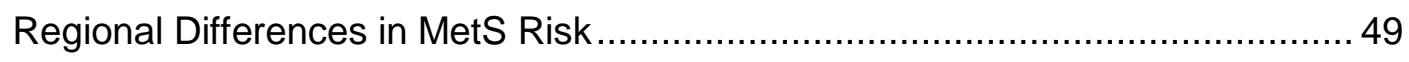

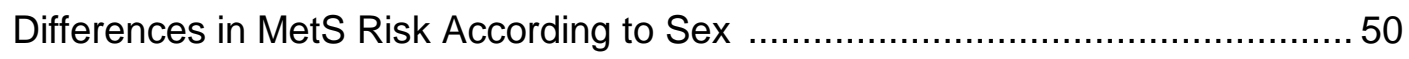

MetS Components and hsCRP Levels ...................................................... 52

Differences in hsCRP Levels According to Sex .............................................. 52

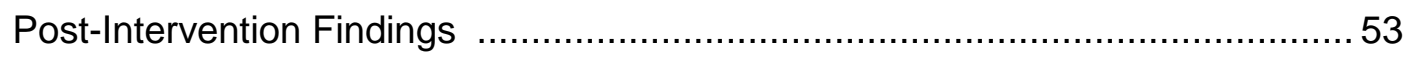

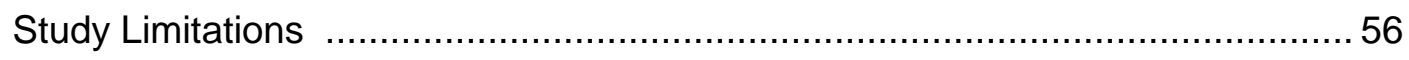

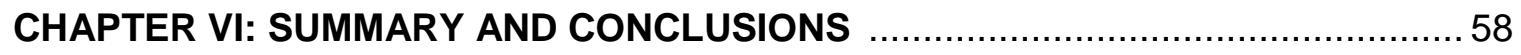

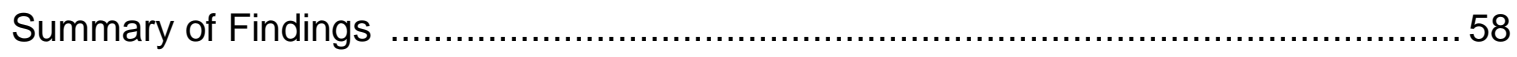

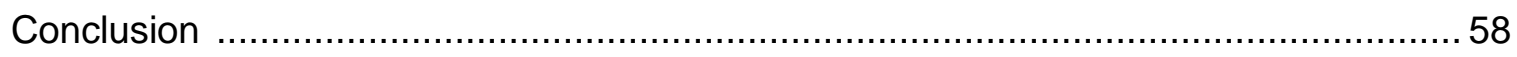

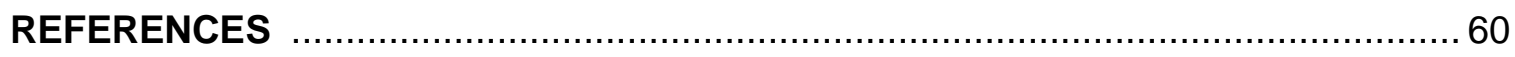




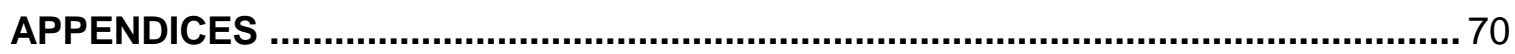

Appendix A: Boys 2 to 20 years BMI-for-age Percentile Chart ………..................... 71

Appendix B: Girls 2 to 20 years BMI-for-age Percentile Chart ………….................... 72

Appendix C: YEAH Project Screening “Staging” Questions ........................................ 73

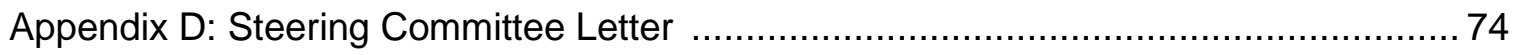

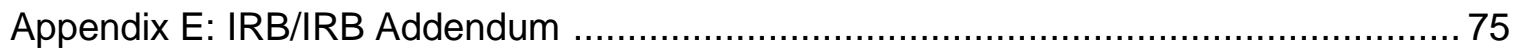

Appendix F: YEAH Project Recruitment Flyer ……………………………..... 79

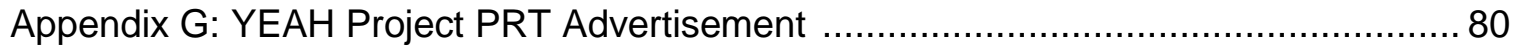

Appendix H: YEAH Project Website Informed Consent ............................................ 81

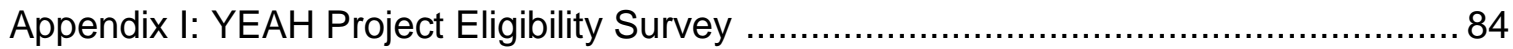

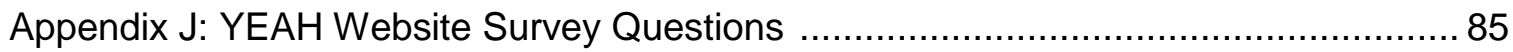

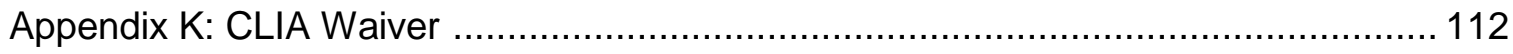

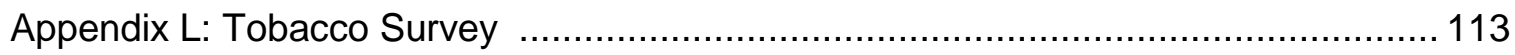

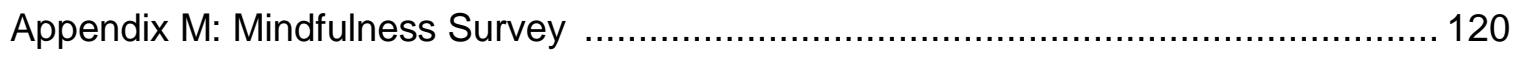

Appendix N: Post-Intervention Survey …………………................................ 121

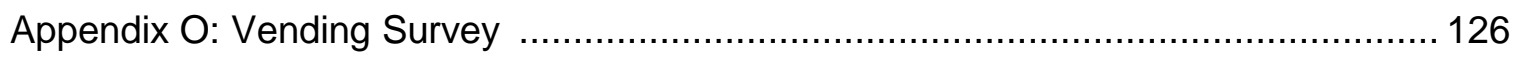

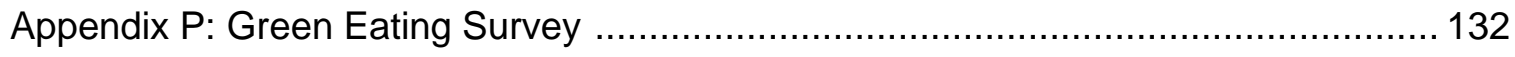

Appendix Q: Car Calories Survey ........................................................................ 142 


\section{LIST OF TABLES}

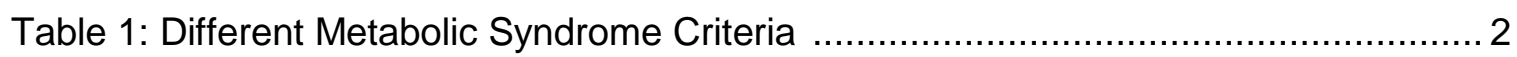

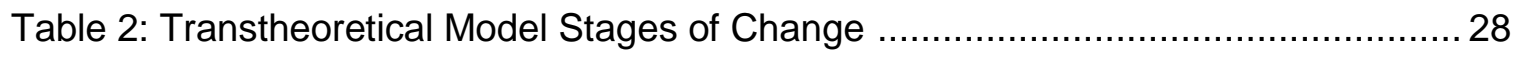

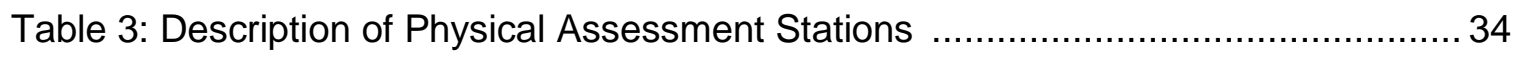

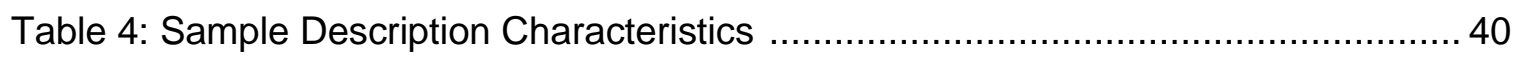

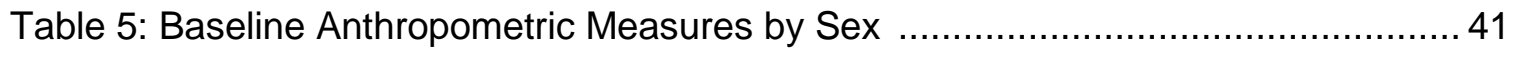

Table 6: Baseline Biochemical Characteristics by Sex ...................................... 42

Table 7: Biochemical and Anthropometric Measures by Region ............................... 42

Table 8: Correlations for BMI, CRP and MetS Components ................................ 43

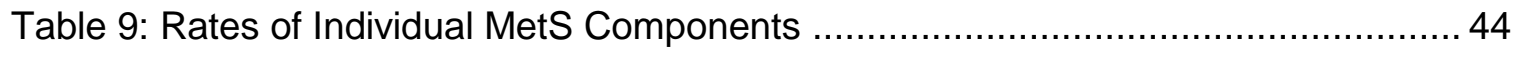

Table 10: Frequency of MetS and Number of MetS Components .......................... 45

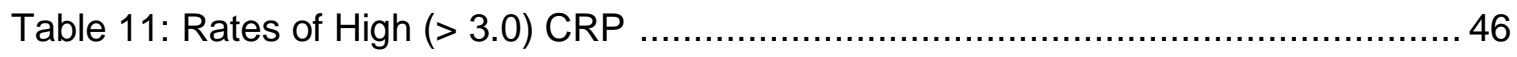

Table 12: Mixed Model Results Changes from Baseline ...................................... 47

Table 13: Mets Analysis for Baseline, 3 Months and 15 Months ............................. 48

Table 14: Prevalence of MetS at Baseline for Three Universities .............................50

\section{LIST OF FIGURES}

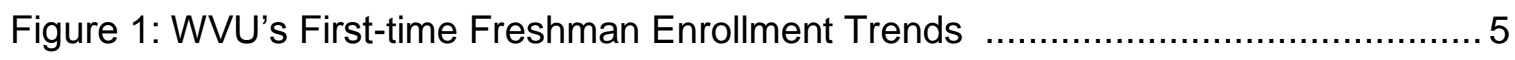

Figure 2: YEAH Project Webpage Portal ....................................................... 12

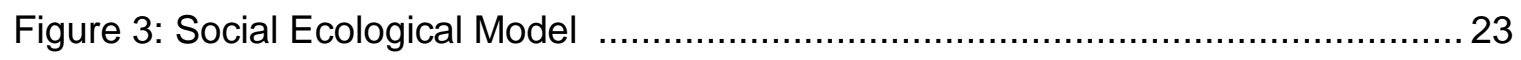

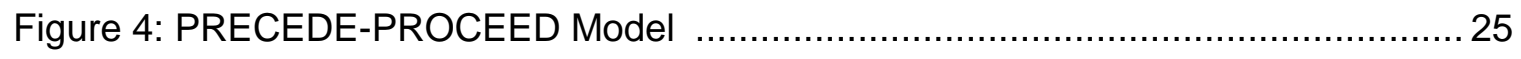

Figure 5: Development of the Web-based Intervention ..................................... 26

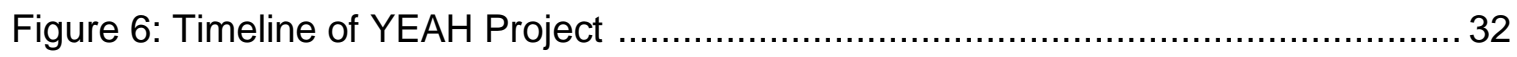




\section{LIST OF ABBREVIATIONS}

AHA - American Heart Association

$\mathrm{BP}$ - blood pressure

$\mathrm{BMI}$ - body mass index

CDC - Centers for Disease Control

CHD - Coronary Heart Disease

CLIA - Clinical Laboratory Improvement Amendments

CRP - c-reactive protein

CVD - Cardiovascular Disease

FBG - fasting blood glucose

FTF - first-time freshman

HDL-C - high-density lipoprotein cholesterol

hsCRP - highly sensitive c-reactive protein

IDF - International Diabetes Federation

IFG - impaired fasting glucose

IGT - impaired glucose tolerance

IL-6 - interleukin-6

$\mathrm{IR}$ - insulin resistance

IRB - Institutional Review Board

LDL-C - low-density lipoprotein cholesterol

MetS - Metabolic Syndrome

NCEP ATP III - Third National Cholesterol Education Program Adult Treatment Panel

NCHRBS- National College Health Risk Behavior Survey

NHANES - National Health \& Nutrition Examination Survey

OC - oral contraceptive

POC - Point-of-care 
T2DM - Type II Diabetes Mellitus

TNF- $\alpha$ - tumor necrosis factor- $\alpha$

TGs- triglycerides

US - United States

WHO - World Health Organization

WHR - waist-to-hip ratio

WV - West Virginia

WVU - West Virginia University

YEAH - Young Adults Eating \& Active for Health 


\section{CHAPTER I}

INTRODUCTION

\section{Scope of the Obesity Epidemic in Young Adults}

Young adults, ages 18 to 24 years, serve as an important, yet overlooked, age group for establishing long-term health behaviors. In the past 30 years, the prevalence of obesity among this particular age group has more than doubled (1). First year college students exhibit weight gain faster than the average adult, up to 11 times faster (2). This increase in weight subsequently increases the likelihood of developing Metabolic Syndrome (MetS) risk criteria (2, 3). Further, obesity rates have increased most rapidly among individuals aged18 to 29 years as well as those with some college education (3-6). As many as 30 to $35 \%$ of college students are reported to be overweight or obese (3-5). Obesity, particularly abdominal obesity, is directly related to the development of MetS and cardiovascular risk $(7,8)$.

\section{Metabolic Syndrome (MetS)}

The Third Report of the National Cholesterol Education Program Adult Treatment Panel (NCEP ATP-III) defines MetS in terms of five risk factors: 1) abdominal obesity measured by waist circumference $(\mathrm{WC})($ men $>102 \mathrm{~cm}$, women $>88 \mathrm{~cm}), 2)$ increased triglycerides $(\mathrm{TGs})(\geq$ $150 \mathrm{mg} / \mathrm{dL}$ ), 3) low high-density lipoprotein cholesterol (HDL-C) (men < 40 mg/dL, women < 50 $\mathrm{mg} / \mathrm{dL})$, 4) high blood pressure (BP) ( $\geq 130 / 85 \mathrm{mmHg}$ ) and 5) impaired fasting blood glucose (FBG) ( $\geq 100 \mathrm{mg} / \mathrm{dL})(9)$. Individuals presenting three or more of these risk factors are diagnosed as having MetS, which contributes to the development of chronic diseases such as cardiovascular disease (CVD) and type II diabetes mellitus (T2DM) (2, 9, 10). The NCEP ATP III views CVD as well as coronary heart disease $(\mathrm{CHD})$ as the primary clinical outcome of MetS (11). 
Over the past decade, several different sets of criteria have been proposed for the diagnosis of MetS (7). According to the NCEP ATP III, MetS becomes apparent when individuals exhibit a combination of any three of the five defined risk criteria; however, the World Health Organization (WHO) and the International Diabetes Federation (IDF) take a different approach (Table 1). Both organizations require an essential risk criterion to be met alongside two additional components of MetS. The WHO requires evidence of impaired glucose tolerance (IGT), impaired fasting glucose (IFG) or insulin resistance (IR) (12), whereas, the IDF requires abdominal obesity assessed by increased WC (men $\geq 94 \mathrm{~cm}$, women $\geq 90 \mathrm{~cm})(12)$. In comparison to the WHO, the NCEP ATP III and IDF definitions include WC as a risk criterion for MetS, which places greater emphasis on excess adiposity located in the abdominal region (12). The WHO assesses excess adiposity by either body mass index (BMI) or waist-to-hip ratio (WHR) (12).

Overall, the NCEP ATP III's definition of MetS appears to be the most clinically applicable because it is based on common clinical measures (Table 1). The NCEP ATP III's definition of MetS does not place emphasis on a single risk factor; instead, the definition recognizes MetS consists of multiple, interrelated risk factors (7). In 2005, Grundy et al. reported the NCEP ATP III's diagnostic criteria should be maintained throughout clinical practice and research with only minor modifications (7). Therefore, this definition of MetS is used most often in clinical and research settings (7).

Table 1: Different MetS Criteria

\begin{tabular}{|l|c|c|c|}
\hline & WHO & NCEP & IDF \\
\hline Definition & $\begin{array}{c}\text { Diabetes, IFG, IGT or IR } \\
\text { plus 2 or more of the } \\
\text { following: }\end{array}$ & $\begin{array}{c}\text { Exhibiting any } 3 \text { of the } \\
\text { following : }\end{array}$ & $\begin{array}{c}\text { Central obesity (WC) } \\
\text { plus 2 or more of the } \\
\text { following: }\end{array}$ \\
\hline $\begin{array}{l}\text { Fasting Blood } \\
\text { Glucose }\end{array}$ & $\geq 110 \mathrm{mg} / \mathrm{dL}$ & $\geq 100 \mathrm{mg} / \mathrm{dL}$ & $\geq 100 \mathrm{mg} / \mathrm{dL}$ \\
\hline $\begin{array}{c}\text { Adiposity } \\
\text { Males: }>0.90\end{array}$ & $\begin{array}{c}\text { WC } \\
\text { Females: }>0.85 \\
\text { BMl } \geq 30\end{array}$ & Females: $>88 \mathrm{~cm}$ & $\begin{array}{c}\text { Males: } \geq 102 \mathrm{~cm} \\
\text { Females: } \geq 88 \mathrm{~cm}\end{array}$ \\
\hline Triglycerides & $\geq 150 \mathrm{mg} / \mathrm{dL}$ & $\geq 150 \mathrm{mg} / \mathrm{dL}$ & $\geq 150 \mathrm{mg} / \mathrm{dL}$ \\
\hline
\end{tabular}




\begin{tabular}{|l|c|c|c|}
\hline HDL Cholesterol & $\begin{array}{c}\text { Males: }<40 \mathrm{mg} / \mathrm{dL} \\
\text { Females }:<50 \mathrm{mg} / \mathrm{dL}\end{array}$ & $\begin{array}{c}\text { Males: }<40 \mathrm{mg} / \mathrm{dL} \\
\text { Females }:<50 \mathrm{mg} / \mathrm{dL}\end{array}$ & $\begin{array}{c}\text { Males: }<40 \mathrm{mg} / \mathrm{dL} \\
\text { Females: }<50 \mathrm{mg} / \mathrm{dL}\end{array}$ \\
\hline Blood Pressure & $\geq 140 / 90 \mathrm{mmHg}$ & $\geq 130 / 85 \mathrm{mmHg}$ & $\geq 130 / 85 \mathrm{mmHg}$ \\
\hline
\end{tabular}

Many researchers have identified obesity as the leading risk factor for developing MetS(13). IR generally rises with increasing body fat, yet insulin sensitivities can exist at any given level of body fat (11). Therefore, it is common for most individuals with MetS to also exhibit IR, which can lead to the development of T2DM (11). When T2DM becomes clinically apparent, the risk of CVD increases significantly (11). Individuals exhibiting MetS are estimated to be twice as likely to develop CVD and five times more likely to develop T2DM $(3,7)$. Researchers have also linked pro-inflammatory states to the onset of IR $(14,15)$ as well as the development of atherosclerosis (16-19). C-reactive protein (CRP), a biomarker of inflammation, has recently emerged as an important predictor of MetS, T2DM as well as CVD (10).

Few studies have investigated young adults in terms of chronic disease risk, including MetS and other disease states associated with this condition $(2,3)$, although CHD is the second leading cause of death in young adults, ages 18 to 29 years (2). There is evidence to suggest CRP measures are associated with metabolic risk factors as well as adiposity in children, adolescents and adults. Health care professionals and researchers should consider measuring CRP levels alongside traditional MetS risk criteria in young adults, ages 18 to 24 , in order to aid in early detection or identification of MetS risk and prevention of additional comorbities later in life.

\section{Target Population Selection}

The 2010 Census Bureau estimates around 23 million students are currently attending college or graduate school in the United States (US) (20). Of those 23 million, roughly 10 million 18 to 24 year olds are enrolled in public college or graduate school (20). For many college students, the transition from living at home to a college environment provides freedom from 
parental supervision. However, such freedom often presents additional responsibilities (21). Student health and lifestyle behaviors become influenced by new social, academic, financial and personal stresses associated with the college environment (21). During this time, young adults should be educated on the value of engaging in healthy lifestyle behaviors to reduce their risk of chronic disease later in life (21). Implementing behavioral interventions in the college setting could potentially reduce our nation's ongoing struggle to overcome obesity, which is estimated to affect $51 \%$ of the population by 2030 (22).

According to the Centers for Disease Control (CDC), the prevalence of obesity has reached epidemic proportions within the Appalachian region (23). The Appalachian region extends from Northeastern Mississippi to Southern New York (24), with its epicenter lying entirely within the state of West Virginia (WV) (25). Researchers have estimated $50 \%$ of the adults and adolescents residing in WV are categorized as obese, based upon their BMI measures (23). In 2005, a statewide survey reported a high proportion of overweight teens (19\%), with more overweight males (25\%) than females (15\%), with an additional $16 \%$ classified as at risk for overweight (26). In addition, researchers have indicated the prevalence of obesity across the Appalachian region is substantially higher in comparison to other regions in the US (27).

In 2010 , there were a total of 22,303 undergraduate students ( $55 \%$ male $(n=12,228)$ and $45 \%$ female $(n=10,075))$ attending West Virginia University (WVU) (28). The student body was primarily Caucasian (87\%), followed by African American (3\%), Hispanic (3\%), Asian (1\%), two or more races (2\%), non-resident aliens (2\%) and those with unknown race/ethnicity (1\%)(28). The undergraduate enrollment during 2010 consisted of more out-of-state residents in comparison in-state residents (54\% vs. $45 \%$ ) (28), perhaps due to the lower tuition costs for outof-state students. The Assistant Director of Admissions \& Recruitment at WVU reported approximately $23 \%(n=5,034)$ of those students were first-time freshman (FTF). The 
enrollment trends for FTF at WVU have steadily increased since 1995 (28) (Figure 1), which is consistent with the national trend for higher education enrollment (20). Therefore, more opportunities to target obesity prevention efforts in young adults, ages 18 to 24 , have presented in the past two decades.

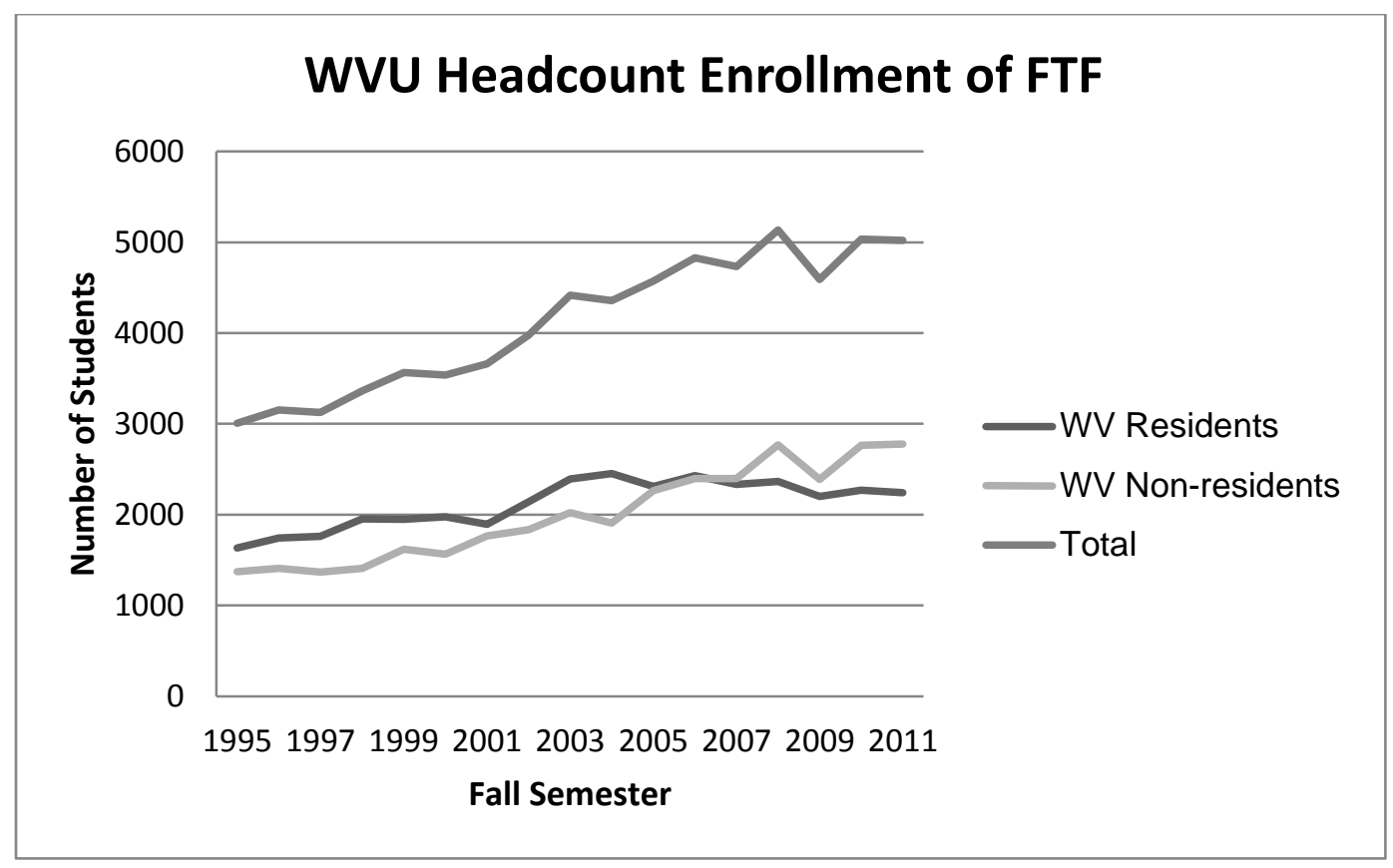

Figure 1: WVU's First-time Freshman Enrollment Trends 


\section{Study Objectives}

The primary objective of this study was to recruit 18 to 24 year olds attending WVU for the YEAH Project while also collecting descriptive baseline anthropometric (including height, weight, BMI, body fat percentage, waist circumference and neck circumference) and biochemical data (including total cholesterol, HDL cholesterol, LDL cholesterol, triglycerides, fasting blood glucose, hemoglobin A1c, highly sensitive c-reactive protein, hemoglobin and hematocrit measures) to describe of the chronic disease status of this specific population.

The secondary objective was to assess change in MetS risk, according to the National Cholesterol Education Program's definition (including waist circumference, HDL cholesterol, triglycerides, fasting blood glucose and blood pressure risk criteria), following a 10 week webbased behavioral change intervention which included weekly emails that addressed the participants specific goals they had identified upon beginning the program based on the stage of change they were progressing through and again at the 15 month follow-up visit. 


\section{CHAPTER II}

\section{REVIEW OF LITERATURE}

\section{Transition of Adolescence into Young Adulthood}

Young adulthood is marked by important transitions such as leaving home and increasing autonomy (1). During this time, it is important for young people to adopt lasting health behavior patterns (1) and stress management skills (29). Psychological stress can contribute to unhealthy lifestyle behaviors such as decreased fruit and vegetable intake, smoking, and alcohol consumption (29). Several factors may affect the dietary patterns of college students including: financial problems, meal skipping, fad diets, greater consumption of snack foods, and avoidance of certain types of nutritious foods or food groups (30, 31). According to Dodd et al., many college students consume excessive amounts of alcohol (29), which contributes to increased energy intake. Further, research indicates 20 to $68 \%$ of college students do not meet the American College of Sports Medicine physical activity recommendations (32). Therefore, the increasing prevalence of obesity observed throughout young adulthood appears to be attributed to poor dietary habits, increased energy intake, excessive alcohol consumption, decreased physical activity and increased sedentary behavior.

Colleges and universities serve as important settings for the surveillance, prevention, and intervention of potential health risks in young adults, ages 18 to 24 (33). Although many college campuses provide students with student health and/or wellness programs, the collegiate lifestyle continues to be characterized by negative health behaviors such as poor diet quality, increased alcohol consumption, sedentary behaviors, and unhealthy weight gain. During the first 3 to 4 months of college, students gain anywhere from 1.5 to 6.8 pounds, with the amount of overweight or obese students often doubling by the end of the semester (1). Researchers estimate approximately $70 \%$ of weight gain occurs during students' first two years and begins to 
plateau throughout the rest of their college career (1). Therefore, targeting excessive weight gain during freshman and sophomore years may have a greater impact on weight status.

\section{Potential Health Risk in Young Adults}

The transition between adolescence and young adulthood serves as a period of increased risk for excess weight gain $(34,35)$ due to negative health behaviors. The most recent National Health and Nutrition Examination Survey (NHANES) reported 33.2\% of men and $31.9 \%$ of women, ages 20 to 39 years, were classified as obese according to their body mass index (BMI) (36). Young adults who are classified as obese are at increased risk of remaining obese throughout adulthood (32). In addition, obesity has been identified as one of the most important underlying risk factors for MetS (7). Targeting obesity prevention efforts earlier in life could be particularly beneficial in reducing our nation's increased incidence of obesity and MetS. Recently, the Young Adults Eating \& Active for Health (YEAH) Project, targeting excess weight gain among young adults (18 to 24 years), was implemented across 14 different states. The findings from this project will help guide future obesity prevention efforts among this particular age group.

\section{Point-of-Care Testing}

A number of researchers have identified MetS as a precursor for $\operatorname{CHD}(2,10,11)$, which is the leading cause of death among US adults (37). Although hyperlipidemia has become a well-established risk factor for CHD, researchers estimate only $50 \%$ of the general population has their cholesterol levels checked (37). The NCEP ATP III recommends screening for abnormal lipid values at the age of 20 (2). Therefore, incorporating point-of-care (POC) devices, such as the Cholestech LDX, in a screening process for young adults could aid in early detection of hyperlipidemia (37). The Cholestech device requires knowledge of basic laboratory skills and is capable of reporting TC, HDL-C, LDL-C, TGs, FBG and alanine aminotransferase 
(37). In addition, hsCRP test cassettes have recently become available for this device (38).

Elevated levels of CRP have been associated with increased risk of CVD, even in the absence of hyperlipidemia or other related risk factors (38). In the future, screening for chronic disease risk in all age groups may be simplified by the use of POC devices.

\section{Prevalence of MetS in Young Adults}

In 2004 , a study done by Huang et al. reported $27 \%$ of the college students ( $n=163$, ages 18-24) at the University of Kansas exhibited at least one component of MetS (5). The most prevalent of the MetS risk components was low HDL-C (13.5\%) (5). The frequencies of other risk components were as follows: impaired FBG (4.3\%) increased TGs (2.5\%), increased WC (1.8\%) and high BP (1.2\%) (5). Overweight students (BMI $\geq 25 \mathrm{~kg} / \mathrm{m}^{2}$ ) were 2.9 times more likely to exhibit least one component of MetS in comparison to normal weight students (BMI $18.5-24.9 \mathrm{~kg} / \mathrm{m}^{2}$ ) (5). The results of this study strengthen evidence of metabolic abnormalities in overweight young adults as well as the prevalence of MetS risk criteria in this age group.

A later study also conducted at the University of Kansas by Huang et al. in 2007 revealed similar findings with a larger sample size $(n=300,103$ males $(44 \%)$ and 198 females (66\%), ages 18-24) (4). Based on the NCEP ATP III definition of MetS, 33\% $(n=99)$ of the subjects exhibited at least one component, whereas, $5.7 \%(n=17)$ displayed two components of MetS (4). Leading rates of MetS risk components included: low HDL-C (24.3\%), impaired FBG (9.0\%) and increased TGs (9.0\%) (4). Male subjects were more likely to exhibit MetS risk criteria than female subjects. This was likely due to the findings showing male subjects were more likely to exhibit a BMI $\geq 30 \mathrm{~kg} / \mathrm{m}^{2}$, increased BP, and increased TGs $(p<0.01)$ after adjustments were made for age, ethnicity and smoking status (4). Males also displayed a higher prevalence of obesity in comparison to females using the NCEP ATP III WC measures $(2.9 \%$ vs. $2.5 \%$ ) (4). 
The studies done by Huang et al. had some limitations. The use of volunteer samples may have only captured students with specific traits rather than a sample representative of the entire student population. Further, the samples included mostly white students and cannot be generalized to other ethnic groups. For future research, larger population-based studies with diverse populations are needed. However, the study results provide evidence to support the prevalence of MetS risk criteria within this particular age group, especially for those who are overweight or obese.

Another study conducted by Keown et al. reported $43 \%$ of students ( $n=21$, ages $18-24$ ) at a southeastern university had at least one component of MetS, whereas, $14.3 \%$ of the sample exhibited two components (3). The sample size was modest; yet, it is important to note the same clinician performed each of the assessments leading to decreased variability (3). Results showed $52 \%$ (4 males, 7 females) of the subjects had a BMI $\geq 24.9 \mathrm{~kg} / \mathrm{m}^{2}$, categorizing them as overweight (3). Of the students who were overweight (BMI $25-29.9 \mathrm{~kg} / \mathrm{m}^{2}$ ) or obese $\left(\mathrm{BMI} \geq 30 \mathrm{~kg} / \mathrm{m}^{2}\right), 81.5 \%$ had at least one component of MetS (3). However, $51 \%$ of those exhibiting a normal BMI (BMI $18.5-24.9 \mathrm{~kg} / \mathrm{m}^{2}$ ) also had at least one component of MetS (3). The results of this study strengthen evidence of metabolic abnormalities in overweight and obese young adults as well as the prevalence of MetS in this age group, regardless of weight status. However, the uneven gender distribution weakens the study findings.

A recent study by Fernandes et al. in 2009, found $28 \%$ of students ( $n=189,61$ males (32.3\%) and 128 females (67.7\%), ages 18-24) at the University of Rhode Island exhibited at least one risk component of MetS, whereas, 7.4\% exhibited two risk components of MetS (2). Overall, $3.7 \%$ of the sample presented with three or more risk components, indicative of MetS (2). This study also revealed obese $\left(B M I \geq 30 \mathrm{~kg} / \mathrm{m}^{2}\right)$ and overweight (BMI $\left.25-29.99 \mathrm{~kg} / \mathrm{m}^{2}\right)$ subjects were more likely to exhibit three or more risk components than under $\left(<18.5 \mathrm{~kg} / \mathrm{m}^{2}\right)$ or normal weight $\left(18.5-24.9 \mathrm{~kg} / \mathrm{m}^{2}\right)$ subjects (2). There are limitations to using BMI as an 
adiposity measure, which will be discussed. This sample also included a (2:1) ratio in terms of sex (2). There were twice as many female subjects in comparison to males (2). The uneven sex distribution weakens the study findings. However, the results of this study strengthen evidence of metabolic abnormalities seen throughout overweight or obese young adults. In addition, the results of this study indicate MetS is present within this particular age group.

The latest study conducted by Morrell et al. reported $77.2 \%$ of males and $53.8 \%$ of females ( $n=2,103$, ages 18-24) at the University of New Hampshire exhibited at least one component of MetS (39). Overall, MetS was present in $9.9 \%$ of males and $3.0 \%$ females (39). Low HDL-C and elevated BP was the most common individual MetS criteria observed in this sample (39). Male and female subjects with BMls $\geq 30 \mathrm{~kg} / \mathrm{m}^{2}$ exhibited significantly more MetS criteria than those who's BMls were categorized as overweight $\left(25-29.9 \mathrm{~kg} / \mathrm{m}^{2}\right)$ or normal $\left(18.5-24.9 \mathrm{~kg} / \mathrm{m}^{2}\right)(39)$. In addition, the overweight males and females had significantly more MetS criteria than the normal weight individuals (39). The results of this study strengthen evidence of metabolic abnormalities in overweight and obese young adults as well as the prevalence of MetS in this age group. However, the study outcomes should be interpreted with caution due to the uneven sex distribution (39). Since the prevalence of MetS has been demonstrated in university settings across different regions of the US (i.e. mid-west, southeast, and northeast), researchers should consider screening CRP levels throughout young adulthood to aid in early detection of chronic disease risk.

In 2010, the Young Adults Eating \& Active for Health (YEAH) Project was implemented throughout 13 different universities and one job core site. Each state was encouraged to recruit 186 participants. The YEAH Project included the development of a 10 week web-based intervention designed to prevent excessive weight gain among 18 to 24 year olds. Each subject was staged at the beginning of the study for their readiness to make behavioral changes regarding fruit and vegetable intake, physical activity and stress management. The intervention 
group subjects were encouraged to visit the web portal page (Figure 2) in order to complete web-based, mini-module activities with the option to set a weekly goal to obtain one or all three behaviors on a weekly basis. As the participant progressed through the weeks the stage would continue to be appropriately matched with the progress they were demonstrating. The primary outcome measure was body weight $(\mathrm{kg})$. Additional outcome measures included: fruit and vegetable intake, physical activity and coping with stress measures. The overarching difference between this intervention and others previously reported is that the intervention was created using steering committees, which included members of the target population that were involved in all aspects of assessment, development, testing and evaluation of the intervention. Three of the YEAH Project institutions also chose to collect biochemical and anthropometric measures in order to assess for MetS risk.

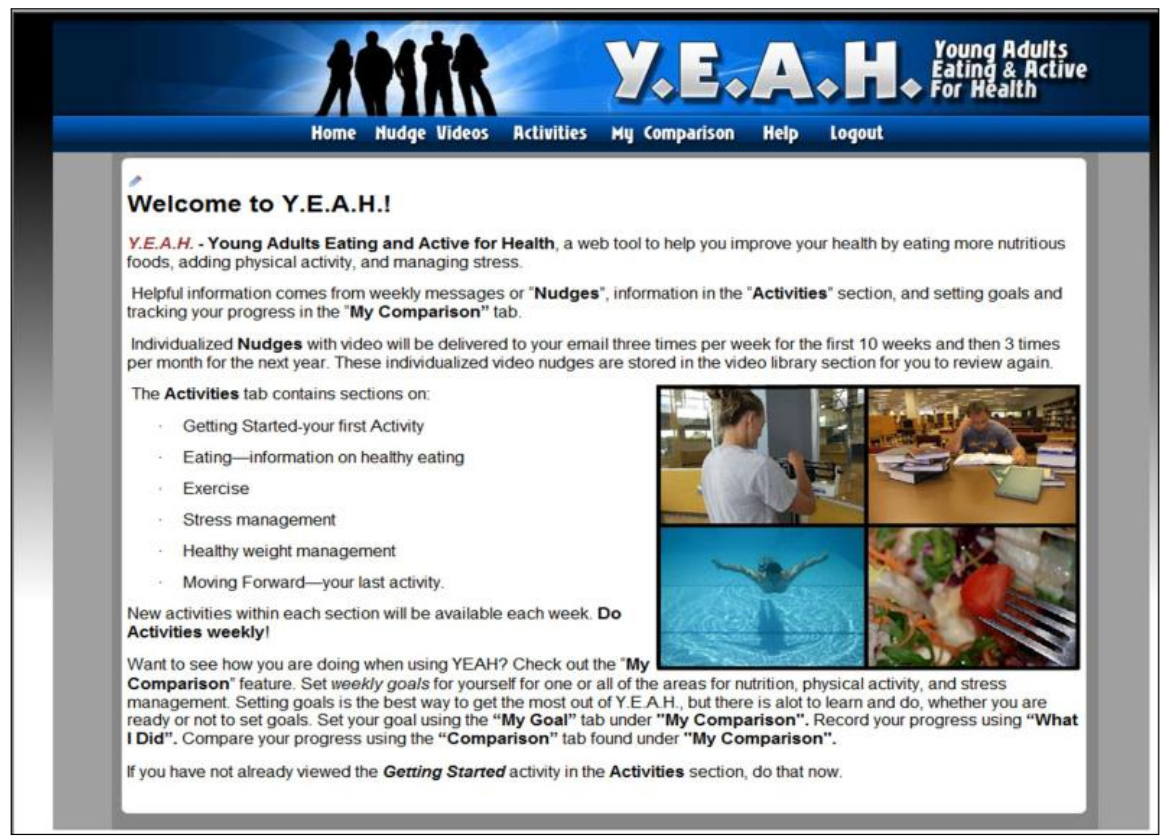

Figure 2: YEAH Project Webpage Portal 


\section{Inflammation and Risk of Chronic Disease}

CRP is a biomarker of low-grade inflammation $(17,40)$ produced mainly by the liver and to some extent by the adipose tissue (19). Some researchers believe the accumulation of fat causes adipocytes to increase in size, which triggers the release of inflammatory cytokines (41), such as tumor necrosis factor (TNF)- $\alpha$ and interleukin (IL)-6 (42). The release of TNF- $\alpha$ is regulated by the production of IL-6, which in turn stimulates the liver to produce CRP (42). Therefore, the next section discusses CRP and evaluates its use as a risk criterion in MetS.

\section{C - Reactive Protein (CRP)}

Among children, adolescents and adults, MetS risk criteria have been associated with measures of inflammation, such as CRP $(14,43,44)$. Further, increased levels of CRP during childhood and adolescence have been shown to continue into adulthood (18). CRP levels have shown positive correlations with the following MetS risk criteria: increased WC $(19,45,46)$, increased circulating TGs $(14,19,44-47)$, decreased HDL-C $(14,44,46,47)$, increased BP $(19,44$, 47) and impaired FBG $(14,19,45,47)$. Epidemiological studies have also reported increases in CRP levels can predict the onset of T2DM as well as CVD in otherwise healthy adults (16). Consequently, many researchers have begun to encourage the use of CRP as an additional diagnostic criterion for MetS.

In 2003, the CDC and the American Heart Association (AHA) published the first set of guidelines to endorse the use of highly sensitive c-reactive protein (hsCRP) alongside traditional cardiovascular risk factor screening $(19,48)$. HsCRP assays have recently replaced the traditional CRP assays, which only identified CRP levels of $\geq 3 \mathrm{mg} / \mathrm{dL}$ (48). The hsCRP assays currently used in clinical and research settings identify CRP levels as low as $0.1 \mathrm{mg} / \mathrm{dL}(48)$. HsCRP assays are used in clinical and research settings due to their low cost, availability to 
primary care physicians, ease of administration, existing standardization protocols as well as method of retrieval using capillary stick or venipuncture (49).

In a recent update for clinicians published in 2011, hsCRP levels $<1 \mathrm{mg} / \mathrm{dL}$ were categorized as low, 1 to $3 \mathrm{mg} / \mathrm{dL}$ intermediate and $\geq 3 \mathrm{mg} / \mathrm{dL}$ as high cardiovascular risk (48). These values are consistent with the first guidelines published by the CDC and AHA in 2003 (48). Young adults exhibiting MetS risk criteria could benefit from hsCRP screening as a way to identify a pro-inflammatory state. HsCRP should be considered as an addition to routine lipid screening advised by the NCEP ATP III to begin at age 20 (2). As young adults continue to exhibit excessive weight gain, efforts to monitor obesity-related disease states need to be addressed.

\section{Obesity, MetS and CRP}

The NCEP ATP III reported the current "obesity epidemic" is largely responsible for the increase in the prevalence of MetS in adulthood (11). Obesity throughout childhood and adolescence is a strong predictor of becoming overweight or obese as a young adult (50). In 2009 , researchers estimated more than $20 \%$ of all children and adolescents were overweight (8). As childhood obesity continues to increase, it will become imperative to establish mechanisms for identifying obesity-related chronic disease risk early.

Adiposity measures, such as WC and BMI have emerged as strong predictors of elevated CRP (51-53). Adult BMI classifications were established in 1995 by the Expert Panel on the Identification, Evaluation, and Treatment of Overweight and Obesity in Adults (54). The expert panel performed a systematic review process of 394 randomized control trials (54). Individuals displaying a BMI of $<18.5 \mathrm{~kg} / \mathrm{m}^{2}$ were classified as underweight, a BMI of 18.5-24.5 $\mathrm{kg} / \mathrm{m}^{2}$ as normal weight, a BMI of $25.0-29.9 \mathrm{~kg} / \mathrm{m}^{2}$ as overweight and a $\mathrm{BMI} \geq 30 \mathrm{~kg} / \mathrm{m}^{2}$ as 
obese (54). Currently, the BMI classifications established by the expert panel are still practiced in clinical and research settings.

Assessing weight status in children and adolescents is done by calculating their BMI and plotting this value on a BMI-for-age growth chart (Appendices A and B). There are separate charts for each sex (boys ages 2 to 20, girls ages 2 to 20) (55). Age is listed on the horizontal axis of the chart and BMI values are listed vertically on each side of the chart (55). Once an individual's sex and age have been identified, their BMI value is plotted and corresponds to a specific percentile (55). Individuals whose BMI is plotted $\geq 85^{\text {th }}$ percentile are overweight, $\geq 95^{\text {th }}$ percentile are obese and $\geq 97^{\text {th }}$ percentile are extremely obese (55).

Bosy-Westphal et al. indicate WC serves as the best predictor of metabolic risk (56). However, there is currently no universally accepted measurement protocol for WC (52). WC measurement sites commonly used in clinical and research settings include: above the iliac crest, midpoint between iliac crest and lowest rib, at level of umbilicus as well as at minimal waist (52). The NCEP ATP III cut points for MetS risk (men $>102 \mathrm{~cm}$, women $>88 \mathrm{~cm}$ ) were derived from WC measurements taken mid-way between the lowest rib and iliac crest (52). Researchers recommend the use of WC to accurately depict the prevalence of visceral or abdominal obesity (47). Abdominal fat distribution is more associated with adverse health outcomes in comparison to lower body fat distributions (57). Further, the distribution of body fat has recently emerged as an important determinant of chronic disease risk as early as childhood (8).

Abdominal obesity has been shown to directly relate to the development of MetS (11) and cardiovascular risk (8). Excess adipose tissue residing in the abdominal region serves as an endocrine organ (45). Aside from storing calories as triglycerides, abdominal adipocytes also secrete different hormones and inflammatory proteins, such as CRP (45). Components of MetS 
occur more often amongst overweight and obese individuals (12). Some researchers suggest the relationship between weight status and the development of MetS can be attributed to excess adiposity increasing the risk of IR (12). Individuals who display IR are more likely to develop increased TGs, low HDL-C, increased BP and exhibit a pro-inflammatory state (12), thus providing a potential mechanism for increased adiposity contributing to the development of MetS.

Although still controversial, some researchers suggest BMI may be a better representation for adiposity in children and adolescents due to continued growth and maturation, whereas, WC measures have been the most representative of abdominal adiposity in overweight or obese adults. However, limitations exist for each measurement. Future research is needed in order to reach a national consensus on which location is the most representative of abdominal adiposity in terms of chronic disease risk. Since the prevalence of obesity is rising across all age groups (34), establishing a standard WC measurement protocol would allow for better prediction of obesity-related disease risk.

\section{Prevalence of MetS and CRP Measures}

Currently, there is no national consensus for the diagnosis of MetS in adolescents (12 to 19 years) $(50,58)$. However, researchers continue to publish on the prevalence of MetS within this particular age range, using various MetS definitions as well as modified risk criteria. Regardless of diagnosing MetS risk criteria uniformly, there appears to be overlap in several of the studies' findings. In addition, many studies have used the hsCRP assays to measure CRP levels, ensuring a more accurate representation of CRP levels versus traditional CRP assays.

In a study examining NHANES data from 1999-2000, de Ferranti et al. reported median hsCRP levels were increased in adolescents, aged 12 to 19 years, with MetS risk criteria in comparison to those without (44). MetS was defined by exhibiting three or more of the following 
risk criteria: increased triglycerides ( $\geq 100 \mathrm{mg} / \mathrm{dL}$ ), low HDL-C $(<50 \mathrm{mg} / \mathrm{dL},<45 \mathrm{mg} / \mathrm{dL}$ for boys 15-19), impaired FBG ( $\geq 110 \mathrm{mg} / \mathrm{dL})$ and increased WC $\left(>75^{\text {th }}\right.$ percentile for age and sex $)(44)$. The overweight adolescents exhibiting MetS displayed greater hsCRP levels in comparison to overweight adolescents without MetS (1.6 mg/dL vs. $0.3 \mathrm{mg} / \mathrm{dL}, \mathrm{p}<0.0001)$ (44). HsCRP levels were higher for females in comparison to males $(0.5 \mathrm{mg} / \mathrm{dL}$ vs. $0.4 \mathrm{mg} / \mathrm{dL}, \mathrm{p}=0.01)(44)$. These findings demonstrate a positive relationship between hsCRP, weight status and a modified formal definition of MetS among adolescents, ages 12 to 19 years.

Another study by Ford et al. reported mean levels of hsCRP were increased among subjects exhibiting MetS in comparison to those who did not (3.8 mg/dL vs. $1.4 \mathrm{mg} / \mathrm{dL})(40)$. Of the subjects presenting with MetS, $39.4 \%$ had hsCRP levels > $3 \mathrm{mg} / \mathrm{dL}(40)$, which is indicative of high cardiovascular risk in adulthood (48). Ford et al. also reported female subjects, ages 16 to 19 years, had significantly greater hsCRP levels in comparison to male subjects (40). Following log transformations, hsCRP was found to be increased among subjects with abdominal obesity (WC $\geq 90^{\text {th }}$ percentile for sex), increased serum TGs $(\geq 110 \mathrm{mg} / \mathrm{dL})$, low HDL-C ( $\leq 40 \mathrm{mg} / \mathrm{dL})$ and increased BP ( $\geq 90^{\text {th }}$ percentile for age, sex and height $)(40)$. The findings of this study provide further evidence of a positive relationship between increased hsCRP and the presence of modified NCEP ATP III MetS risk criteria among adolescents, ages 12 to 17 years. This study also suggests sex differences in hsCRP levels may develop during late adolescence and become more apparent throughout young adulthood.

In 2005, Raitakari et al. published one of the few articles on the distribution and determinants of hsCRP in young adults, ages 24 to 39 years (19). However, many researchers would argue this age range approaches middle adulthood and may result in poor representation of young adulthood (19). This study revealed females exhibited higher mean hsCRP levels in comparison to males $(p<0.001)(19)$. Both sexes exhibited correlations between hsCRP levels, obesity, increased TGs and elevated BP (19). For males, hsCRP correlated significantly with 
WC $(p<0.0001)$ and inversely with HDL-C $(p=0.024)(19)$. For females, hsCRP significantly correlated with TGs $(p<0.0001)$. Overall, 9 to $10 \%$ of the subjects exhibited hsCRP levels $>3$ $\mathrm{mg} / \mathrm{dL}$, which is indicative of high cardiovascular risk in adulthood (19). In addition, these percentages are somewhat greater than those reported for adolescents. Sex differences appear to become more apparent in young adulthood. This scenario may relate to age-specific lifestyle behaviors such as smoking and oral contraceptive use, both of which have been shown to increase CRP levels $(59,60)$.

Many of these studies exhibit a positive relationship between hsCRP, weight status, as well as MetS risk criteria. However, measures of adiposity were not consistent throughout each of the studies. Some studies utilized WC measures, whereas, others took into account BMI measures. Still, adolescents displaying certain components of MetS appear to exhibit greater hsCRP levels in comparison to those without. In addition, females consistently seem to exhibit increased hsCRP levels. Researchers have estimated this may due to estrogen use, while other researchers argue body fat distribution is increased among females, identifying a potential mechanism for increased hsCRP levels. Although increased hsCRP levels appeared to consistently correlate with poor lipid panel characteristics, such as increased TGs and low HDL$\mathrm{C}$, more research is needed to explain the incidence of increased hsCRP levels among female adolescents and young adults.

\section{Appalachian Risk for MetS}

The Appalachian region is characterized by unhealthy eating behaviors and inactivity, which leads to the increased incidence of chronic disease among this population (24). Ely et al. recently reported the increased risk of chronic disease, related to excessive weight gain and poor health behaviors, is not realistically perceived by Appalachian residents (61). Inadequate transportation (23), poverty $(26,62)$, lack of access to medical care $(23,26)$ and lack of insurance 
are additional factors directly impacting the health and nutritional status of individuals in this region (26). Some researchers suggest the cultural attitudes within this region may serve as a significant barrier to obtaining health care (63). Many residences of Appalachia consider seeking medical care a "last resort" due to distrust of health providers (63). Therefore, many chronic disease states may go several years without proper diagnosis.

In 2010, Blake et al. conducted a population-based study of Appalachian adults in six communities in Ohio and WV (27). The participants were 18 years and older $(n=14,783,50.9 \%$ women) (27). Researchers categorized participants into the following BMI categories: normal (< $\left.25 \mathrm{~kg} / \mathrm{m}^{2}\right)$, overweight $\left(25-29.9 \mathrm{~kg} / \mathrm{m}^{2}\right)$ and obese $\left(\geq 30 \mathrm{~kg} / \mathrm{m}^{2}\right)(27)$. The results of this study indicated $25.6 \%$ of normal-weight adults displayed clustering of $\geq 2$ cardiometabolic abnormalities, defined as the presence of hypertension, elevated TGs ( $\geq 150 \mathrm{mg} / \mathrm{dL}$ ), decreased HDL-C (men $<40 \mathrm{mg} / \mathrm{dL}$, women $<50 \mathrm{mg} / \mathrm{dL}$ ), elevated FBG $(\geq 100 \mathrm{mg} / \mathrm{dL})$, IR (homeostasis model assessment $>5.13$ ), or elevated CRP (>3 mg/dL) (27). The prevalence of $\geq 2$ cardiometabolic risk factors was higher in subjects who were 25 years and older, male sex, current and former smokers, and former alcohol drinkers (27). Prevalence was lower in women, those with high school education or higher, those who drank at least 2 alcoholic drinks per day, and those who exercised twice on a weekly basis (27). Interestingly, $36.8 \%$ of overweight/obese adults displayed $<2$ cardiometabolic abnormalities (27). These findings suggest the need to intervene on metabolic risk factors in addition to weight status within the Appalachian region.

In terms of chronic disease risk, WV has reported the highest age-adjusted incidence of diabetes as well as the highest diabetes-related deaths in the nation (23). Overall, Appalachians are 1.4 times more likely to have diabetes than non-Appalachians, with the highest rates occurring among individuals with low incomes (23). In 2011, the prevalence of diagnosed diabetes was $9.8 \%$ within the Appalachian region and $7.8 \%$ for the rest of the nation (63). Health professional shortage areas (HPSAs) account for $69 \%$ of the counties within the 
Appalachian region (63). Further, $91 \%$ of those counties are categorized as distressed in regards to economic levels (63). According to Barker et al.'s findings in 2011 , roughly $30 \%$ of WV counties are categorized as distressed (63). Obesity, lack of physical activity, and smoking, all of which contribute to T2DM, are common in distressed counties. Therefore, residents of distressed counties are at increased risk for developing diabetes (63).

\section{Appalachian Adolescents and Young Adults}

The prevalence of obesity among children and adolescents has reached epidemic proportions in the US (24). The problem has become even more severe among rural children and adolescents (24). Of the current studies, only three publications address health behaviors among Appalachian adolescents (ages 14 to 16 years) or young adults (ages 18 to 24 years). Due to the increased incidence of overweight and obesity in Appalachia (27), weight status should be closely monitored throughout childhood, adolescence and young adulthood.

Overweight adolescents and young adults are especially at risk of becoming obese throughout adulthood $(6,64)$ in comparison to obese children. More research is needed to determine the relationship between lifestyle behaviors and the incidence of overweight and obesity among young adults in this region.

Wu et al. conducted a survey in 2009 to assess eating behaviors among students ( $n=$ 416) attending five public high schools in four Appalachian counties located in northeastern Tennessee (24). In this study, a healthy eater was described as someone who eats three moderately portioned balanced meals daily that include fruits and vegetables but who avoids junk food (fast food, chips, sweets, and dessert) (24). Only $29.8 \%$ of the students reported definite intentions to eat healthfully during the next two weeks (24). Students who were teased about their weight conveyed negative attitudes toward healthy eating. Roughly $23 \%$ of students reported witnessing weight teasing almost every day (24). These findings suggest group norms, 
peer pressure, and social support play an important role in eating decisions within this age group (24). Wu et al. suggest incorporating social support for healthy eating, establishing peer role models, and reducing weight teasing could prevent negative attitudes toward health eating, leading to a stronger intention for healthy eating among these students (24). As a stronger intention for healthy eating develops, the incidence of overweight and obesity observed in this region could potentially improve.

In 2008, Williams et al. conducted focus group interviews among students, 14 to 18 years, enrolled in health and physical education classes in four different rural WV schools (26). One of the first items addressed in the focus group interviews was the definition of a healthy weight (26). The students who participated in the focus groups indicated there was an absolute weight or BMI value, conveyed by a physician, which determined a healthy weight (26). They also specified students who participated in extracurricular activities exhibited a healthier weight status (26). The students characterized their peers who eat "junk food" and snacks, and those who overeat as exhibiting an unhealthy weight (26). When asked about the incidence of childhood obesity, the students indicated they were "used to [seeing] it" (26). Therefore, research efforts should address the general acceptance of a higher average body weight and educate students on the stereotypes that were reported to affect weight status in order to reduce the incidence of overweight and obesity in rural Appalachia.

In 2005, Rozmus et al. conducted a study in 18 to 24 year olds $(n=251)$ attending a small, rural, southern university to assess health promotion and risk behaviors of college students (21). Students reported lower rates of binge drinking (25\% vs. $34.5 \%)$; regular cigarette smoking ( $12 \%$ vs. $16.5 \%)$ and marijuana use ( $27 \%$ vs. $48.7 \%)$ in comparison to the results from the 1995 National College Health Risk Behavior Survey (NCHRBS) (21). Approximately $1 / 5$ of the students were overweight based on their BMI, which was determined by self-reported height and weight (21). Although students in this sample exhibited lower health risk behaviors in 
comparison with the NCHRBS, their increased BMI measures should not be ignored. The number of overweight young adults in this sample illustrates the need for interventions that address physical activity and nutrition as well as the relationship between excessive weight gain and chronic disease.

Young adults, ages 18 to 24 years, residing in the Appalachian region have been overlooked in terms of health and chronic disease risk. Yet, researchers have identified the Appalachian region as one of the unhealthiest regions in the nation. The idea of targeting young adults that choose to attend higher education institutions or pursue employment could be particularly beneficial in terms of implementing prevention programs. The environmental changes taking place during this transition period can introduce different perspectives from those learned at home. Many young people take this time to develop a clearer sense of self and establish life-long behavior patterns (21). Research interventions that target positive behavioral lifestyle changes, such as increased physical activity or increased fruit and vegetable consumption, could be particularly beneficial during this period of increased autonomy.

\section{Web-based Interventions to Change Behavior}

The use of the Internet has become a popular way to disseminate information to a vast amount of people. Jones et al. suggest American college students make frequent use of the Internet in their daily lives (65). Research indicates $86 \%$ of American college students have gone online compared to $59 \%$ of the general population (65). In addition, nearly $60 \%$ of colleges in the US use web-based resources to address health-related topics on their websites (66). Young adults have reported using the Internet to seek health information due to the accessibility, availability, privacy, and confidentiality of web-based information (66). Male college students report using the Internet as a source of entertainment, whereas, female college students indicate they are more likely to go online for communicative and educational purposes. 
However, males and females do exhibit comparable rates of Internet use for academic or e-mail purposes (65). Overall, web-based programs targeting lifestyle modification have the potential to provide information to numerous young adults at a relatively low cost with high anonymity (67).

\section{Social Ecological Model}

The development of the YEAH project was guided by the Social Ecological Model (SEM) due to its consideration of multiple levels of influence on health behaviors. The SEM suggests that individual, interpersonal, community, organizational, and societal factors should all be considered when planning and implementing health promotion interventions (68) (Figure 2). Therefore, the SEM allowed research investigators to integrate knowledge from several experts across campus and coordinate ideas from faculty, staff, students and outlying community members of the different campuses. This multi-level, interactive approach is as an effective way to identify the various influences on health-related behaviors and conditions pertinent to each campus.

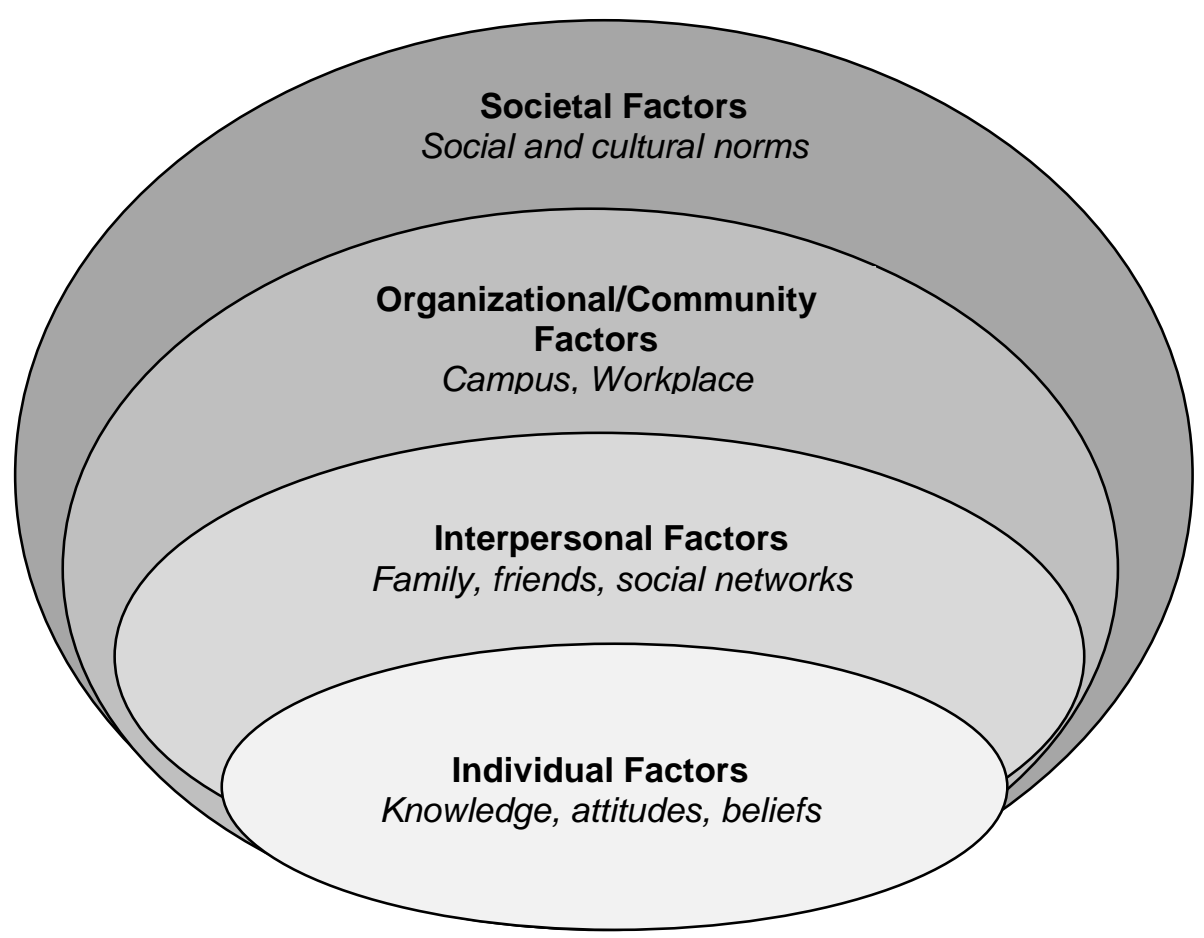




\section{Figure 3: Social Ecological Model}

\section{Community Based Participatory Research (CBPR)}

The use of a community-based participatory research (CBPR) is believed to enhance the efficacy of an intervention targeting behavior changes within a community. The CBPR process utilizes community members from the target population in the development, assessment, testing and evaluation of the effectiveness of an intervention. CBPR is often used to address a number of complex factors associated with health concerns, such as excessive weight gain. The YEAH Project was developed and evaluated using the campus community, which consisted of students, faculty and staff, in order to effectively target excessive weight gain in the young adult population. To date, the multistate group was the first to systematically develop and test a tailored, web-based program to prevent excessive weight gain in 18 to 24 year olds using the community based research process of PRECEDE-PROCEED.

\section{PRECEDE-PROCEED Model}

PRECEDE-PROCEED is a CBPR model that can be used among local communities to understand complex behavioral and environmental factors that influence health and quality of life. The goal of PRECEDE-PROCEED is to explain health-related behaviors and environments, and to design and evaluate the interventions that influence particular health outcomes such as excessive weight gain. In order to achieve and sustain change in environmental factors and behavior patterns, it is essential to use a participatory model to both plan and implement multiple strategies.

The PRECEDE-PROCEED model phases are interdependent parts of an ecological planning system (Figure 3). Phase 1 provides the assessment of social and cultural circumstances of a targeted population. At this point, the community identifies their own needs and objectives. Epidemiological assessment (Phase 2) allows for identification of the specific 
health goals or problems that were identified in the first phase. Phase 2 includes assessment of behavior and environmental determinants of health. In the third phase, educational and ecologic assessment, casual factors are categorized into predisposing (knowledge, attitudes, believes, values, perceptions), reinforcing (rewards and feedback from others), and enabling (skills, resources, barriers) factors. Phases 4,5 , and 6 finish the final assessments of the PRECEDE component and begin the first phase of PROCEED. Intervention alignment, administrative and policy assessment, implementation and process evaluation are included in these phases. Lastly, in Phases 7 and 8 impact and outcome evaluations are completed.

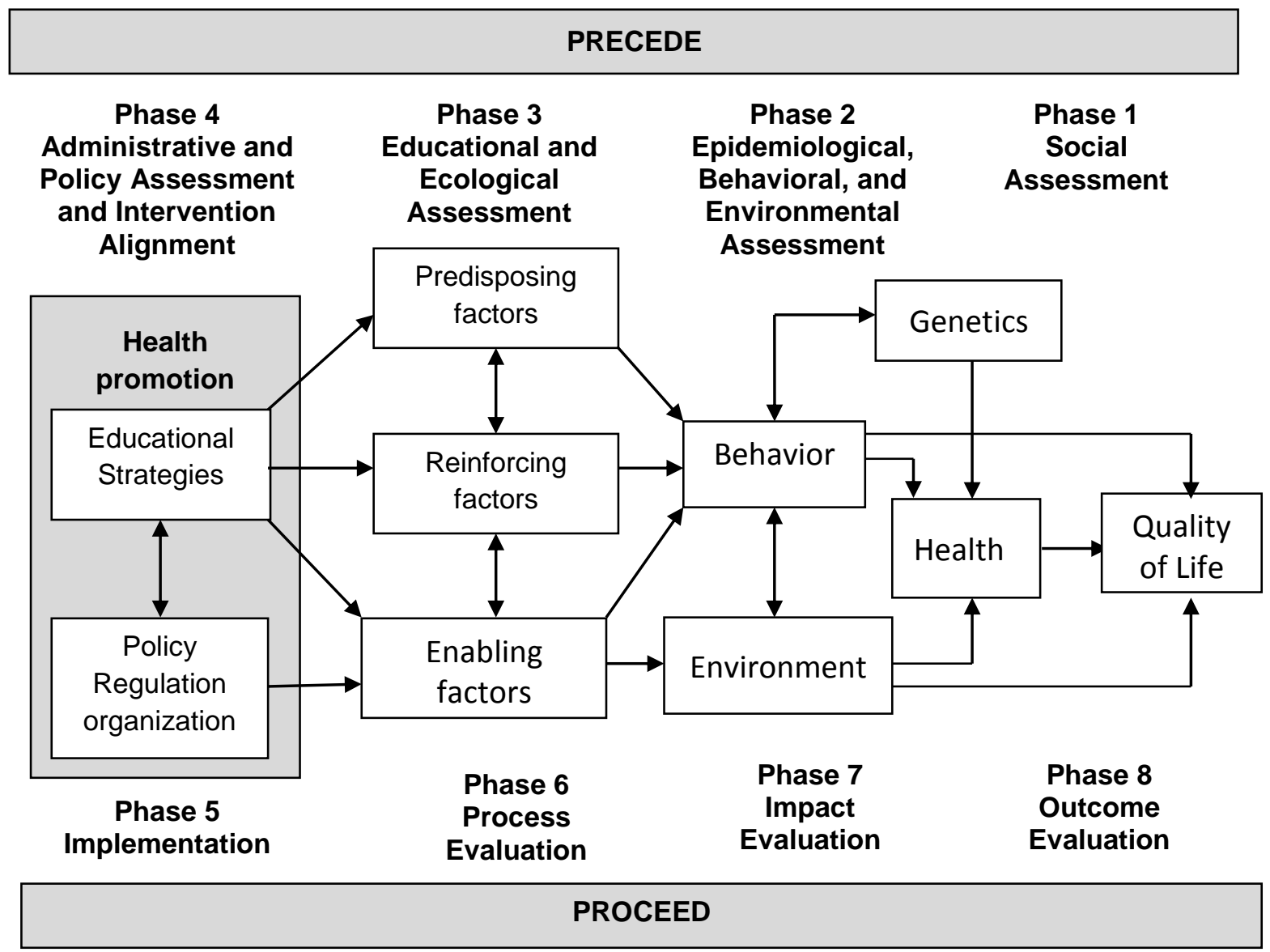

Figure 4: PRECEDE-PROCEED Model 


\section{Development of the Web-based Intervention}

A multistate team of investigators from 1) Tuskegee University (in Alabama), 2) Purdue University (in Indiana), 3) University of Florida, 4) Kansas State University, 5) University of Maine, 6) Michigan State University, 7) University of New Hampshire, 8) University of Wisconsin-Madison, 9) Syracuse University (in New York), 10) Rutgers University (in New Jersey), 11) East Carolina University (in North Carolina), 12) University of Rhode Island, 13) South Dakota State University and 14) West Virginia University (WVU) participated in the development of the web-based intervention (Figure 4). Based on the PRECEDE-PROCEED model and SEM, the study was developed using focus groups of 18 to 24 year olds to explore health-related factors affecting quality of life. In addition, each state formed a steering committee, consisting of key faculty members, staff and students, in order to identify problems related to obesity prevention efforts at each of the different institutions. In 2009, each institution performed an environmental assessment to determine if the campus environments were supportive or not supportive of obesity prevention. During 2010, each state worked alongside their steering committee to tailor and design a web-based intervention using the focus group information obtained from each institution. The lessons were cognitively tested by the steering committees to assure understanding and interest for this age group. During this time, SDSU also worked to create a functional website and administrative management portal. Each institution recruited students, ( $n=280$, ages 18 to 24 years), to pilot test the intervention for its relevancy to the target audience. 
Focus groups were held with 18 to 24 year olds to obtain factors affecting quality of life (QOL)
Each state's PI collabored with a steering committee to prioritize problems related to obesity prevention
An environmental audit

was conducted to assess

how the target populations

environment is supportive

or not of obesity prevention

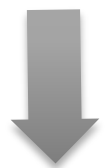

2010:

The lead institution (SDSU) worked with a software company to create a functional website and administrative management portal
Each state's PI worked with steering committees to tailor and design a web-based intervention

Figure 5: Development of the Web-based Intervention

\section{Web-Based Intervention Description}

The YEAH Project intervention component was designed to capitalize on young adults' use of the Internet and e-mail. The intervention took place over 10 weeks between a baseline and post-intervention ( 3 month) assessment. Participants received the web-based intervention through a personal portal page. Through this portal page, participants were staged for physical activity, fruit and vegetable intake, and stress coping skills; they were also encouraged to set a weekly goal to obtain one or all three behaviors and complete the web-based mini-module activities delivered. Participants received three stage tailored messages per week via e-mail, encouraging healthful behaviors that support physical activity, fruit and vegetable intake, and mechanisms for coping with stress over a 10 week period. A fourth message was delivered each week to remind the participant to access the website and review their goal. Once the 10 week intervention was complete, participants received four messages per month via e-mail, three stage tailored messages and one reminder to visit the website for 10 months until they were asked to schedule their 15 month follow-up assessment. 


\section{Transtheoretical Model}

The Transtheoretical Model (TTM) is an integrative framework for understanding how individuals and populations progress toward adopting and maintaining health behavior changes (69). The TTM consists of stages of change, processes of change, decisional balance and selfefficacy (69). For the YEAH Project, research investigators used the stages of change (precontemplation, contemplation, preparation, action and maintenance) to develop participant "nudge" e-mails appropriate for their progression through the stages of change (Table 2). The TTM suggests that "people move from precontemplation, not intending to change, to contemplation, intending to change within 6 months, to preparation, actively planning to change, to action, overtly making changes, and into maintenance, taking steps to sustain change and resist temptation to relapse" (69). Each participant's stage was determined at baseline by their response to three survey questions (Appendix C). Students were staged at the beginning of the study and "nudged" accordingly in an effort to move them to the next stage of change in terms of health behaviors.

Table 2: Transtheoretical Model Stages of Change

\begin{tabular}{|l|l|}
\hline Constructs & Description \\
\hline Stages of Change & No intention to take action within the next 6 months \\
\hline Precontemplation & Intends to take action within the next 6 months \\
\hline Contemplation & $\begin{array}{l}\text { Intends to take action within the next } 30 \text { days and has taken some } \\
\text { behavioral steps in this direction }\end{array}$ \\
\hline Preparation & Changed overt behavior for less than 6 months \\
\hline Action & Changed behavior for more than 6 months \\
\hline Maintenance &
\end{tabular}




\section{Study Objectives}

The primary objective of this study was to recruit 18 to 24 year olds attending WVU for the YEAH Project while also collecting descriptive baseline anthropometric (including height, weight, BMI, body fat percentage, waist circumference and neck circumference) and biochemical data (including total cholesterol, HDL cholesterol, LDL cholesterol, triglycerides, fasting blood glucose, hemoglobin A1c, highly sensitive c-reactive protein, hemoglobin and hematocrit measures) to describe of the chronic disease status of this specific population.

The secondary objective was to assess change in MetS risk, according to the National Cholesterol Education Program's definition (including waist circumference, HDL cholesterol, triglycerides, fasting blood glucose and blood pressure risk criteria), following a 10 week webbased behavioral change intervention which included weekly emails that addressed the participants specific goals they had identified upon beginning the program based on the stage of change they were progressing through and again at the 15 month follow-up visit. 


\section{CHAPTER III}

\section{METHODOLOGY}

\section{Community Based Steering Partnership}

WVU faculty, staff, students and outlying community representatives were invited in October of 2010 to serve as a steering committee member for their expertise and/or helpful insight in nutrition, physical activity, stress management, sleep, alcohol/tobacco use and other related factors pertaining to the YEAH Project (Appendix D). A number of faculty members and students, including the Office of Wellness and Health Promotion's Director, Student Health Personnel, Fitness and Wellness Manager of the Student Rec Center, President of Student Wellness Advisory Board, Residence Hall Wellness Coordinators, Public Health students and so on attended the steering committee meeting. Recruitment for the YEAH Project and delivery of the web-based intervention were discussed during this time.

Steering committee members were involved in the planning phase for recruitment and incentivizing students on each of the different campuses. At WVU, committee members encouraged using the campus listserve (MIX), hanging flyers in key places on campus (i.e. Residence Halls, Mountainlair, and Student Rec Center), targeting the Personal Rapid Transport (PRT) stations and seeking donations from local businesses to accompany the monetary incentive $(\$ 75.00)$ for participants. The members also provided information pertaining to healthy snacks that are popular among undergraduate students (i.e. 100 calorie snack packs, Nutrigrain bars).

The entire committee agreed upon the following unhealthy lifestyle behaviors pertaining to WVU's undergraduate students: poor diet quality, lack of physical activity, regular alcohol consumption, frequent tobacco use and increased stress. One of the barriers to consuming fresh fruits and vegetables provided by committee members was the limited availability and decreased quality of fruits and vegetables offered to students in the residence halls. They also 
identified students' alcohol consumption, Thursday through Sunday, as a barrier to consuming healthy foods. Some members attributed consuming fast/convenience food items during early morning hours to students' alcohol consumption. The group agreed upon the increased accessibility of alcohol on WVU's campus, illustrated by the high density of alcohol outlets within a 3 mile radius of campus and the frequency of events encouraging alcohol consumption (i.e. Football games, Fall Fest).

\section{IRB and Training of Research Assistants}

The Institutional Review Board (IRB) at West Virginia University approved the YEAH Project in December of 2010 (Appendix E). There was an amendment in November of 2011 (Appendix E) and an annual renewal in January of 2012. Undergraduate students from various disciplines, including nutrition, exercise physiology, pharmacy and public health, were recruited to join the YEAH Project research team. All research team members completed the Collaborative Institutional Training Initiative (CITI) training in order to perform physical assessment measures, at baseline, post-intervention ( 3 months) and 15 months. Inter-rater reliability (IRR) trainings were held before the baseline, post-intervention (3 month) and 15 month physical assessments. The campus coordinator at each of the universities was responsible for training, coordinating and managing all research team members.

\section{Timeline of the YEAH Project}

The development of the web-based intervention, titled Young Adults Eating \& Active for Health (YEAH) Project took place from 2009 to 2010 (Figure 5). WVU's IRB approved the YEAH Project during November of 2010. A steering committee meeting was held during November 2010, which consisted of WVU faculty, staff, students and outlying community representatives. The recruitment process began at the beginning of the 2011 spring semester (January February). Baseline physical assessments were scheduled between January and February of 
2011. The intervention component was delivered over a 10 week period spanning from January to April 2011. Post-intervention physical assessments were held during April 2011. "Nudge" emails were delivered to participants from May 2011 to February 2012. Participants were contacted via e-mail to schedule their 15 month follow-up physical assessment in March 2012. Statistical analysis took place from April to May of 2012.

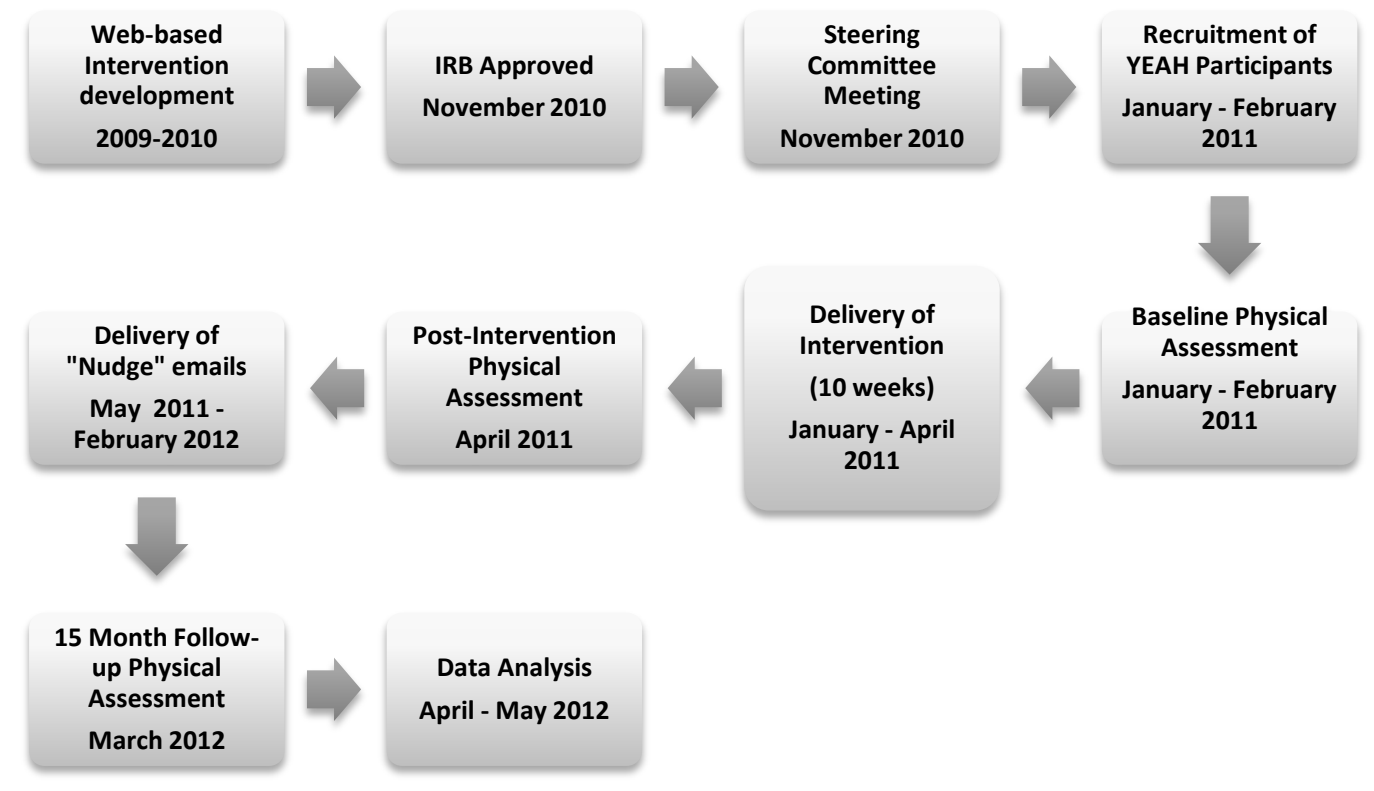

Figure 6: Timeline of YEAH Project

\section{Recruitment}

Undergraduate students were recruited by campus flyers ( $81 / 2 \times 11$ in) (Appendix F), a screen advertisement on the Personal Rapid Transport (PRT) monitor (Appendix G), campus listserve announcements, in class announcements and word of mouth. Research team members also held recruitment booths in highly-trafficked areas on campus, such as the Student Rec Center and the largest resident hall complex. Students were eligible to sign up for the YEAH Project if they met the following inclusion criteria: 18-24 years of age, $\mathrm{BMI} \geq 18.5$, fulltime first, second or third year college student, free from life threatening illness or other conditions that would prevent participation in an online nutrition and fitness program and/or 
prevent accurate physical assessment measures. Students were also required to have regular access to a computer with internet connection. Exclusion criteria included: students majoring in nutrition, exercise science, and/or other health-promotion majors or enrollment in a nutrition course.

\section{Informed Consent Process}

All students read and signed an informed consent that was approved by WVU's IRB prior to scheduling their physical assessment. After signing the informed consent, students were directed to the YEAH project website (www.yeahproject.com) to create their own personal account. Once the students logged into the YEAH Project website, they were asked to read and agree to another informed consent (Appendix $\mathrm{H}$ ) and complete the eligibility survey (Appendix I). Upon agreeing to the additional informed consent, the students were directed to thirteen different online surveys (Appendix J). After completing the online surveys, students were prompted to schedule their physical assessment. Available dates/times to schedule physical assessments were entered into the YEAH Project website by the campus coordinator using the backdoor management.

\section{Physical Assessment}

YEAH participants completed a total of three physical assessments (baseline, 3 month and 15 month). All physical assessments were performed at WVU's School of Pharmacy Health Education Lab located on the Health Sciences Campus. The School of Pharmacy's Health Education Lab received the Clinical Laboratory Improvement Amendments (CLIA) Certificate of Waiver prior to the beginning of the study (Appendix K). There were a total of five stations for the participant to complete throughout the physical assessment (Table 3).

During each physical assessment, blood pressure, anthropometric and biochemical parameters were collected. Subjects were classified as Appalachian or Non-Appalachian based 
on their self-reported home address. Prior to performing the anthropometric measures, research team members instructed the participants to: 1) empty bladder if necessary, 2) remove excess clothing, 3) remove shoes and socks, 4) empty pockets and 5) remove hair ornaments. Each anthropometric measurement was taken twice following standard procedures by trained research team members using calibrated equipment and recorded immediately. Blood samples were drawn by research team members after confirming an 8-10 hour overnight fast via capillary stick. All blood samples were immediately analyzed using direct enzymatic methods for serum FBG, TC, TG, HDL-C, and hs-CRP; LDL-C was calculated using the Friedewald equation by the analyzer.

Table 3: Description of Physical Assessment Stations

\begin{tabular}{|c|c|c|}
\hline Measure/Unit(s) & Equipment/Manufacturer & Protocol \\
\hline \multicolumn{3}{|c|}{ Station 1: Blood Pressure/Anthropometrics } \\
\hline Blood Pressure $(\mathrm{mmHg})$ & $\begin{array}{l}\text { Model HEM-907XL, Omron } \\
\text { Digital Model } \\
\text { Lake Forest, IL }\end{array}$ & $\begin{array}{l}\text { 1. Ensure participant is seated in a rested position for } \\
5 \text { minutes } \\
\text { 2. During this time, measure arm circumference to } \\
\text { determine appropriate cuff size } \\
\text { 3. Measure BP twice using the participant's left arm } \\
\text { 4. Set a } 1 \text { minute interval between measures } \\
\text { 5. Record average of the two measures }\end{array}$ \\
\hline Height $(\mathrm{cm})$ & $\begin{array}{l}\text { Model } 235 \text { Heightronic } \\
\text { Digital Stadiometer } \\
\text { Issaquah, WA }\end{array}$ & $\begin{array}{l}\text { 1. Have participants remove shoes and hair } \\
\text { ornaments } \\
\text { 2. Instruct participants to look straight ahead and } \\
\text { maintain four points of contact (heels, buttocks, } \\
\text { shoulder blades, back of head) with the wall } \\
\text { 3. Have participant take a deep breath and stand tall } \\
\text { 4. Move the stadiometer top slide and fix it in place, } \\
\text { make sure it is firmly against participant's head } \\
\text { 6. Record height to the nearest } 0.01 \mathrm{~cm} \\
\text { 7. Repeat until measures are within } 0.2 \mathrm{~cm}\end{array}$ \\
\hline $\begin{array}{l}\text { Weight }(\mathrm{kg}) \\
\text { BMI }\left(\mathrm{kg} / \mathrm{m}^{2}\right) \\
\text { Body Fat Percentage (\%) }\end{array}$ & $\begin{array}{l}\text { Model TBF -300A Tanita } \\
\text { Electronic Scale } \\
\text { Arlington Heights, IL }\end{array}$ & $\begin{array}{l}\text { 1. Zero the scale } \\
\text { 2. Have participants remove excess clothing and } \\
\text { empty bladder } \\
\text { 3. Ask participant to center both feet on the scale } \\
\text { while standing still } \\
\text { 4. Record weight to the nearest } 0.01 \mathrm{~kg} \\
\text { 5. Repeat until within } 0.2 \mathrm{~kg} \\
\text { 6. Record average to two decimal points } \\
\text { 7. Record BMl calculated during each weight }\end{array}$ \\
\hline
\end{tabular}




\begin{tabular}{|c|c|c|c|}
\hline & & 8. & $\begin{array}{l}\text { Record BF\% calculated via bioelectrical impedance } \\
\text { during each weight assessment }\end{array}$ \\
\hline \multirow[t]{6}{*}{ Waist Circumference $(\mathrm{cm})$} & \multirow[t]{6}{*}{ Gulick tape } & 1. & $\begin{array}{l}\text { Have participant raise their shirt and lower their } \\
\text { shorts directly below the top of the iliac crests (hip } \\
\text { bones) }\end{array}$ \\
\hline & & & $\begin{array}{l}\text { Palpate for the top of the participant's iliac crests } \\
\text { (hip bones) and place gulick tape measure } \\
\text { accordingly }\end{array}$ \\
\hline & & & $\begin{array}{l}\text { Have participants take a deep breath and exhale; } \\
\text { measure at the end of the expiration }\end{array}$ \\
\hline & & 4. & Tighten the tape gently \\
\hline & & 5. & Repeat until two measures are within $0.5 \mathrm{~cm}$ \\
\hline & & 6. & Record average to two decimal places \\
\hline \multirow[t]{5}{*}{ Neck Circumference $(\mathrm{cm})$} & \multirow[t]{5}{*}{ Gulick tape } & 1. & $\begin{array}{l}\text { Have participant stand and look straight ahead with } \\
\text { their shoulders down }\end{array}$ \\
\hline & & 2. & $\begin{array}{l}\text { Stand behind participant and have them swallow, } \\
\text { while palpating their neck to locate the bottom of } \\
\text { their larynx (Adam's Apple) if not visible }\end{array}$ \\
\hline & & 3. & $\begin{array}{l}\text { Place gulick tape measure around the point below } \\
\text { the Adam's Apple }\end{array}$ \\
\hline & & 4. & Repeat until two measures are within $0.5 \mathrm{~cm}$ \\
\hline & & 5. & Record average to two decimal places \\
\hline \multirow[t]{5}{*}{ Hip Circumference (cm) } & \multirow[t]{5}{*}{ Gulick tape } & 1. & $\begin{array}{l}\text { Have participant stand facing you so their buttocks } \\
\text { is visible in the mirror }\end{array}$ \\
\hline & & & $\begin{array}{l}\text { Have another research team member gather the } \\
\text { sides of the participants' shorts and/or pants to } \\
\text { tighten the fabric around the buttocks }\end{array}$ \\
\hline & & & $\begin{array}{l}\text { Place the gulick tape measure around the greatest } \\
\text { protrusion of the buttocks }\end{array}$ \\
\hline & & 4. & Repeat until two measures are within $0.5 \mathrm{~cm}$ \\
\hline & & 5. & Record average to two decimal places \\
\hline \multicolumn{4}{|l|}{ Station 2: Biochemical } \\
\hline \multirow{11}{*}{$\begin{array}{l}\text { Total Cholesterol (mg/dL) } \\
\text { HDL Cholesterol (mg/dL) } \\
\text { LDL Cholesterol (mg/dL) } \\
\text { TC/HDL-C Ratio } \\
\text { Triglycerides (mg/dL) } \\
\text { Blood Glucose (mg/dL) } \\
\text { C-reactive Protein (mg/dL) }\end{array}$} & \multirow{11}{*}{$\begin{array}{l}\text { Cholestech LDX Analyzer } \\
\text { San Diego, CA }\end{array}$} & 1. & Wipe finger with alcohol swab and allow to air dry \\
\hline & & 2. & Firmly prick the site with a lancet \\
\hline & & 3. & Gently squeeze the finger to obtain a large drop of \\
\hline & & 4. & Wipe off the first large drop of blood \\
\hline & & 5. & Squeeze the finger gently until a large drop of \\
\hline & & 6. & $\begin{array}{l}\text { Hold the capillary tube horizontally by the end with } \\
\text { the plunger }\end{array}$ \\
\hline & & & $\begin{array}{l}\text { Fill the lipid panel capillary tube with } 35 \mu \mathrm{L} \text { of blood } \\
\text { within } 10 \text { seconds }\end{array}$ \\
\hline & & 8. & Do not allow any bubbles to enter the capillary tube \\
\hline & & & $\begin{array}{l}\text { Place the end of the capillary tube into the sample } \\
\text { well of the cassette and dispense by pushing the } \\
\text { plunger }\end{array}$ \\
\hline & & 10. & $\begin{array}{l}\text { Press the RUN button on the Analyzer to open the } \\
\text { cassette drawer }\end{array}$ \\
\hline & & 11. & $\begin{array}{l}\text { Immediately place the cassette into the Analyzer } \\
\text { drawer with the black reaction bar toward the } \\
\text { Analyzer and the brown magnetic stripe on the }\end{array}$ \\
\hline
\end{tabular}




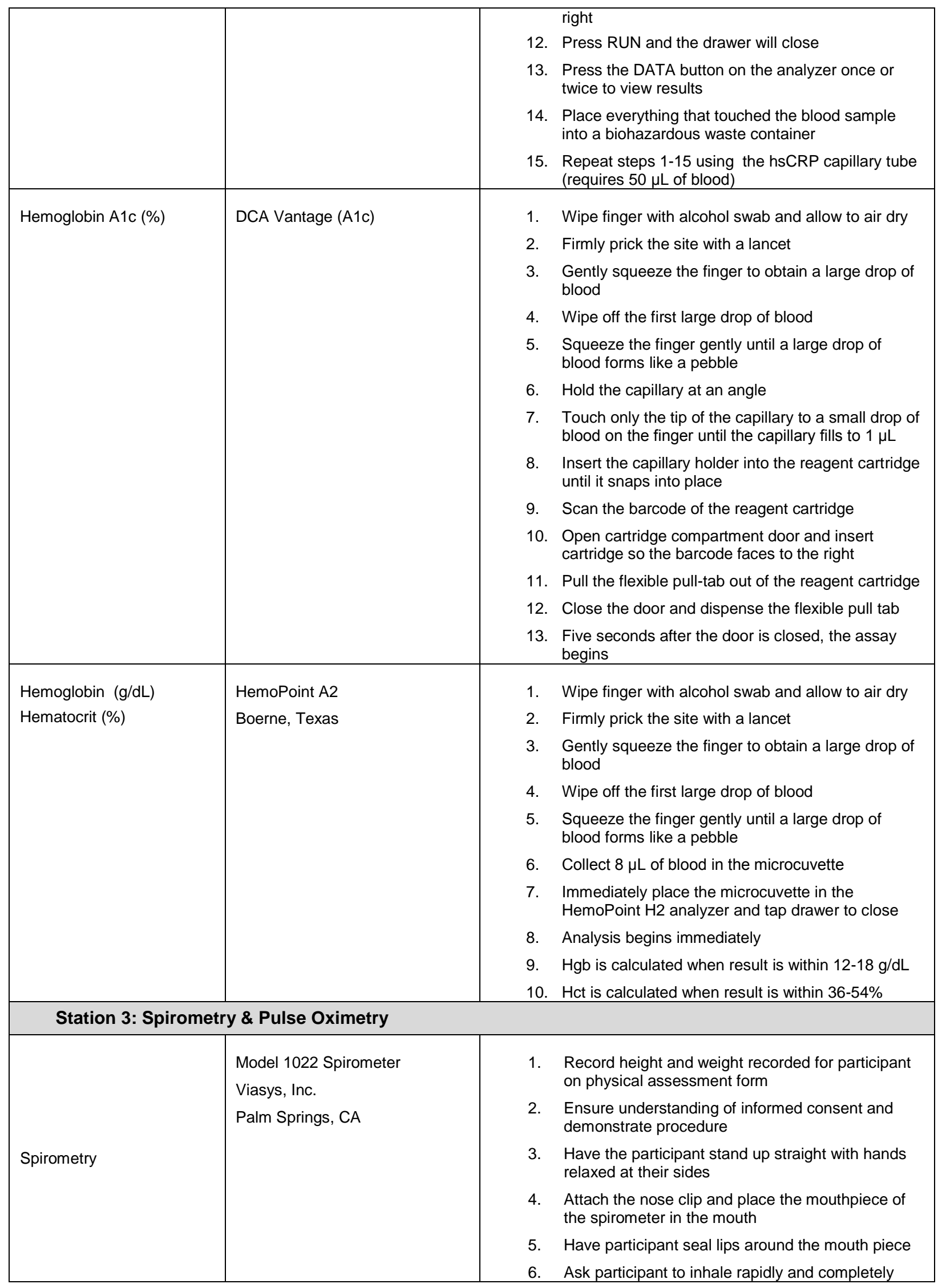




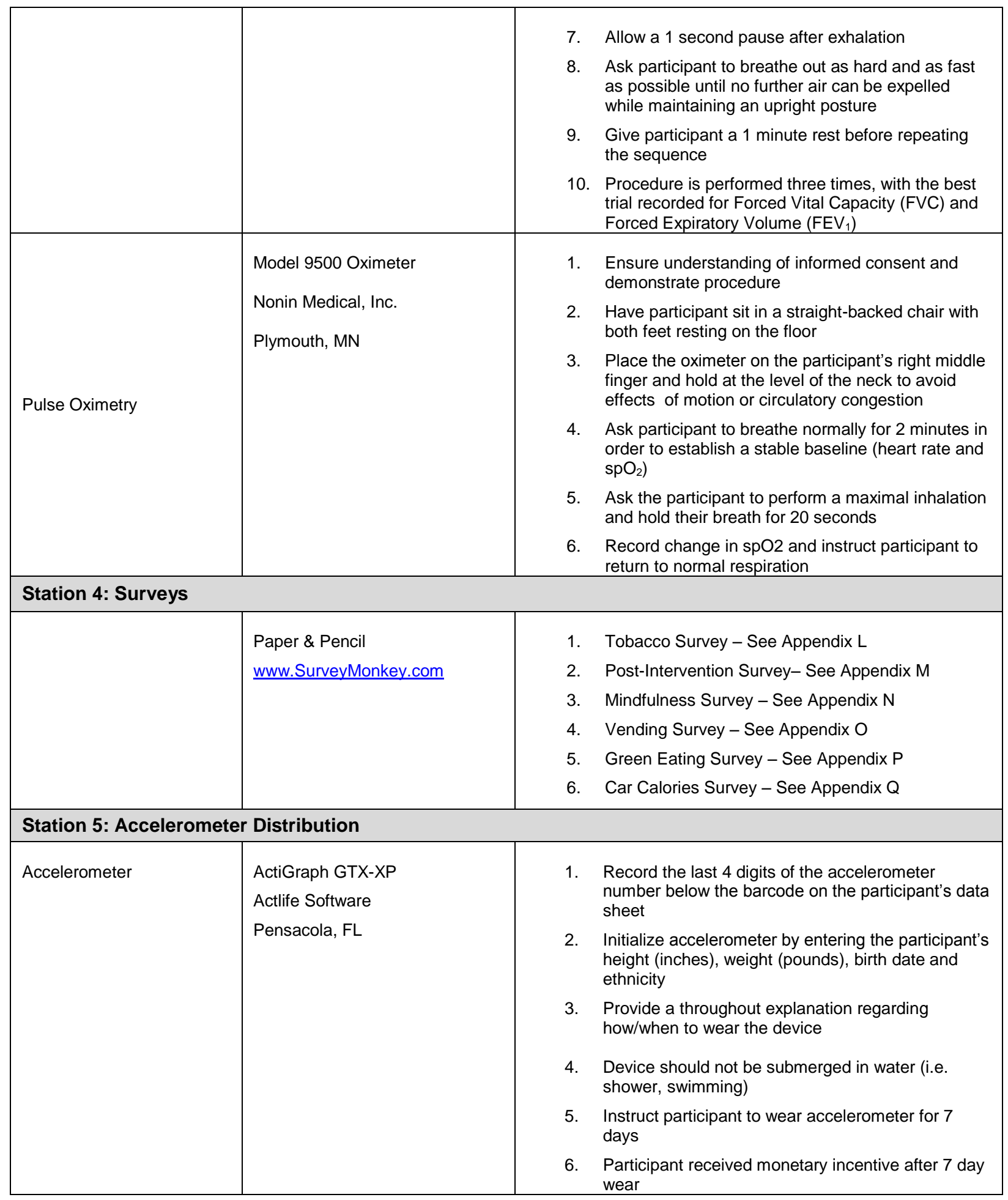

For data collection purposes only, participants were asked to complete a Tobacco Use and Exposure survey at the baseline, 3 month and 15 month physical assessments (Appendix 
L). During the 3 month assessment, intervention and control participants were also asked to complete a Post-Intervention survey (Appendix M), tailored to their designation to the intervention or control group, as well as a vending survey (Appendix O). In addition, participants were asked to complete a Mindfulness Questionnaire (Appendix N) at baseline and 3 months. During the 15 month assessment, participants were asked to complete a Green Eating Survey (Appendix P) and a Car Calories Survey (Appendix Q) in addition to the Tobacco Use and Exposure Survey for data collection purposes.

The participants were given an accelerometer to wear for a seven day period for data collection purposes. Monetary incentives ( $\$ 10$ - baseline, $\$ 25$ - 3 month and $\$ 40$ - 15 month) were distributed to the participant when they returned their accelerometer. All anthropometric and biochemical measures were entered into an Excel database at the end of each day. Specific anthropometric measures (i.e. height, weight, BMl and WC) were entered into the YEAH Project website. A research team member verified all data recorded by the campus coordinator into the Excel database as well as into the YEAH Project website at the end of each day.

\section{Data Analysis}

Statistical analysis was performed using SAS 9.3 statistical software for baseline, 3 month and 15 month physical assessment data. Simple t-tests were performed to compare the differences between anthropometric and biochemical measures by sex. Each participant was assessed for MetS risk according to the NCEP ATP III's definition. Chi-square tests were run in order to identify associations between the MetS and sex, as well as MetS and region (Appalachian vs. Non-Appalachian). The associations between these two demographic variables (sex and region) and ordinal outcomes were tested using the Mantel-Haenszel test. Differences among rates of each individual MetS component were compared by sex and region 
by using chi-square tests. Rates of high CRP (> $3 \mathrm{mg} / \mathrm{dL})$ were calculated and compared by sex, region, MetS status, number of MetS components, and by each MetS component, using Fisher's exact t-test or the Cochran-Armitage exact test for trend, when appropriate, due to small sample size. Participants exhibiting CRP levels $\geq 10 \mathrm{mg} / \mathrm{dL}$ were excluded from the analysis $(n=5)$. Statistical significance was defined as a $p$-value $<0.05$.

Power analysis was done at the origin of the developmental portion of the project considering all states and their access to participants. At that time, an $n=1,600$ was considered sufficient across all states. 


\section{CHAPTER IV}

\section{RESULTS}

\section{Subject Description Characteristics}

Data reported here are only for WVU. A total sample of 93 subjects were recruited and randomized into control and intervention groups with no significant differences across descriptive characteristics (Table 4). There were no significant differences between sex (48 males $(51.6 \%)$ and 45 females $(48.4 \%))$. The subjects were primarily Caucasian $(n=77$, 82.8\%) followed by African American ( $n=10,10.7 \%)$, Hispanic/Latino ( $n=3,3.2 \%$ ) and Asian ( $n=1,2.2 \%)$ descent. One subject's ethnicity was not reported. The subjects were categorized as Appalachian $(n=63,67.7 \%)$ or Non-Appalachian $(n=30,32.3 \%)$ based on their selfreported home address. College credit hours completed determined subjects' class year standing. Roughly forty-two percent of the subjects $(n=39)$ were classified as first year students, 30\% $(n=28)$ second year students and $26 \%(n=24)$ third year students. Two subjects' did not report year. Subjects were recruited from a broad spectrum of declared majors. Nutrition, exercise physiology and health promotion majors were excluded from the study.

Table 4: Sample Description Characteristics

\begin{tabular}{|l|c|c|}
\hline \multicolumn{2}{|l|}{ Total (n = 93) } & Percentage (\%) \\
\hline Sex & 45 & 48.4 \\
\hline Female & 48 & 51.6 \\
\hline Male & & 82.8 \\
\hline Ethnicity & 77 & 10.7 \\
\hline African American & 10 & 3.2 \\
\hline Hispanic/Latino & 3 & 2.2 \\
\hline Asian & 2 & 1.1 \\
\hline Not reported & 1 & 67.7 \\
\hline Permanent Address & & 32.3 \\
\hline Appalachian & 63 & 41.9 \\
\hline Non-Appalachian & 30 & 30.1 \\
\hline School Year & 39 & 25.8 \\
\hline First & 28 & 2.2 \\
\hline Second & 24 & 8.6 \\
\hline Third & 2 & \\
\hline Not reported & 8 & \\
\hline College & & \\
\hline Davis College of & & \\
\hline
\end{tabular}




\begin{tabular}{|l|c|c|}
\hline $\begin{array}{l}\text { Agriculture, Natural } \\
\text { Resources \& Design }\end{array}$ & 24 & 25.8 \\
\hline $\begin{array}{l}\text { Eberly College of Arts \& } \\
\text { Sciences }\end{array}$ & 7 & 7.5 \\
\hline $\begin{array}{l}\text { College of Business \& } \\
\text { Economics }\end{array}$ & 4 & 4.3 \\
\hline College of Creative Arts & 13 & 14.0 \\
\hline $\begin{array}{l}\text { College of Engineering } \\
\text { and Mineral Resources }\end{array}$ & 8 & 8.6 \\
\hline $\begin{array}{l}\text { College of Human } \\
\text { Resources \& Education }\end{array}$ & 6 & 6.5 \\
\hline $\begin{array}{l}\text { Perley Isaac Reed School } \\
\text { of Journalism }\end{array}$ & 4 & 4.3 \\
\hline $\begin{array}{l}\text { College of Physical } \\
\text { Activity \& Sports Sciences }\end{array}$ & 9 & 9.7 \\
\hline $\begin{array}{l}\text { Robert C. Byrd Health } \\
\text { Sciences Center }\end{array}$ & 3 & 3.2 \\
\hline Dual Major & 7 & 7.5 \\
\hline $\begin{array}{l}\text { Undecided Major/ Not } \\
\text { Reported }\end{array}$ & & \\
\hline
\end{tabular}

\section{Baseline Anthropometric Measures by Sex}

As shown in Table 5, the average BMI value for all subjects was $24.70 \pm 4.81 \mathrm{~kg} / \mathrm{m}^{2}$ with no significant differences between male and female subjects $\left(25.25 \pm 5.82 \mathrm{~kg} / \mathrm{m}^{2} \mathrm{vs} .24 .19 \pm\right.$ $3.69 \mathrm{~kg} / \mathrm{m}^{2}, \mathrm{p}=.2930$ ). No significant differences were observed for weight or WC between male and female subjects. However, significant differences were observed for \%BF (15.91 \pm $6.79 \%$ and $22.84 \pm 10.64 \%, p<0.0001$ ), with female subjects exhibiting significantly more \%BF in comparison to male subjects. Male subjects exhibited significantly greater height $(178.30 \pm 6.63 \mathrm{~cm}$ vs. $165.01 \pm 5.20 \mathrm{~cm}, \mathrm{p}<0.0001)$ and NC measures $(38.17 \pm 2.17 \mathrm{~cm}$ vs. $35.68 \pm 3.70 \mathrm{~cm}, \mathrm{p}<0.0001)$ in comparison to female subjects.

Table 5: Baseline Anthropometric Measures by Sex

\begin{tabular}{|l|c|c|c|c|c|c|c|}
\hline & \multicolumn{2}{|c|}{ All (n= 93) } & \multicolumn{2}{c|}{ Female (n = 45) } & \multicolumn{2}{c|}{ Male (n= 48) } & $\begin{array}{c}\text { Sex } \\
\text { Differences }\end{array}$ \\
\hline Measures & Mean & SD & Mean & SD & Mean & SD & P value \\
\hline Height $(\mathrm{cm})$ & 171.87 & 8.94 & 165.01 & 5.20 & 178.30 & 6.63 & $<0.0001^{*}$ \\
\hline Weight $(\mathrm{kg})$ & 73.04 & 15.58 & 68.74 & 16.53 & 77.08 & 13.61 & $0.0092^{*}$ \\
\hline BMI $\left(\mathrm{kg} / \mathrm{m}^{2}\right)$ & 24.70 & 4.81 & 25.25 & 5.82 & 24.19 & 3.61 & 0.2930 \\
\hline BF $(\%)$ & 22.84 & 10.64 & 30.22 & 8.89 & 15.91 & 6.79 & $<0.0001^{*}$ \\
\hline WC $(\mathrm{cm})$ & 84.13 & 15.73 & 85.07 & 19.77 & 83.25 & 10.80 & 0.5796 \\
\hline NC $(\mathrm{cm})$ & 35.68 & 3.70 & 33.04 & 3.12 & 38.17 & 2.17 & $<0.0001^{*}$ \\
\hline
\end{tabular}

$\mathrm{SD}$ - standard deviation

\section{Baseline Biochemical Measures by Sex}

As shown in Table 6, male subjects exhibited significantly higher SBP measures in comparison to female subjects $(123.80 \pm 13.30 \mathrm{mmHg}$ vs. $117.74 \pm 13.23 \mathrm{mmHg}, \mathrm{p}<0.0001)$, 
also they exhibited significantly higher $\mathrm{Hgb}$ and $\mathrm{Hct}$ measures in comparison to females ( $\mathrm{Hgb}$ $15.45 \pm 1.56 \mathrm{~g} / \mathrm{dL}$ vs. $13.14 \pm 1.86 \mathrm{~g} / \mathrm{dL}, \mathrm{p}<0.0001$ and Hct $45.13 \pm 4.35 \%$ vs. $38.36 \pm 5.43 \%, \mathrm{p}$ $<0.0001)$. Whereas, female subjects exhibited significantly higher HDL-C levels in comparison to males $(58.84 \pm 18.31 \mathrm{mg} / \mathrm{dL}$ vs. $47.65 \pm 17.76 \mathrm{mg} / \mathrm{dL}, \mathrm{p}=0.0035)$ as well as TC levels $(176.82 \pm 38.06 \mathrm{mg} / \mathrm{dL}$ vs. $155.30 \pm 32.08 \mathrm{mg} / \mathrm{dL}, \mathrm{p}=0.004)$. Significant sex differences were also observed for CRP, with female subjects exhibiting greater CRP levels in comparison to male subjects ( $3.47 \pm 3.43 \mathrm{mg} / \mathrm{dL}$ vs. $1.15 \pm 1.48 \mathrm{mg} / \mathrm{dL}, \mathrm{p}<0.0001)$. No significant differences were observed for DBP, LDL-C, TG, FBG and HgbA1c between male and female subjects.

Table 6: Baseline Biochemical Characteristics by Sex

\begin{tabular}{|c|c|c|c|c|c|c|c|}
\hline \multirow[b]{2}{*}{ Characteristic } & \multicolumn{2}{|c|}{ All $(n=93)$} & \multicolumn{2}{|c|}{ Female $(n=45)$} & \multicolumn{2}{|c|}{ Male $(n=48)$} & \multirow{2}{*}{$\begin{array}{c}\text { Sex } \\
\text { Differences } \\
\text { P value }\end{array}$} \\
\hline & Mean & SD & Mean & SD & Mean & SD & \\
\hline $\mathrm{SBP}(\mathrm{mmHg})$ & 117.74 & 13.23 & 111.27 & 9.68 & 123.80 & 13.30 & $<0.0001^{*}$ \\
\hline LDL-C (mg/dL & 97.73 & 29.23 & 100.18 & 27.00 & 95.14 & 31.60 & 0.4618 \\
\hline HDL-C (mg/dL) & 53.06 & 18.79 & 58.84 & 18.31 & 47.65 & 17.76 & $0.0035^{*}$ \\
\hline $\mathrm{TC}(\mathrm{mg} / \mathrm{dL})$ & 165.72 & 36.54 & 176.82 & 38.06 & 155.30 & 32.08 & $0.004^{*}$ \\
\hline FBG (mg/dL) & 98.84 & 13.87 & 97.38 & 15.97 & 100.21 & 11.57 & 0.3280 \\
\hline CRP $(\mathrm{mg} / \mathrm{dL})$ & 2.77 & 2.84 & 3.47 & 3.43 & 1.15 & 1.48 & $<0.0001^{*}$ \\
\hline HBA1c (\%) & 5.28 & 0.40 & 5.31 & 0.50 & 5.25 & 0.29 & 0.4869 \\
\hline $\mathrm{Hgb}(\mathrm{g} / \mathrm{dL})$ & 14.33 & 2.06 & 13.14 & 1.86 & 15.45 & 1.56 & $<0.0001^{*}$ \\
\hline Hct (\%) & 41.98 & 5.93 & 38.36 & 5.43 & 45.13 & 4.35 & $<0.0001^{*}$ \\
\hline
\end{tabular}

SD - standard deviation

\section{Biochemical and Anthropometric Measures by Region}

There were no significant differences in anthropometric measures (height, weight, BMI \%BF, WC or NC) between Appalachian and Non-Appalachian subjects (Table 7). There were also no significant differences in biochemical measures (DBP, LDL-C, HDL-C, TC, TG, FBP, CRP, HbA1C, Hgb or Hct between Appalachian and Non-Appalachian subjects, except for TC (Appalachian $171.39 \pm 38.58$ vs. Non-Appalachian $152.77 \pm 28.43, p=0.021$ ).

Table 7: Biochemical and Anthropometric Measures by Region

\begin{tabular}{|c|c|c|c|c|c|c|c|}
\hline \multirow[b]{2}{*}{ Characteristic } & \multicolumn{2}{|c|}{$\begin{array}{c}\text { All } \\
(n=93)\end{array}$} & \multicolumn{2}{|c|}{$\begin{array}{l}\text { Appalachian } \\
(n=62)\end{array}$} & \multicolumn{2}{|c|}{$\begin{array}{c}\text { Non-Appalachian } \\
(\mathrm{n}=30)\end{array}$} & \multirow{2}{*}{$\begin{array}{c}\begin{array}{c}\text { Regional } \\
\text { Differences }\end{array} \\
\mathbf{P} \text { value } \\
\end{array}$} \\
\hline & Mean & SD & Mean & SD & Mean & SD & \\
\hline Height (cm) & 171.87 & 8.94 & 170.94 & 9.00 & 174.22 & 8.33 & 0.097 \\
\hline Weight (kg) & 73.04 & 15.58 & 73.19 & 16.78 & 73.05 & 13.3 & 0.968 \\
\hline BMI $\left(\mathrm{kg} / \mathrm{m}^{2}\right)$ & 24.70 & 4.81 & 25.04 & 5.40 & 23.99 & 3.34 & 0.332 \\
\hline $\mathrm{BF}(\%)$ & 22.84 & 10.64 & 23.37 & 11.27 & 21.45 & 9.30 & 0.420 \\
\hline $\mathrm{WC}(\mathrm{cm})$ & 84.13 & 15.37 & 83.28 & 13.56 & 82.67 & 9.38 & 0.825 \\
\hline $\mathrm{NC}(\mathrm{cm})$ & 35.68 & 3.70 & 35.51 & 3.79 & 36.12 & 3.58 & 0.466 \\
\hline $\mathrm{SBP}(\mathrm{mmHg})$ & 117.74 & 13.23 & 117.63 & 12.92 & 118.07 & 14.27 & 0.833 \\
\hline $\mathrm{DBP}(\mathrm{mmHg})$ & 69.41 & 8.97 & 70.18 & 8.60 & 67.93 & 9.80 & 0.265 \\
\hline LDL-C $(\mathrm{mg} / \mathrm{dL}$ & 97.93 & 29.23 & 101.21 & 32.39 & 87.81 & 16.50 & 0.076 \\
\hline
\end{tabular}




\begin{tabular}{|c|c|c|c|c|c|c|c|}
\hline HDL-C (mg/dL) & 53.06 & 18.79 & 53.34 & 19.55 & 52.50 & 17.75 & 0.843 \\
\hline $\mathrm{TC}(\mathrm{mg} / \mathrm{dL})$ & 165.72 & 36.64 & 171.39 & 38.58 & 152.77 & 28.43 & $0.021^{*}$ \\
\hline $\mathrm{TG}(\mathrm{mg} / \mathrm{dL})$ & 99.51 & 57.69 & 104.95 & 60.17 & 87.00 & 51.64 & 0.164 \\
\hline FBG (mg/dL) & 98.84 & 13.87 & 99.02 & 15.43 & 98.30 & 10.40 & 0.819 \\
\hline CRP (mg/dL) & 2.77 & 2.84 & 2.55 & 3.07 & 1.69 & 2.28 & 0.174 \\
\hline HBA1c (\%) & 5.28 & 0.40 & 5.32 & 0.44 & 5.18 & 0.29 & 0.115 \\
\hline $\mathrm{Hgb}(\mathrm{g} / \mathrm{dL})$ & 14.33 & 2.06 & 14.25 & 2.02 & 14.39 & 2.11 & 0.748 \\
\hline Hct (\%) & 41.98 & 5.93 & 41.62 & 5.78 & 42.37 & 6.10 & 0.584 \\
\hline
\end{tabular}

SD - standard deviation

\section{Correlations for BMI, CRP and MetS Components}

Significant correlations were found between BMI and elevated WC, low HDL-C, elevated DBP and increased TGs $(p<0.05)$ (Table 8). No significant correlations were noted for BMI and elevated SBP or impaired FBG measures. CRP significantly correlated with WC as well as DBP and TGs $(p<0.05)$. No significant correlations were observed between CRP and elevated SBP, low HDL-C, or impaired FBG.

Table 8: Correlations for BMI, CRP and MetS Components

\begin{tabular}{|c|c|c|c|c|c|c|}
\hline & WC & SBP & DBP & HDL-C & TG & FBG \\
\hline BMI & $.857^{*}$ & .121 & $.293^{*}$ & $-.426^{*}$ & $.223^{*}$ & .193 \\
\hline CRP & $.407^{*}$ & -.178 & $.245^{*}$ & -.088 & $.270^{*}$ & .017 \\
\hline
\end{tabular}

\section{Rates of Individual MetS Components}

The most common component of MetS exhibited by the total sample was elevated FBG (37.6\%, $n=35)$, followed by low HDL-C $(35.5 \%, n=33)$, elevated BP $(20.4 \%, n=19)$, elevated WC $(19.4 \%, n=18)$ and elevated TGs $(18.3 \%, n=17)$ (Table 9). For males, $8.3 \%(n=4)$ had elevated WC, 31.3\% $(n=19)$ elevated BP, 16.7\% $(n=8)$ elevated TGs, $47.9 \%(n=23)$ elevated FBG and 35.5\% $(n=19)$ low HDL-C. For females, 31.1\% $(n=14)$ had elevated WC, 8.9\% $(n=4)$ elevated BP, $20.0 \%(n=9)$ elevated TGs, $26.7 \%(n=12)$ elevated FBG and $31.1 \%(n=14)$ low HDL-C. Overall, females exhibited significantly greater WC $(31.1 \%(n=14)$ vs. $8.3 \%(n=4), p=0.0055)$, whereas, males displayed significantly greater BP $(31.3 \%(n=15)$ vs. $8.9 \%(n=4), p=0.0075)$ and FBG $(47.9 \%(n=23)$ vs. $26.7 \%(n=12), p=0.0345)$. For the subjects categorized to the Appalachian region, $21.0 \%(n=13)$ had elevated WC, $19.4 \%(n=$ 12) elevated BP, 21.0\% $(n=13)$ elevated TGs, 37.1\% $(n=23)$ elevated FBG and $35.5 \%(n=$ 22) low HDL-C. For the subjects categorized to the Non-Appalachian region, $16.7 \%(n=5)$ had 
elevated WC, 23.3\% $(n=7)$ elevated BP, 13.3\% $(n=4)$ elevated TGs, 36.7\% $(n=11)$ elevated FBG and $36.7 \%(n=11)$ low HDL-C. There were no significant differences observed between Appalachian vs. Non-Appalachian subjects in the rates of individual MetS components.

Table 9: Rates of Individual MetS Components

\begin{tabular}{|c|c|c|c|c|c|c|c|}
\hline \multirow[t]{2}{*}{ MetS Component } & \multicolumn{7}{|c|}{ Number (\%) with MetS Component (Total n/ Percentage \%) } \\
\hline & Overall & Males & Females & $P$ value & App & Non-App & P value $^{1}$ \\
\hline Elevated WC & $\begin{array}{c}18 \\
(19.4 \%)\end{array}$ & $\begin{array}{c}4 \\
(8.3 \%)\end{array}$ & $\begin{array}{c}14 \\
(31.1 \%)\end{array}$ & $0.0055^{*}$ & $\begin{array}{c}13 \\
(21.0 \%)\end{array}$ & $\begin{array}{c}5 \\
(16.7 \%)\end{array}$ & 0.6259 \\
\hline Elevated BP & $\begin{array}{c}19 \\
(20.4 \%)\end{array}$ & $\begin{array}{c}15 \\
(31.3 \%)\end{array}$ & $\begin{array}{c}4 \\
(8.9 \%)\end{array}$ & $0.0075^{*}$ & $\begin{array}{c}12 \\
(19.4 \%)\end{array}$ & $\begin{array}{c}7 \\
(23.3 \%)\end{array}$ & 0.6586 \\
\hline Elevated TGs & $\begin{array}{c}17 \\
(18.3 \%)\end{array}$ & $\begin{array}{c}8 \\
(16.7 \%)\end{array}$ & $\begin{array}{c}9 \\
(20.0 \%)\end{array}$ & 0.6777 & $\begin{array}{c}13 \\
(21.0 \%)\end{array}$ & $\begin{array}{c}4 \\
(13.3 \%)\end{array}$ & 0.3765 \\
\hline Elevated FBG & $\begin{array}{c}35 \\
(37.6 \%)\end{array}$ & $\begin{array}{c}23 \\
(47.9 \%)\end{array}$ & $\begin{array}{c}12 \\
(26.7 \%)\end{array}$ & $0.0345^{*}$ & $\begin{array}{c}23 \\
(37.1 \%)\end{array}$ & $\begin{array}{c}11 \\
(36.7 \%)\end{array}$ & 0.9680 \\
\hline Low HDL-C & $\begin{array}{c}33 \\
(35.5 \%)\end{array}$ & $\begin{array}{c}19 \\
(39.6 \%)\end{array}$ & $\begin{array}{c}14 \\
(31.1 \%)\end{array}$ & 0.3935 & $\begin{array}{c}22 \\
(35.5 \%)\end{array}$ & $\begin{array}{c}11 \\
(36.7 \%)\end{array}$ & 0.9117 \\
\hline
\end{tabular}

${ }^{1}$ Chi-square test

\section{Frequency of MetS and Number of MetS Components}

As shown in Table 10, 15.1\% $(n=14)$ of the total sample exhibited MetS; $28.0 \%(n=26)$ exhibited zero components, 33.1\% $(n=31)$ exhibited one component, $23.7 \%(n=22)$ exhibited two components, $10.8 \%(n=10)$ exhibited three components, $3.2 \%(n=3)$ exhibited four components and $1.1 \%(n=1)$ exhibited five components of MetS. There were no significant associations between the frequency of MetS by $\operatorname{sex}(p=0.3033)$ or the number of MetS components by sex $(p=0.2770)$. More male subjects presented with MetS in comparison to female subjects $(18.8 \%(n=9)$ vs. $11.1 \%(n=5))$. For males, $25.0 \%(n=12)$ exhibited zero components, $31.3 \%(n=15)$ exhibited one component, $25.0 \%(n=12)$ exhibited two components, $12.5 \%(n=6)$ exhibited three components, $6.3 \%(n=3)$ exhibited four components and $0 \%(n=0)$ exhibited five components of MetS. For females, $31.1 \%(n=14)$ exhibited zero components, 35.6\% $(n=16)$ exhibited one components, $22.2 \%(n=10)$ exhibited two components, $8.9 \%(n=4)$ exhibited three components, $0 \%(n=0)$ exhibited four components and $2.2 \%(n=1)$ exhibited five components of MetS. 
There were no significant differences between the frequency of MetS by region $(p=$ $0.3325)$ or the number of MetS components by region $(p=0.7795)$ (Table 10). More Appalachian participants presented with MetS in comparison to Non-Appalachian subjects $(17.7 \%(n=11)$ vs. $10.0 \%(n=3))$. For the subjects categorized to the Appalachian region $(n=$ 62), $29.0 \%(n=18)$ exhibited zero components, 30.7\% ( $n=19)$ exhibited one component, 22.6\% $(n=14)$ exhibited two components, 8.9\% $(n=4)$ exhibited three components, $0 \%(n=0)$ exhibited four components and 2.2\% $(n=1)$ exhibited five components of MetS. For the subjects categorized to the Non-Appalachian region $(n=30), 26.7 \%(n=8)$ exhibited zero components, $36.7 \%(n=11)$ exhibited one component, $26.7 \%(n=8)$ exhibited two components, 3.3\% $(n=1)$ exhibited three components, $6.7 \%(n=2)$ exhibited four components and $0 \%(n=0)$ exhibited five components of MetS.

Table 10: Frequency of MetS and Number of MetS Components

\begin{tabular}{|c|c|c|c|c|c|c|c|c|c|c|}
\hline \multirow{2}{*}{$\begin{array}{l}\text { Demographic } \\
\text { Variable }\end{array}$} & \multirow[t]{2}{*}{$\mathbf{N}$} & \multirow{2}{*}{$\begin{array}{l}\text { Total } n \\
\text { (\%) with } \\
\text { MetS }\end{array}$} & \multirow{2}{*}{$\begin{array}{l}\mathbf{P} \\
\text { value }^{1}\end{array}$} & \multicolumn{6}{|c|}{ Number of MetS Components (Total n/ Percentage \%) } & \multirow{2}{*}{$\begin{array}{l}\text { P } \\
\text { value }^{2}\end{array}$} \\
\hline & & & & 0 & 1 & 2 & 3 & 4 & 5 & \\
\hline Overall & 93 & $\begin{array}{c}14 \\
(15.1 \%)\end{array}$ & -- & $\begin{array}{c}26 \\
(28.0 \%)\end{array}$ & $\begin{array}{c}31 \\
(33.3)\end{array}$ & $\begin{array}{c}22 \\
(23.7)\end{array}$ & $\begin{array}{c}10 \\
(10.8)\end{array}$ & $\begin{array}{c}3 \\
(3.2 \%)\end{array}$ & $\begin{array}{c}1 \\
(1.1)\end{array}$ & \\
\hline Sex & & & 0.3033 & & & & & & & 0.2770 \\
\hline Males & 48 & $\begin{array}{c}9 \\
(18.8 \%)\end{array}$ & & $\begin{array}{c}12 \\
(25.0 \%)\end{array}$ & $\begin{array}{c}15 \\
(31.3)\end{array}$ & $\begin{array}{c}12 \\
(25.0)\end{array}$ & $\begin{array}{c}6 \\
(12.5)\end{array}$ & $\begin{array}{c}3 \\
(6.3 \%)\end{array}$ & $\begin{array}{c}0 \\
(0 \%)\end{array}$ & \\
\hline Females & 45 & $\begin{array}{c}5 \\
(11.1 \%)\end{array}$ & & $\begin{array}{c}14 \\
(31.1 \%)\end{array}$ & $\begin{array}{c}16 \\
(35.6)\end{array}$ & $\begin{array}{c}10 \\
(22.2)\end{array}$ & $\begin{array}{c}4 \\
(8.9 \%)\end{array}$ & $\begin{array}{c}0 \\
(0 \%)\end{array}$ & $\begin{array}{c}1 \\
(2.2)\end{array}$ & \\
\hline Region & & & 0.3325 & & & & & & & 0.7795 \\
\hline Appalachian & 62 & $\begin{array}{c}11 \\
(17.7 \%)\end{array}$ & & $\begin{array}{c}18 \\
(29.0 \%)\end{array}$ & $\begin{array}{c}19 \\
(30.7)\end{array}$ & $\begin{array}{c}14 \\
(22.6)\end{array}$ & $\begin{array}{c}9 \\
(14.5)\end{array}$ & $\begin{array}{c}1 \\
(1.6 \%)\end{array}$ & $\begin{array}{c}1 \\
(1.6)\end{array}$ & \\
\hline $\begin{array}{l}\text { Non- } \\
\text { Appalachian }\end{array}$ & 30 & $\begin{array}{c}3 \\
(10.0 \%)\end{array}$ & & $\begin{array}{c}8 \\
(26.7 \%)\end{array}$ & $\begin{array}{c}11 \\
(36.7)\end{array}$ & $\begin{array}{c}8 \\
(26.7)\end{array}$ & $\begin{array}{c}1 \\
(3.3 \%)\end{array}$ & $\begin{array}{c}2 \\
(6.7 \%)\end{array}$ & $\begin{array}{c}0 \\
(0 \%)\end{array}$ & \\
\hline
\end{tabular}

Chi-square test

${ }^{2}$ Mantel-Haenszel test for trend

\section{Rates of High hsCRP}

Table 11 shows that $20.7 \%(n=18)$ of the 87 subjects with available data exhibited a CRP level > $3.0 \mathrm{mg} / \mathrm{dL}$. Overall, females exhibited significantly higher CRP levels in comparison to males $(33.3 \%(n=13)$ vs. $10.4 \%(n=5), p=0.0152)$. Appalachian subjects tended to have a greater percentage of high CRP (Appalachian 24.6\% ( $n=14)$ vs. Non-Appalachian 13.8\% ( $n=$ $4)$, but this difference did not reach statistical significance $(p=0.2790)$. For the subjects 
exhibiting MetS, 27.3\% $(n=3)$ displayed high CRP levels, whereas 19.7\% $(n=15)$ of those without MetS also displayed CRP levels $>3.0 \mathrm{mg} / \mathrm{dL}$. There were no trends identified by the Cochran-Armitage test between the number of components and the incidence of high CRP $(p=$ 1.0000). Of the subjects with elevated WC (males $>102 \mathrm{~cm}$, females $>88 \mathrm{~cm}), 46.7 \%(\mathrm{n}=7)$ had high CRP levels, whereas, only $15.3 \%(n=11)$ with normal WC measures had high CRP level, exhibiting a statistical difference $(p=0.0152)$. Of the subjects with elevated BP $(\geq 130 / 85$ $\mathrm{mmHg}), 11.8 \%(\mathrm{n}=2)$ had high CRP levels and $22.9 \%(\mathrm{n}=16)$ with normal BP also had high CRP levels. Of the participants with elevated TGs ( $\geq 150 \mathrm{mg} / \mathrm{dL}), 16.7 \%(\mathrm{n}=2)$ displayed high levels of CRP and $21.3 \%(n=16)$ with normal TG levels also exhibited high CRP levels. For the subjects with elevated FBG $(\geq 100 \mathrm{mg} / \mathrm{dL}), 11.8 \%(\mathrm{n}=4)$ exhibited high CRP levels, whereas, 26.4\% $(n=14)$ with normal FBG also displayed high CRP levels. For the subjects with low HDLC (males $<40 \mathrm{mg} / \mathrm{dL}$, females $<50 \mathrm{mg} / \mathrm{dL}), 24.1 \%(\mathrm{n}=7)$ exhibited high CRP, whereas, $19.0 \%$ ( $n=11$ ) with normal levels of HDL-C also had high CRP levels.

Table 11: Rates of High (> 3.0) CRP

\begin{tabular}{|c|c|c|c|}
\hline Demographic Characteristic & $\mathbf{N}$ & $\begin{array}{c}\text { Frequency (\%) with } \\
\text { High CRP }\end{array}$ & $P$ value \\
\hline Overall & 87 & $18(20.7 \%)$ & -- \\
\hline $\begin{array}{l}\text { Sex } \\
\text { Males } \\
\text { Females }\end{array}$ & $\begin{array}{l}48 \\
39\end{array}$ & $\begin{array}{c}5(10.4 \%) \\
13(33.3 \%)\end{array}$ & $0.0152^{*}$ \\
\hline $\begin{array}{l}\text { Region } \\
\text { Appalachian } \\
\text { Non-Appalachian }\end{array}$ & $\begin{array}{l}57 \\
29\end{array}$ & $\begin{array}{c}14(24.6 \%) \\
4(13.8 \%)\end{array}$ & 0.2790 \\
\hline $\begin{array}{l}\text { Metabolic Syndrome } \\
\text { Yes } \\
\text { No }\end{array}$ & $\begin{array}{l}11 \\
76\end{array}$ & $\begin{array}{c}3(27.3 \%) \\
15(19.7 \%)\end{array}$ & 0.6904 \\
\hline $\begin{array}{l}\text { Number of MetS } \\
\text { Components } \\
0 \\
1 \\
2 \\
3 \\
4 \\
5\end{array}$ & $\begin{array}{c}26 \\
29 \\
21 \\
8 \\
3 \\
0\end{array}$ & $\begin{array}{c}7(26.9 \% \\
3(10.3 \%) \\
5(23.8 \%) \\
3(27.5 \%) \\
0(0 \%) \\
--\end{array}$ & $1.0000^{2}$ \\
\hline $\begin{array}{l}\text { WC } \\
\text { Elevated } \\
\text { Normal }\end{array}$ & $\begin{array}{l}15 \\
72\end{array}$ & $\begin{array}{c}7(46.7 \%) \\
11(15.3 \%)\end{array}$ & $0.0121^{*}$ \\
\hline $\begin{array}{l}\text { BP } \\
\text { Elevated } \\
\text { Normal }\end{array}$ & $\begin{array}{l}17 \\
70\end{array}$ & $\begin{array}{c}2(11.8 \%) \\
16(22.9 \%)\end{array}$ & 0.5059 \\
\hline $\begin{array}{l}\text { TG } \\
\text { Elevated } \\
\text { Normal }\end{array}$ & $\begin{array}{l}12 \\
75\end{array}$ & $\begin{array}{c}2(16.7 \%) \\
16(21.3 \%)\end{array}$ & 1.0000 \\
\hline $\begin{array}{l}\text { FBG } \\
\text { Elevated } \\
\text { Normal }\end{array}$ & $\begin{array}{l}34 \\
53\end{array}$ & $\begin{array}{c}4(11.8 \%) \\
14(26.4 \%)\end{array}$ & 0.1134 \\
\hline
\end{tabular}




\begin{tabular}{|l|c|c|c|}
\hline HDL-C & & & 0.5850 \\
Low & 29 & $7(24.1 \%)$ & \\
Normal & 58 & $11(19.0 \%)$ & \\
\hline
\end{tabular}

'Unless otherwise noted, $p$-value based on Fisher's Exact Test

${ }^{2}$ Cochran-Armitage test for trend (exact $p$-value)

\section{Anthropometric and Biochemical Changes from Baseline}

There were no significant changes in weight, BMI, WC or \%BF in the intervention (I) versus control (C) group post-intervention (baseline to 3 months) (Table 12). There were also no significant changes in SBP, DBP, LDL-C, HDL-C, TG or CRP. In the intervention group only, there was a significant difference in FBG levels from baseline to 3 months demonstrated by the $95 \% \mathrm{Cl}$ not containing zero (7.37, -1.19). There was also a significant change in FBG observed in the intervention group from baseline to 3 months in comparison to the control group $(-4.29(-7.37,-1.19)$ vs. $0.66(-2.64,3.95), p=0.0318)$. In addition, there was a significant difference in CRP levels in the control group from baseline to 3 months demonstrated by the $95 \% \mathrm{Cl}$ not containing zero $(0.07,1.72)$. There were also additional trends of improvement that failed to reach significance covered in the discussion. There were no significant changes in weight, BMI, WC or \%BF in the intervention versus control group from baseline to the 15 month follow-up. In the intervention group only, there was a significant difference between their baseline and 15 month values for FBG demonstrated by the $95 \% \mathrm{CI}$ not containing zero $(-6.01,-0.06)$. There were no significant changes in WC, SBP, DBP, LDL-C, HDL-C, TG, FBP or CRP observed in the intervention versus control group.

Table 12: Mixed Model Results Changes from Baseline

\begin{tabular}{|c|c|c|c|c|c|c|c|c|c|c|c|c|}
\hline \multirow[b]{3}{*}{ Measure } & \multicolumn{6}{|c|}{ Number of Observations } & \multirow{2}{*}{\multicolumn{3}{|c|}{$\begin{array}{c}\text { Mean Change } \\
(3 \text { mo - Baseline }) \\
(95 \% \mathrm{Cl})^{*}\end{array}$}} & \multirow{2}{*}{\multicolumn{3}{|c|}{$\begin{array}{c}\text { Mean Change } \\
(15 \text { mo - Baseline }) \\
(95 \% \mathrm{Cl})^{*}\end{array}$}} \\
\hline & \multicolumn{2}{|c|}{ Baseline } & \multicolumn{2}{|c|}{$3 \mathrm{mo}$} & \multicolumn{2}{|c|}{$15 \mathrm{mo}$} & & & & & & \\
\hline & 1 & C & 1 & C & I & C & Intervention & Control & Pvalue & Intervention & Control & pvalue \\
\hline Weight & 49 & 44 & 34 & 30 & 28 & 29 & $-0.12(-0.95,0.71)$ & $0.37(-0.50,1.23)$ & 0.4230 & $0.86(-0.69,2.42)$ & $-0.15(-0.69,2.42)$ & 0.3662 \\
\hline BMI & 49 & 44 & 34 & 29 & 27 & 29 & $-0.01(-0.29,0.27)$ & $0.24(-0.05,0.54)$ & 0.2201 & $0.42(-0.11,0.95)$ & $0.42(-0.11,0.95)$ & 0.3072 \\
\hline BF & 49 & 44 & 34 & 30 & 28 & 29 & $0.12(-0.35,0.58)$ & $0.46(-0.03,0.95)$ & 0.3105 & $0.69(-0.40,1.78)$ & $0.04(-1.02,1.11)$ & 0.4033 \\
\hline wc & 49 & 99 & 34 & 30 & 28 & 29 & $0.49(-0.81,1.80)$ & $-0.23(-1.60,1.13)$ & 0.4431 & $1.60(-1.33,4.54)$ & $-1.43(-4.38,1.52)$ & 0.1504 \\
\hline SBP & 49 & 44 & 35 & 31 & 27 & 29 & $-5.76(-8.34,-3.17)$ & $-4.76(-7.49,-2.01)$ & 0.5984 & $-3.03(-6.01,-0.06)$ & $-2.62(-5.52,0.28)$ & 0.8433 \\
\hline DBP & 49 & 44 & 35 & 31 & 27 & 29 & $-0.21(-2.29,1.86)$ & $-0.14(-2.35,2.07)$ & 0.9604 & $-0.09(-2.38,2.21)$ & $0.24(-2.00,2.47)$ & 0.8409 \\
\hline LDL-C & 39 & 35 & 22 & 18 & 21 & 19 & $7.02(-3.48,17.53)$ & $11.22(-0.29,22.73)$ & 0.5898 & $4.62(-6.36,15.60)$ & $4.67(-6.83,16.17)$ & 0.9954 \\
\hline HDL-C & 49 & 44 & 34 & 30 & 26 & 29 & $0.11(-3.29,3.52)$ & $-3.20(-6.83,0.44)$ & 0.1882 & $0.96(-4.62,6.54)$ & $1.88(-3.38,7.14)$ & 0.8103 \\
\hline TG & 49 & 44 & 34 & 29 & 26 & 29 & $-1.70(-16.30,12.90)$ & $-9.09(-24.89,6.70)$ & 0.4952 & $0.81(-14.22,15.84)$ & $-0.76(-15.14,13.64)$ & 0.8805 \\
\hline FBG & 49 & 44 & 34 & 29 & 26 & 29 & $-4.29(-7.37,-1.19)$ & $0.66(-2.64,3.95)$ & $0.0318^{*}$ & $8.99(-1.00,18.98)$ & $2.18(-7.26,11.61)$ & 0.3249 \\
\hline CRP & 49 & 43 & 33 & 28 & 26 & 29 & $0.08(-0.67,0.83)$ & $0.90(0.07,1.72)$ & 0.1479 & $0.65(-0.39,1.69)$ & $-0.11(-1.10,1.69)$ & 0.2893 \\
\hline
\end{tabular}

$\mathrm{I}=$ Intervention group, $\mathrm{C}=$ Control group 


\section{Metabolic Risk at Baseline, Post-Intervention and Follow-Up}

No significant differences in the prevalence of MetS risk criteria were found between the intervention and control groups at baseline, post-intervention (3 months) or during the follow-up (15 months) physical assessments, illustrated by Table 13. Both groups exhibited fairly even distributions in the number of MetS elevations during each of the three assessments. On average, FBG was the leading MetS risk factor for both groups at baseline, followed by decreased HDL-C. At 3 months, decreased HDL-C was the leading MetS risk factor postintervention, followed by increased FBG, increased WC, increased TGs, and increased WC. During the 15 month follow-up increased FBG became the dominant MetS risk factor for both groups, followed by decreased HDL-C, increased BP, increased WC and increased TGs.

Overall, the most common MetS risk factors observed for this study's sample was increased FBG and decreased HDL-C.

Table 13: Mets Analysis for Baseline, 3 Months and 15 Months

\begin{tabular}{|c|c|c|c|}
\hline Characteristic & $\begin{array}{l}\text { Intervention Group } \\
\text { Mean }(95 \% \mathrm{Cl})\end{array}$ & $\begin{array}{c}\text { Control } \\
\text { Group } \\
\text { Mean }(95 \% \mathrm{Cl}) \\
\end{array}$ & p-value ${ }^{1}$ \\
\hline MetS & & & 0.5028 \\
\hline 0 months & $14.2(6.8,27.5)$ & $15.9(7.6,30.2)$ & \\
\hline 3 months & $6.5(1.7,21.3)$ & $18.1(7.9,36.2)$ & \\
\hline 15 months & $8.6(2.2,28.0)$ & $11.0(3.7,28.6)$ & \\
\hline Number of MetS Elevations & & & 0.3909 \\
\hline 0 months & $1.3(1.0,1.7)$ & $1.3(1.0,1.7)$ & \\
\hline 3 months & $0.9(0.6,1.2)$ & $1.2(0.8,1.6)$ & \\
\hline 15 months & $1.1(0.8,1.5)$ & $1.3(0.9,1.7)$ & \\
\hline High WC & & & 0.4721 \\
\hline 0 months & $18.4(9.7,32.1)$ & $20.5(10.8,35.3)$ & \\
\hline 3 months & $15.2(7.1,29.3)$ & $18.0(8.7,33.5)$ & \\
\hline 15 months & $18.0(8.7,33.6)$ & $14.3(6.1,29.9)$ & \\
\hline High FBG & & & 0.0977 \\
\hline 0 months & $36.7(24.3,51.3)$ & $38.6(25.3,54.0)$ & \\
\hline 3 months & $12.3(4.6,28.7)$ & $37.4(21.6,56.5)$ & \\
\hline 15 months & $47.6(29.1,66.9)$ & $42.6(25.7,61.5)$ & \\
\hline High BP & & & 0.5840 \\
\hline 0 months & $20.4(11.2,34.3)$ & $20.5(10.8,35.3)$ & \\
\hline 3 months & $8.8(2.9,23.9)$ & $15.8(6.6,33.1)$ & \\
\hline 15 months & $18.8(8.4,36.6)$ & $17.7(7.8,35.2)$ & \\
\hline High TGs & & & 0.5595 \\
\hline 0 months & $20.4(11.2,34.3)$ & $15.9(7.6,30.2)$ & \\
\hline 3 months & $11.7(4.4,27.3)$ & $14.8(5.9,32.5)$ & \\
\hline 15 months & $8.3(2.3,26.3)$ & $13.1(4.9,30.3)$ & \\
\hline Low HDL-C & & & 0.8024 \\
\hline 0 months & $34.7(22.5,49.3)$ & $36.4(23.3,51.7)$ & \\
\hline 3 months & $35.8(22.2,49.3)$ & $38(23.3,55.4)$ & \\
\hline 15 months & $24.5(11.2,45.4)$ & $35.6(19.9,55.2)$ & \\
\hline
\end{tabular}




\section{CHAPTER V}

\section{DISCUSSION}

\section{Prevalence of MetS and Risk Components}

Overall, $15.1 \%$ (Table 10) of the study population exhibited MetS, which is higher than what has been reported in previous studies $(0.6 \%$ to $10 \%)(2-5,39)$ of young adults, 18 to 24 years. Of the 93 WVU-based subjects, 33.3\% $(n=21)$ displayed one component and $23.7 \%(n$ = 22) displayed two components of MetS (Table 10). A previous study by Fernandes et al. (2011) reported $28.0 \%$ of the subjects attending the University of Rhode Island exhibited at least one component (2), whereas, Keown et al. (2009) reported as many as $43 \%$ of the subjects ( $n=$ 9) attending a southeastern university had at least one component (3), which is consistent with the findings in this particular study. An earlier study performed by Huang et al. (2004) at the University of Kansas reported $25.2 \%$ of the subjects displayed one component and only $1.2 \%$ of the subjects displayed two components of MetS (5). Taken together, these findings suggest the prevalence of MetS risk is increasing among young adults, ages 18 to 24 years, adding additional evidence of increasing national trends of MetS over the past several decades (70).

\section{Regional Differences in MetS Risk}

No significant differences in the prevalence of MetS, number of MetS components or rate of MetS components were found for subjects categorized as Appalachian or NonAppalachian (Table 7). These findings were surprising to the researchers and may be due to several reasons. First, this study contained a small sample size so these regional groups may not accurately represent the entire population. Other causes may include: self-reported home address, unequal distribution of Appalachian vs. Non-Appalachian subjects (Table 4) or recent address change. However, when comparing these data to those from other multi-state partners, regional differences in biochemical measures were found between the University of New 
Hampshire (UNH), Rutgers University (RU) and WVU. As described in Table 14, greater number of subjects from WVU (15.2\%) displayed MetS in comparison to those at the UNH (3.1\%) and RU (4.7\%) (Table 14). Previous studies have reported the prevalence of MetS in young adults to be $0.6 \%$ (5) to $1.3 \%$ (4) in the Midwestern region, $3.7 \%$ (2) in the New England region and up to $10 \%$ (3) in the Southeastern region. Although differences between Appalachian and Non-Appalachian subjects were not found at WVU, the multi-state data shows that students attending college in the Appalachian region were found to have a greater prevalence of obesity and risk of developing MetS when compared to other US region, a finding that is consistent with national survey data (27).

Table 14: Prevalence of MetS at Baseline for Three Universities

\begin{tabular}{|l|c|c|c|}
\hline & Total & Men & Women \\
\hline Rutgers University (\%) & 4.7 & 3.2 & 5.3 \\
\hline University of New Hampshire (\%) & 3.1 & 2.7 & 3.4 \\
\hline West Virginia University (\%) & 15.2 & 18.8 & 11.4 \\
\hline
\end{tabular}

\section{Differences in MetS Risk According to Sex}

Overall, male subjects attending WVU were more likely to exhibit MetS in comparison to female subjects (Table 10). This finding could be attributed to the increased incidence of high BP and impaired FBG observed in the male subjects (Table 9). Another study by Morrell et al. (2012) reported male subjects exhibited significantly higher BP and FBG levels, which attributed to their increased prevalence of MetS when compared to female subjects (9.9\% vs. 3.0\%) (39). Huang et al. (2007) also reported that males were more likely to exhibit MetS in comparison to females, which they attributed to the higher prevalence of abdominal obesity, illustrated by increased WC, among the male participants (4). Yet, this was not the case for WVU's male subjects who exhibited lower WC measures in comparison to their female counterparts (Table 9). 
Research evaluating the prevalence of MetS in the young adult population has been limited by uneven sex distributions $(2,39)$. Although the study by Morrell et al. had more female subjects ( 1,528 females vs. 575 males), a greater percentage of males exhibited MetS in comparison to females $(9.9 \%$ vs. $3.0 \%)$. In contrast, the study by Fernandes et al. found female subjects had greater percentages for each MetS risk factor in comparison to the male subjects (2). This study indicates female subjects are more likely to develop MetS, yet, the female to male ratio was reported to be 2:1 (2). To date, researchers have yet to reach a consensus regarding sex differences in terms of MetS risk. Additional studies containing equal sex distributions are needed in order to evaluate a relationship between MetS risk and sex.

In this study, female subjects were more likely to be overweight and obese in comparison to the male subjects, demonstrated by greater BMI and WC and significantly greater $\mathrm{BF} \%$ (Table 5). This finding could be attributed to the increased number of females categorized as Appalachian residents ( $n=32,71 \%$ ), which increases the likelihood of poor diet quality and sedentary behavior (24). Further, over half of the female subjects $(n=29,64.4 \%)$ were categorized as first or second year students, with research literature supporting that $70 \%$ of weight gain occurs during students' first two years and begins to plateau throughout the rest of their college career ${ }^{1}$. A recent study by Morrell et al. reported female subjects attending the $\mathrm{UNH}$ were less likely to be overweight or obese $\left(\mathrm{BMI} \geq 25 \mathrm{~kg} / \mathrm{m}^{2}\right)$ in comparison to the male subjects (27.2\% vs. $46.9 \%)$ (39) . However, two additional studies by Fernandes et al. and Huang et al. reported males had significantly greater BMI and mean WC measures in comparison to the female subjects $(2,4)$. Although the male subjects in this study were less likely to be overweight or obese, they still exhibited greater risk of developing MetS due to other risk factors. Another study by Keown et al. reported $50 \%$ of subjects exhibiting a normal BMI $\left(18.5-24.9 \mathrm{~kg} / \mathrm{m}^{2}\right)$ had at least one component of MetS (3). Therefore, future research should consider screening young adults, regardless of weight status, for MetS risk factors. 


\section{MetS Components and hsCRP Levels}

In this study, significant correlations were found between CRP and WC $(p<0.001)$ as well as elevated DBP and TGs $(p<0.05)$. There were no significant correlations between BMI and SBP or FBG (Table 8). These findings are similar to another study by Raitakari et al. in young adults, ages 24 to 39 years, that reported significant correlations between hsCRP and WC $(p<0.0001)$ in males and between hsCRP and TGs for females $(p<0.0001)(19)$ suggesting inflammation markers and blood fat may be an important measurement in risk screening for this population. Another study by Keown et al. in 18 to 24 year olds also found significant correlations between BMI and TGs and well as BMI and WC $(p<0.01)(3)$. Nearly twenty percent of the subjects had high levels of hsCRP (>3.0 mg/dL), but did not exhibit MetS. Another study by El-Shorbagy et al. also reported $12.7 \%$ of the subjects that did not display MetS had hsCRP levels $>3 \mathrm{mg} / \mathrm{dL}$ (17). While, these data question the value of using hsCRP in the assessment of MetS, more research is needed in this young adult population in order to assess the value of including hsCRP measures alongside traditional MetS criteria.

\section{Differences in hsCRP Levels According to Sex}

A number of researchers have reported a positive relationship between increased BMI and hs-CRP levels (53). This could explain why the female subjects' hsCRP levels were significantly greater in comparison to their male counterparts $(3.47 \pm 3.43 \mathrm{mg} / \mathrm{dL}$ vs. $1.15 \pm 1.48$ $\mathrm{mg} / \mathrm{dL}$ ). Additional research has also shown subjects displaying central obesity also have higher hsCRP levels $(13,71)$, which is consistent in this particular sample of students. Some researchers believe that differences in hsCRP concentrations according to sex in adults could be explained by the use of oral contraceptives (OC) (16). In this study, $47 \%(n=21)$ of the females reported taking OCs at baseline and roughly half $(n=11)$ exhibited hsCRP levels $\geq 3$ $\mathrm{mg} / \mathrm{dL}$, indicative of high cardiovascular risk. A study conducted by Cauci et al. on young 
women ( $n=277$, mean age 23 years) reported OC users were four times more likely to have hsCRP at intermediate ( 1 to $3 \mathrm{mg} / \mathrm{dL}$ ) and high ( 3 to $10 \mathrm{mg} / \mathrm{dL}$ ) cardiovascular risk levels than non-users (72). Another study by Dreon et al. on women, aged 18 to 40 years, found plasma CRP levels were two times higher among OC users $(2.0 \pm 0.2$ vs. $0.9 \pm 0.3 \mathrm{mg} / \mathrm{dL}, \mathrm{p}<0.0001)$ than non-users (59). Therefore, it appears to be important for researchers to gather information on the use of OCs when measuring hsCRP levels in young adult women.

There was no significant change in hsCRP levels from baseline to 3 months for the intervention group (Table 12). However, a significant change in hsCRP levels was observed from baseline to 3 months for the control group (Table 12). This could be attributed to the positive weight change exhibited by the control group during this time. From baseline to 15 months, the control group exhibited lower hsCRP levels and a negative weight change, whereas, the intervention group exhibited positive weight gain and higher hsCRP levels (Table 12). These findings support the work from De Ferranti et al.'s that suggest a positive relationship exists between weight status and levels of hsCRP (44).

\section{Post-Intervention Findings}

To date, no research studies have been published that evaluate MetS risk pre- and postweb-based intervention in young adults, ages 18 to 24 . Yet, a number of researchers have identified components of MetS in college students across various regions of the US. In 2004, Huang et al. reported $27 \%$ of college students attending the University of Kansas exhibited at least one component of MetS (5). Later in $2007,33 \%$ of students attending this same university exhibited at least one component of MetS (4). Keown et al. found $43 \%$ of students at a southeastern university had at least one component of MetS (3). The most recent study by Fernandes et al reported $28 \%$ of students attending a northern university exhibited at least one component of MetS(2). As researchers continue to publish on the prevalence of MetS in the 
young adult population, the need for risk identification and the development of therapeutic interventions is becoming more evident.

During the baseline physical assessment, the average number of MetS risk factors was 1.3 for the intervention and control group subjects. There was no significant change in the average number of MetS risk factors for the intervention or control groups from baseline to postintervention (3 months) or baseline to 15 months (Table 13). Although, there appeared to be a downward trend moving toward improvement in several of the subjects within the intervention group exhibiting MetS from baseline to post-intervention (3 months), but this trend was not sustained at the 15 month follow-up. A similar downward trend was observed in the number of intervention group subjects exhibiting individual components of MetS, except for HDL-C, from baseline to 3 months. The downward trends observed in the intervention group suggest the 10 week, web-based intervention, was more effective when e-mail messages were sent four times each week to encourage participants to visit the YEAH Project website rather than four times each month over the 15 month follow-up period. These findings suggest the repetitive exposure to behavior change learning and suggestions may need to occur more frequently than the design of this particular study.

Some researchers suggest elevated FBG does not seem to be as much of a factor in this particular population (2). Yet in 2004, Huang et al. reported $>6 \%$ of participants, 18 to 24 years, had pre-diabetes (5). In this study, 34.4\% $(n=32)$ of the subjects had pre-diabetes, illustrated by FBG levels $\geq 100 \mathrm{mg} / \mathrm{dL}$ and $3.2 \%(n=3)$ fell into the diagnostic criteria for diabetes (FBG levels $\geq 126 \mathrm{mg} / \mathrm{dL}$ ) according to the American Diabetes Association. From baseline to post-intervention (3 months), the subjects receiving the intervention component exhibited a significant change in FBG. There was also a significant difference $(p=0.0318)$ between the FBG levels of subjects in the intervention and control group from baseline to 3 months. Subjects in the intervention group improved their FBG levels from baseline to 3 months, 
whereas, the control group subjects exhibited a slight increase in FBG levels. Therefore, the intervention appeared to have a positive effect on FBG measures during the 10 week period. However, these improvements were not sustained from baseline to the 15 month follow-up period. These findings also suggest the incidence of impaired glucose tolerance is increasing among this age group. In order to prevent the onset of T2DM, researchers should consider screening FBG levels in 18 to 24 year olds in order to determine their level of risk and develop risk-specific lifestyle modifications to reverse the progression of chronic disease.

Together, the intervention and control groups both exhibited significant changes in SBP from baseline to post-intervention (3 months) indicating improvement. SBP and DBP measures were reported separately in order to closely monitor SBP, which is an important CVD risk factor. The significant change was sustained by the intervention group from baseline to 15 months. There were no significant differences in SBP between the intervention and control groups from baseline to post-intervention (3 months) or baseline to 15 months. Researchers identified elevated BP as one of the most prevalent components of MetS exhibited by young adults 20 years and older from the 2003-2006 NHANES dataset (2). Although elevated BP was not one of the leading components of MetS displayed by the subjects (Table 13) in this study, routine BP screenings require minimal subject burden with a low cost. Further, a study by Urbina et al. reported increased left ventricular mass, carotid thickness, arterial stiffness, and decreased diastolic function in youth (ages 10 -23 years) with pre-hypertension, all of which set the stage for the onset of CVD (73). Future research is needed to demonstrate the benefits of measuring the individual components (SBP and DBP) of BP in order to prevent the onset of hypertension among young adults.

At this time, the multi-state findings are not available to report for the 14 institution YEAH Project. Many of the questions that arose in this study could be further explained as the multistate data becomes available and is assessed across the different institutions and regions. 
Further, it is recognized that this study's small sample greatly reduced the statistical power leading to many unanswered questions. In order to better understand the findings of this study, the larger sample size from the multi-state data will further inform these findings.

\section{Study Limitations}

Many of the measures were performed in duplicate (i.e. HT, WT, BMI, \%BF, WC, NC, $\mathrm{HC}$, and $\mathrm{BP}$ ), but only single biochemical measures were taken in order to reduce subject burden and research cost. Although this could result in measurement errors which go undetected, biochemical measurements have well established normative values and are frequently used for point-of-care testing. In addition, researchers were able to evaluate each gross measurement during the analysis to monitor for measurement error. The average measurement variability for the Cholestech LDX Analyzer, DCA Vantage and HemoPoint A2 systems is reported to be less than $5 \%$, falling into a $2-3 \%$ range based on the manufacturers precision and variability reports. The lowest difference observed in any of the biochemical assessments was $9 \%$, which indicates the lack of verification from repeated measure outcome should not impact the overall interpretation for any of the biochemical assessments made.

The small sample size of this dataset limits the statistical power and reduces the ability to broadly interpret these data. However, this study is just a piece of a coordinated multi-state effort, using the same protocols and equipment, to address the principal hypothesis that a 10 week, web-based, lifestyle intervention would result in the prevention of weight gain in young adults, 18 to 24 years. Although our target recruitment was 180 subjects, we only obtained a total of 93 subjects. Potential reasons for lower than expected enrollment included, 1) campus chosen for the study was less accessible to students, as several reported transportation and parking issues, 2) students may have felt the baseline monetary incentive $(\$ 10.00)$ was inadequate for their effort and time commitment and 3) baseline assessments were initiated during a time of winter weather conditions, which might have further contributed to the 
transportation issues and recruitment numbers. Although some students were lost during the 3 month physical assessment due to its proximity to finals week, retention rates were maintained throughout the length of study (i.e. $72 \%$ at 3 months and $68 \%$ at 15 months, respectively).

Our ability to compare between Appalachian vs. Non-Appalachian subjects was limited due to an uneven distribution of Appalachian and Non-Appalachian participants (63 vs. 30). Yet, it was expected that Appalachian's would comprise a greater percentage for the study group. However, given that subjects were only instructed to provide their home (permanent) address, researchers were unable to determine the length of stay at the self-reported home address. Therefore, researchers were unable to capture Appalachian participants' exposure to lifestyle behaviors (i.e. obesity/overweight, sedentary behavior, poor dietary habits, increased incidence of diabetes and other comorbidities), that distinguish people living in Appalachia from other regions in the US. A more detailed account for where the subjects were raised and lived needed to be performed to more accurately differentiate true Appalachian vs. Non-Appalachian subjects in this dataset. It will be very useful to compare Appalachian vs. Non-Appalachian subjects when combined with data from the other multi-state partners. 


\section{CHAPTER VI \\ SUMMARY AND CONCLUSIONS}

\section{Summary of Findings}

In summary, the findings from this study demonstrate that MetS risk factors are present in young adults, ages 18 to 24 years. At baseline, male subjects were more at risk of developing MetS in comparison to the female subjects. Although researchers believed regional status may be very telling in this population, there were no significant differences explained by regional status (Appalachian vs. Non-Appalachian). Positive correlations were observed between hsCRP levels and elevated WC, elevated DBP, and increased TGs. In addition, BMI was shown to significantly correlate with WC, supporting the idea that increased adipose tissue located in the abdominal (visceral) region contributes to increased levels of hsCRP. Of all the measures taken, SBP and FBG were the most notable in terms of change. There was a significant change in the FBG levels among the intervention group from baseline to post-intervention as well as a significant difference in FBG levels between the intervention and control subjects from baseline to post-intervention (3 months). A significant improvement in SBP was observed from baseline to post-intervention ( 3 months) as well as baseline to 15 months among the intervention group. Overall, the change in MetS risk over time was minimal, which indicates the dosage of the intervention may not have been strong enough for young adults already exhibiting components of MetS to show improved biomarkers. However, this study supports previous research indicating young adults are at risk for developing MetS.

\section{Conclusion}

This study found approximately $1 / 3$ of the subjects exhibited at least one component of MetS. Due to this large percentage of individuals moving toward the onset of MetS, the intervention component should have been more aggressive and specifically tailored to address this high risk population of subjects. For example, students that were classified as obese (BMI 
$\geq 30 \mathrm{~kg} / \mathrm{m}^{2}$ ) and exhibited FBG levels $\geq 126 \mathrm{mg} / \mathrm{dL}$ (illustrating diabetes) would benefit from an intervention targeting their specific chronic condition and how they can effectively modify their weight status and glucose measures, whereas, students that were regularly exercising, consuming at least 2 servings of fruits and vegetables and exhibiting a normal BMI (18.5 - 24.9 $\mathrm{kg} / \mathrm{m}^{2}$ ) might benefit from a more general intervention promoting ways to incorporate more fruits and vegetables into their diet. Researchers have shown young adults, 18 to 24 years, are at risk for developing MetS. However, no one to our knowledge has implemented a web-based intervention to assess for changes in MetS risk over time. Additional research is needed in order to further assess representative samples of young adults attending higher education institutions and their presentation of chronic disease. In future studies, screening for at risk individuals will allow researchers to tailor and implement effective behavioral interventions across various university settings. 


\section{References}

1. Nelson MC, Story M, Larson NI, Neumark-Sztainer D, Lytle LA. Emerging adulthood and college-aged youth: An overlooked age for weight-related behavior change. Obesity. 2008:16(10):2205-2211.

2. Fernandes J, Lofgren IE. Prevalence of metabolic syndrome and individual criteria in college students. Journal of American College Health. 2011;59(4):313-321.

3. Keown TL, Smith CB, Harris MS. Metabolic syndrome among college students. Journal of Nurse Practitioners. 2009;5(10):754-759.

4. Huang TTK, Shimel A, Lee RE, Delancey W, Strother ML. Metabolic risks among college students: Prevalence and gender differences. Metabolic Syndrome and Related Disorders. $2007 ; 5(4): 365-372$.

5. Huang TT-, Kempf AM, Strother ML, Li C, Lee RE, Harris KJ, Kaur H. Overweight and components of the metabolic syndrome in college students. Diabetes Care. 2004;27(12):30003001.

6. Racette SB, Deusinger SS, Strube MJ, Highstein GR, Deusinger RH. Changes in weight and health behaviors from freshman through senior year of college. Journal of Nutrition Education and Behavior. 2008;40(1):39-42.

7. Grundy SM, Cleeman JI, Daniels SR, Donato KA, Eckel RH, Franklin BA, Gordon DJ, Krauss RM, Savage PJ, Smith Jr SC. Diagnosis and management of the metabolic syndrome.

Circulation. 2005;112(17):2735-2752. 
8. Steinberger J, Daniels SR, Eckel RH, Hayman L, Lustig RH, McCrindle B, Mietus-Snyder ML. Progress and challenges in metabolic syndrome in children and adolescents. Circulation. $2009 ; 119(4): 628-647$.

9. Panel III AT. Executive summary of the third report of the national cholesterol education program (NCEP) expert panel on detection, evaluation, and treatment of high blood cholesterol in adults (adult treatment panel III). Journal of the American Medical Association. $2001 ; 285(19): 2486-2497$.

10. Eckel RH, Grundy SM, Zimmet PZ. The metabolic syndrome. The Lancet. $2005 ; 365(9468): 1415-1428$.

11. Grundy SM, Brewer HB, Cleeman JI, Smith SC, Lenfant C. Definition of metabolic syndrome. Circulation. 2004;109(3):433-438.

12. Reaven GM. The metabolic syndrome: Is this diagnosis necessary? American Journal of Clinical Nutrition. 2006;83(6):1237.

13. Tarantino G, Colicchio P, Conca P, Finelli C, Di Minno M,Nicola Dario, Tarantino M, Capone D, Pasanisi F. Young adult obese subjects with and without insulin resistance: What is the role of chronic inflammation and how to weigh it non-invasively? Journal of Inflammation (London). $2009 ; 6: 6-6$.

14. Lambert M, Delvin EE, Paradis G, O'Loughlin J, Hanley JA, Levy E. C-reactive protein and features of the metabolic syndrome in a population-based sample of children and adolescents. Clinical Chemistry. 2004;50(10):1762. 
15. Weiss R, Dziura J, Burgert TS, Tamborlane WV, Taksali SE, Yeckel CW, Allen K, Lopes M, Savoye M, Morrison J. Obesity and the metabolic syndrome in children and adolescents. New England Journal of Medicine. 2004;350(23):2362-2374.

16. Lambert M, Delvin EE, Paradis G, O'Loughlin J, Hanley JA, Levy E. C-reactive protein and features of the metabolic syndrome in a population-based sample of children and adolescents. Clinical Chemistry. 2004;50(10):1762.

17. El-shorbagy H, Ghoname IA. High-sensitivity C-reactive protein as a marker of cardiovascular risk in obese children and adolescents. Health. 2010;2(9):1078-1084.

18. Pirkola J, Vaarasmaki M, Ala-Korpela M, Bloigu A, Canoy D, Hartikainen A, Leinonen M, Miettola S, Paldanius M, Tammelin TH, Jarvelin M, Pouta A. Low-grade, systemic inflammation in adolescents: Association with early-life factors, gender, and lifestyle. American Journal of Epidemiology. 2010;171(1):72-82.

19. Raitakari M, Mansikkaniemi K, Marniemi J, Viikari JSA, Raitakari OT. Distribution and determinants of serum high-sensitive C-reactive protein in a population of young adults. the cardiovascular risk in young finns study. Journal of Internal Medicine. 2005;258(5):428-434.

20. Sex by College or Graduate School Enrollment by Type of School by Age for the Population 15 Years and Over. Available at: http://factfinder2.census.gov/faces/tableservices/jst/pages/ productview.xhtml?pid=ACS_10_1YR_B14004\&prodType=table. Accessed May 8, 2012.

21. Rozmus CL, Evans R, Wysochansky M, Mixon D. An analysis of health promotion and risk behaviors of freshman college students in a rural southern setting. Journal of Pediatric Nursing. 2005;20(1):25-33. 
22. Finkelstein EA, Thompson H, Dietz W. Obesity and severe obesity forecasts through 2030. American Journal of Preventive Medicine. 2012.

23. Pancoska P, Buch S, Cecchetti A, Parmanto B, Vecchio M, Groark S, Paulsen S, Bardwell G, Morton C, Chester A, Branch R. Family networks of obesity and type 2 diabetes in rural appalachia. Clinical \& Translational Science. 2009;2(6):413-421.

24. Wu T, Snider JB, Floyd MR, Florence JE, Stoots JM, Makamey MI. Intention for healthy eating among southern appalachian teens. American Journal of Health Behavior. $2009 ; 33(2): 115-124$.

25. Self-rated health in rural appalachia: Health perceptions are incongruent with health status and health behaviors. BMC Public Health. 2011;11(1):229-236.

26. Williams KJ, Taylor CA, Wolf KN, Lawson RF, Crespo R. Cultural perceptions of healthy weight in rural appalachian youth. Rural and Remote Health Journal. 2008;8(2):13p-13p.

27. Blake KB, Shankar A, Madhavan S, Ducatman A. Associations among cardiometabolic risk factor clustering, weight status, and cardiovascular disease in an appalachian population. The Journal of Clinical Hypertension (Greenwich). 2010;12(12):964-972.

28. National Center for Education Statistics. West Virginia University. Available at: http://nces.ed.gov/collegenavigator/?id=238032\#programs. Accessed May 9, 2012.

29. Dodd LJ, Al-Nakeeb Y, Nevill A, Forshaw MJ. Lifestyle risk factors of students: A cluster analytical approach. Preventive Medicine. 2010;51(1):73-77. 
30. Driskell JA, Kim Y, Goebel KJ. Few differences found in the typical eating and physical activity habits of lower-level and upper-level university students. Journal of the American Dietetic Association. 2005;105(5):798-801.

31. Brevard PB, Ricketts CD. Residence of college students affects dietary intake, physical activity, and serum lipid levels. Journal of the American Dietetic Association.1996;96(1):35-38.

32. Desai MN, Miller WC, Staples B, Bravender T. Risk factors associated with overweight and obesity in college students. The Journal of American College Health. 2008;57(1):109-114.

33. Undén A, Krakau I, Högbom M, Romanus-Egerborg I. Psychosocial and behavioral factors associated with serum lipids in university students. Social Science \& Medicine. 1995;41(7):915922.

34. Hlaing WW, Nath SD, Huffman FG. Assessing overweight and cardiovascular risks among college students. The American Journal of Health Education. 2007;38(2):83-90.

35. PhD LJLC, PhD KND, BAS RJK, BAS JP. Psychosocial and environmental determinants of eating behaviors, physical activity, and weight change among college students: A qualitative analysis. The Journal of American College Health. 2011;59(6):531-538.

36. Flegal KM, Carroll MD, Kit BK, Ogden CL. Prevalence of obesity and trends in the distribution of body mass index among US adults, 1999-2010. JAMA: Journal of the American Medical Association. 2012;307(5):491-497.

37. Taylor JR, Lopez LM. Cholesterol: Point-of-care testing. The Annals of Pharmacotherapy. $2004 ; 38(7 / 8): 1252-1257$. 
38. Shindelman J, Bellet N, Haley K, Kyung J, Qian S, Lee R, Worthy T. Development of a highsensitivity immunoassay for C-reactive protein on the cholestech LDX, a point-of-care analyzer. Point of Care. 2004;3(4):191.

39. Morrell JS, Lofgren IE, Burke JD, Reilly RA. Metabolic syndrome, obesity, and related risk factors among college men and women. The Journal of American College Health. 2012;60(1):82-89.

40. Ford ES, Ajani UA, Mokdad AH. The metabolic syndrome and concentrations of C-reactive protein among US youth. Diabetes Care. 2005;28(4):878.

41. Taubes G. Prosperity's plague. Science. 2009;325(5938):256-260.

42. Vikram NK, Misra A, Dwivedi M, Sharma R, Pandey RM, Luthra K, Chatterjee A, Dhingra V, Jailkhani BL, Talwar KK, Guleria R. Correlations of C-reactive protein levels with anthropometric profile, percentage of body fat and lipids in healthy adolescents and young adults in urban north india. Atherosclerosis. 2003;168(2):305-313. A.

43. Ford ES, Ajani UA, Mokdad AH. The metabolic syndrome and concentrations of c-reactive protein among U.S. youth. Diabetes Care. 2005;28(4):878-881.

44. De Ferranti SD, Gauvreau K, Ludwig DS, Newburger JW, Rifai N. Inflammation and changes in metabolic syndrome abnormalities in US adolescents: Findings from the 1988-1994 and 1999-2000 national health and nutrition examination surveys. Clinical Chemistry. 2006;52(7):1325.

45. Okosun IS. Metabolic syndrome and C-reactive protein in american adults: The impact of abdominal obesity. Metabolic Syndrome \& Related Disorders. 2008;6(4):289-297. 
46. Williams MJA, Williams SM, Milne BJ, Hancox RJ, Poulton R. Association between Creactive protein, metabolic cardiovascular risk factors, obesity and oral contraceptive use in young adults. International Journal of Obesity \& Related Metabolic Disorders. 2004;28(8):9981003.

47. Singh B, Arora S, Goswami B, Mallika V. Metabolic syndrome: A review of emerging markers and management. Diabetes and Metabolic Syndrome: Clinical Research \& Reviews. $2009 ; 3(4): 240-254$.

48. Windgassen EB, Funtowicz L, Lunsford TN, Harris LA, Mulvagh SL. C-reactive protein and high-sensitivity C-reactive protein: An update for clinicians. Postgraduate Medicine. 2011;123(1):114-119.

49. Ridker PM, Wilson P, Grundy SM. Should C-reactive protein be added to metabolic syndrome and to assessment of global cardiovascular risk? Circulation. 2004;109(23):28182825.

50. Gardner M, Gardner D, Sowers J. The cardiometabolic syndrome in the adolescent. Pediatric Endocrinology Reviews. 2008;5:964-968.

51. McDade TW, Rutherford JN, Adair L, Kuzawa C. Population differences in associations between C-reactive protein concentration and adiposity: Comparison of young adults in the philippines and the united states. American Journal of Clinical Nutrition. 2009;89(4):1237-1245.

52. Mason C, Katzmarzyk PT. Waist circumference thresholds for the prediction of cardiometabolic risk: Is measurement site important? European Journal of Clinical Nutrition. 2010;64(8):862-867. 
53. Rawson ES, Freedson PS, Osganian SK, Matthews CE, Reed G, Ockene IS. Body mass index, but not physical activity, is associated with C-reactive protein. Medicine and Science in Sports and Exercise. 2003;35(7):1160-1166.

54. Clinical guidelines on the identification, evaluation, and treatment of overweight and obesity in adults--the evidence report. national institutes of health. Obesity Research. 1998;6 Suppl 2:51S-209S.

55. Kuczmarski RJ, Ogden CL, Guo SS, Grummer-Strawn LM, Flegal KM, Mei Z, Wei R, Curtin LR, Roche AF, Johnson CL. 2000 CDC growth charts for the united states: Methods and development. Vital Health Statistics 11. 2002;(246)(246):1-190.

56. Bosy-Westphal A, Geisler C, Onur S, Korth O, Selberg O, Schrezenmeir J, Müller MJ. Value of body fat mass vs anthropometric obesity indices in the assessment of metabolic risk factors. International Journal of Obesity. 2006;30(3):475-483.

57. Brooks Y, Black DR, Coster DC, Blue CL, Abood DA, Gretebeck RJ. Body mass index and percentage body fat as health indicators for young adults. American Journal of Health Behavior. 2007;31(6):687-700.

58. Goodman E, Daniels SR, Meigs JB, Dolan LM. Instability in the diagnosis of metabolic syndrome in adolescents. Circulation. 2007;115(17):2316-2322.

59. Dreon DM, Slavin JL, Phinney SD. Oral contraceptive use and increased plasma concentration of C-reactive protein. Life Science. 2003;73(10):1245.

60. O'Loughlin J, Lambert M, Karp I, McGrath J, Gray-Donald K, Barnett TA, Delvin EE, Levy E, Paradis G. Association between cigarette smoking and C-reactive protein in a representative, population-based sample of adolescents. Nicotine Tobacco Research. 2008;10(3):525-532. 
61. Ely G, E., Miller K, Dignan M. The disconnect between perceptions of health and measures of health in a rural appalachian sample: Implications for public health social workers. Social Work in Health Care. 2011;50(4):292-304.

62. Smith SL, Tessaro IA. Cultural perspectives on diabetes in an appalachian population. American Journal of Health Behavior. 2005;29(4):291-301.

63. Barker L, Gerzoff R, Crespo R, Shrewsberry M. Age at diagnosis of diabetes in appalachia. Population Health Metrics. 2011;9:54-54.

64. Lowry R, Galuska DA, Fulton JE, Wechsler H, Kann L, Collins JL. Physical activity, food choice, and weight management goals and practices among US college students. American Journal of Preventative Medicine. 2000;18(1):18-27.

65. Jones S, Johnson-Yale C, Millermaier S, Pérez FS. U.S. college students' internet use: Race, gender and digital divides. Journal of Computer-Mediated Communication. $2009 ; 14(2): 244-264$.

66. Jue JJS, Metlay JP. Web-based health resources at US colleges: Early patterns and missed opportunities in preventive health. Preventing chronic disease. $2011 ; 8(6)$.

67. Kodama S, Saito K, Tanaka S, Horikawa C, Fujiwara K, Hirasawa R, Yachi Y, lida KT, Shimano H, Ohashi Y, Yamada N, Sone H. Effect of web-based lifestyle modification on weight control: A meta-analysis. International Journal of Obesity. 2012;36(5):675-685.

68. Glanz K, Rimer BK, Viswanath K. Health Behavior and Health Education Theory, Research, and Practice. Fourth ed. John Wiley \& Sons, Inc.; 2008. 
69. Cottrell RR, Cirvan JT, McKenzie JF. Principles and Foundations of Health Promotion and Education. Fourth ed. Pearson Benjamin Cummings; 2009.

70. MOZUMDAR A, LIGUORI G. Persistent increase of prevalence of metabolic syndrome among U.S. adults: NHANES III to NHANES 1999-2006. Diabetes Care. 2011;34(1):216-219.

71. Kao T, Lu I, Liao K, Lai H, Loh C, Kuo H. Associations between body mass index and serum levels of C-reactive protein. South African Medical Journal. 2009;99(5):326-330.

72. Cauci S, Di Santolo M, Culhane JF, Stel G, Gonano F, Guaschino S. Effects of thirdgeneration oral contraceptives on high-sensitivity C-reactive protein and homocysteine in young women. Obstetrics \& Gynecology. 2008;111(4):857-864.

73. Urbina EM, Khoury PR, McCoy C, Daniels SR, Kimball TR, Dolan LM. Cardiac and vascular consequences of pre-hypertension in youth. The Journal of Clinical Hypertension (Greenwich). $011 ; 13(5): 332-342$ 


\section{APPENDICES}

Appendix A: Boys 2 to 20 years BMI-for-age Percentile Chart

Appendix B: Girls 2 to 20 years BMI-for-age Percentile Chart

Appendix C: YEAH Project Screening "Staging" Questions

Appendix D: Steering Committee Letter

Appendix E: IRB/IRB Addendum

Appendix F: YEAH Project Recruitment Flyer

Appendix G: YEAH Project PRT Advertisement

Appendix H: YEAH Project Website Informed Consent

Appendix I: YEAH Project Eligibility Survey

Appendix J: YEAH Website Survey Questions

Appendix K: CLIA Waiver

Appendix L: Tobacco Survey

Appendix M: Mindfulness Survey

Appendix N: Post-Intervention Survey

Appendix O: Vending Survey

Appendix P: Green Eating Survey

Appendix Q: Car Calories Survey 


\section{Appendix A}

2 to 20 years: Boys Body mass index-for-age percentiles

NAME

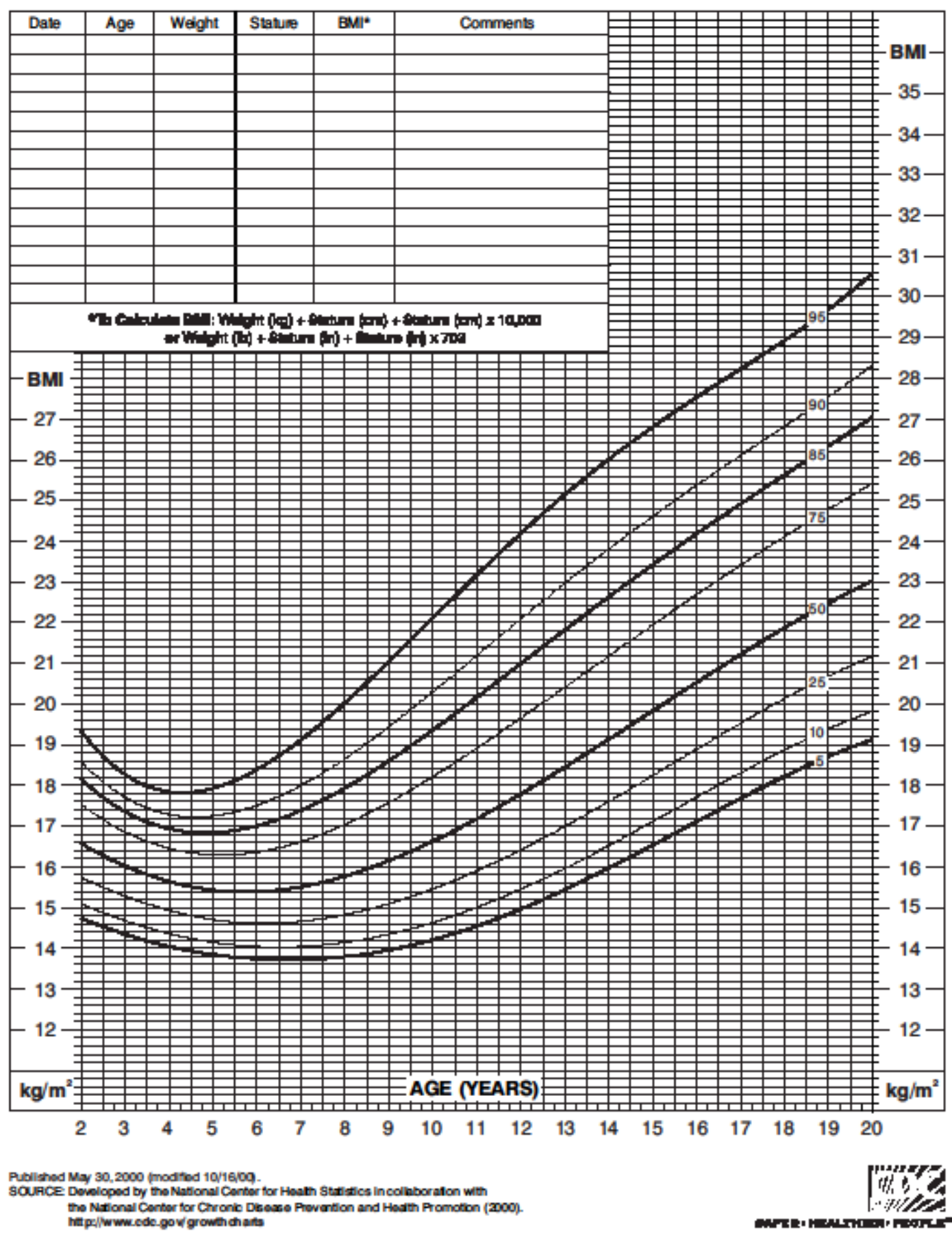




\section{Appendix B}

2 to 20 years: Girls Body mass index-for-age percentiles

NAME

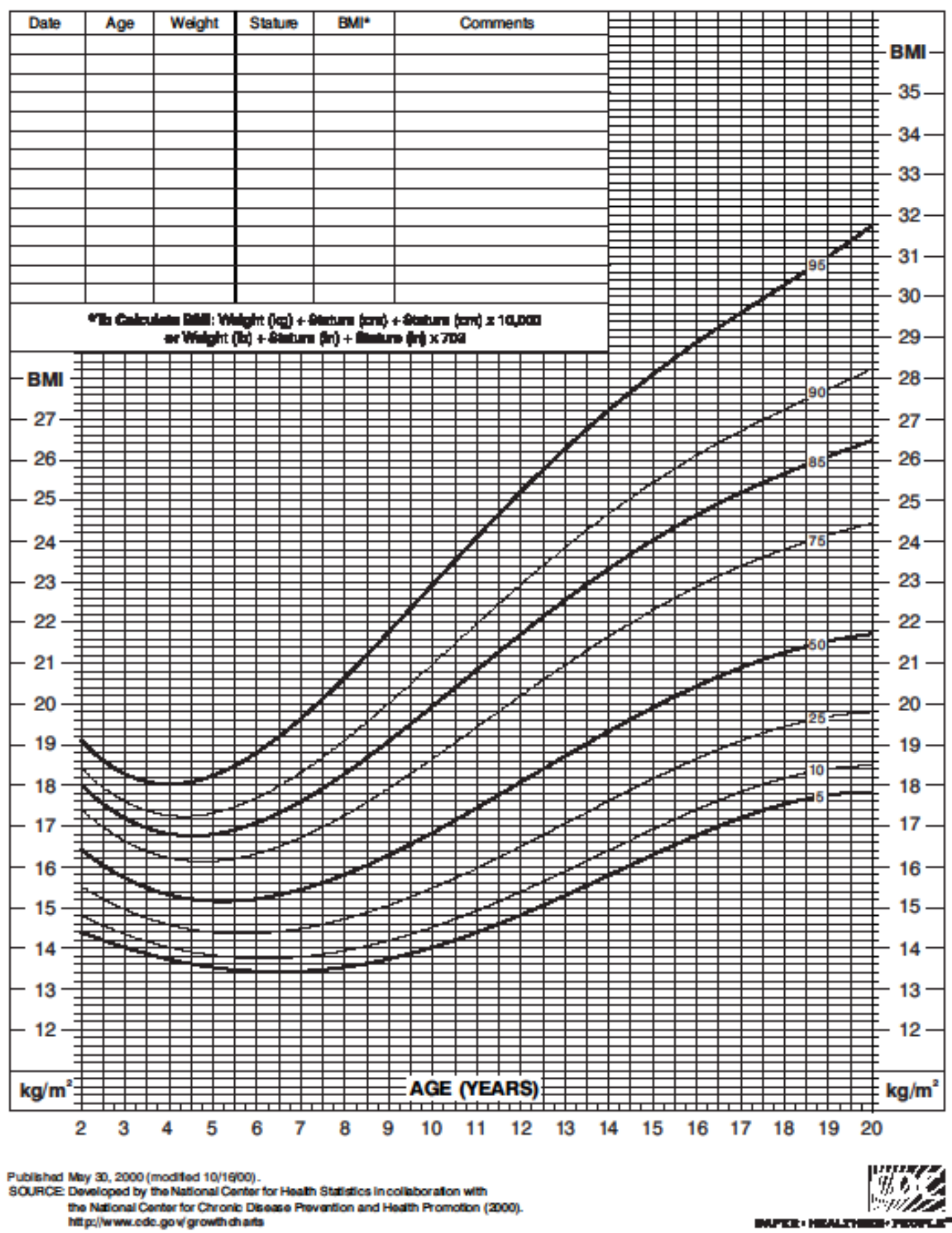




\section{Appendix C}

\section{Exercise Algorithm}

Regular exercise is any planned physical activity (e.g., brisk walking, aerobics, jogging, bicycling, swimming, rowing, etc.) performed to increase physical fitness. Such activity should be performed 3 to 5 times per week for 30 minutes per session. Exercise does not have to be painful to be effective but should be done at a level that increases your breathing rate and causes you to break a sweat.

\section{1) Do you exercise regularly according to that definition?}

(1) No, and I do NOT intend to in the next 6 months

(2) No, but I intend to in the next 6 months

(3) No, but I intend to in the next 30 days

(4) Yes, I have been for LESS than 6 months (GO TO MESSAGES)

(5) Yes, I have been for MORE than 6 months (GO TO MESSAGES)

\section{Fruit/Vegetable Intake Algorithm}

When considering the amount of a food eaten, a cup is about the size of a baseball. US Dietary Guidelines define 1 cup of fruits and vegetables as equal to:

1 cup cooked or raw fruits or vegetables

2 cups of lettuce salad

A piece of fruit about the size of a small apple or large banana

$1 / 2$ cup of dried fruit like raisins, or

1 cup ( 8 ounces) of $100 \%$ fruit juice

\section{2) Do you eat 5 or more cups of fruits and vegetables a day?}

(1) No, and I do NOT intend to in the next 6 months

(2) No, but I intend to in the in the next 6 months

(3) No, but I intend to in the next 30 days

(4) Yes, but I have been for LESS than 6 months (GO TO MESSAGES)

(5) Yes and I have been for MORE than 6 months (GO TO MESSAGES)

\section{Stress Management Algorithm}

Stress management includes regular relaxation and physical activity, talking with others and/or making time for social activities.

3) Do you effectively practice stress management in your daily life? 
(1) No, and I do NOT intend to in the next 6 months

(2) No, but I intend to in the in the next 6 months

(3) No, but I intend to in the next 30 days

(4) Yes, but I have been for LESS than 6 months (GO TO MESSAGES)

(5) Yes and I have been for MORE than 6 months (GO TO MESSAGES) 


\section{Appendix D}

\section{WestVirginiaUniversity}

Davls College of Agrlculture, Forestry and Consumer Sciences

September 22,2010

Name
Title
Address
RE: Young Adults Eating \& Active for Health (Y.E.A.H) Research Project

Dear:

I am writing in regards to joining West Virginia University's steering committee for the Young Adults Eating \& Active for Health (Y.E.A.H) research project. The Y.E.A.H Program is a web-based intervention research project being studied in 14 different states across the country at university campuses in an effort to enhance the prevention of obesity in young adults ages 18 to 24 . This project is looking at several different aspects of student life such as nutrition, physical activity, stress management, sleep, and other related factors. This is a communitybased participatory research approach (CBPR) which is why you have been identified as a potential steering committee member for your expertise and/or helpful insight in one or more of these facets.

This project is in its early stage of development projecting participant recrultment \& intervention to take place Spring Semester. We would like to start putting together our steering committee and have a meeting information-gather from you and other members in October. Many indlviduals have already agreed to come aboard for this project including WVU's School of Pharmacy. We plan to create a rather diverse steering committee consisting of WVU students, faculty, and staff. If you are interested in getting this project moving forward, but may not have the time in your schedule to do so, feel free to recommend key individuals who would be willing to take your place on the committee.

As far as commitment is concerned, there are two meetings planned. We would like to meet in late October and there will be a follow-up meeting next Fall semester 2011 to discuss our research findings and again hear back from you to learn what the next steps would be recommended by the committee. If you have any further questions, feel free to contact myself or the WVU YEAH Project Campus Coordinator, Amanda Dent, at adent1@mix.wvu.edu. We look forward to hearing from you soon.

Sincerely,

Lhasisitio

Melissa Olfert, DrPH, MS, RD

(Principle Investigator for WVU YEAH Research Project)

Assistant Professor of Human Nutrition \& Foods

WVU - Davis College of Agriculture, Forestry \& Design

Division of Animal \& Nutritional Sciences

Ag. Sc. Building Office G016

PO Box 6108, Morgantown, WV 26506-6108

Email: melissa.olfert@mail.wvu.edu

Phone: 304-293-1918

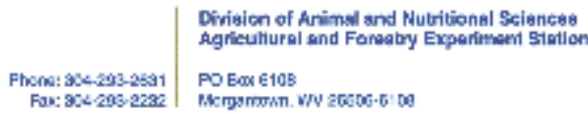

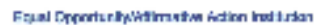




\title{
Appendix E
}

\section{WestVirginiaUniversity. \\ Office of Research Compliance}

\section{Expedited-IRB Protocol-Approval}

\author{
To: $\quad$ Olfert, Melissa \\ From: $\quad$ WVU Office of Research Compliance \\ Date: $\quad$ Tuesday, December 14, 2010 \\ Subject: Approval Letter \\ Tracking \#: $\mathrm{H}-22872$ \\ Title: $\quad$ Preventing Weight Gain \& Metabolic Syndrome Risk in College Adults \\ Using a Tailored, Web-Based Intervention
}

The research study referenced above was reviewed by the West Virginia University Instituional Review Board (IRB) via expedited review procedures and was approved in accordance with 46 CFR 46.101(b).

This protocol was reviewed using the following:

Initial Protocol (Expedited/Full Board) Review Checklist

Advertisement Checklist (210i)

The following documents have been approved and validated for use in this study and are available in the BRAAN system:

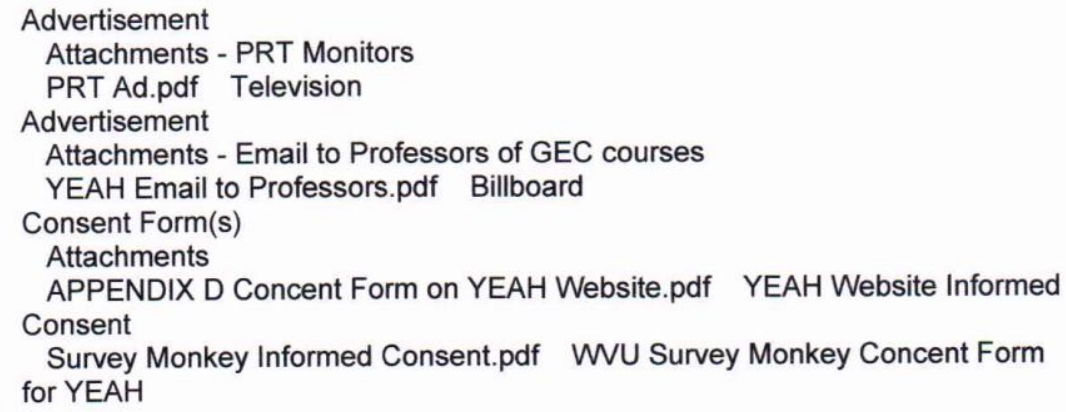




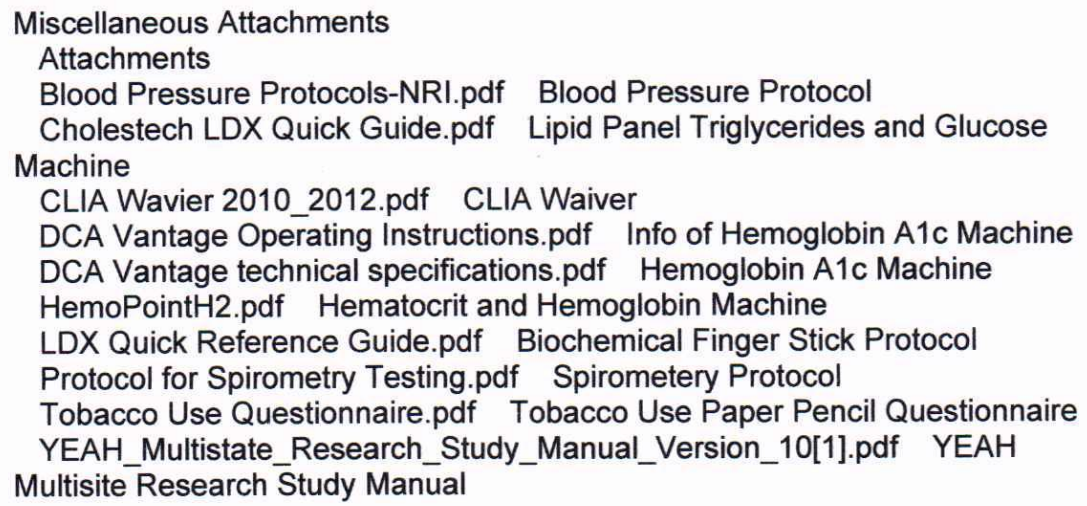

This study involves expedited categories 2 and 7.

The approval period is from December 14, 2010 through December 13, 2011.

Thank you.

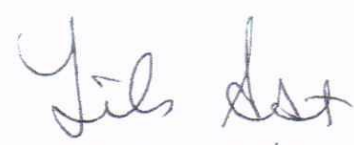

Board Designee: Ast, Lilo

Letter Sent By: Ast, Lilo, 12/14/2010 6:34 PM

Once you begin your human subject research, the following regulations apply:

1. Unanticipated or serious adverse events/side effects encountered in this research study must be reported to the IRB within five (5) days.

2. Any modifications to the study protocol or informed consent form must be reviewed and approved by the IRB prior to implementation.

3. You may not use a modified informed consent form until it has been approved and validated by the IRB. 


\title{
WestVirginiaUniversity. \\ Office of Research Compliance
}

\section{Expedited-Amendment-Approval}

\author{
To: $\quad$ Olfert, Melissa \\ From: $\quad$ WVU Office of Research Compliance \\ Date: $\quad$ Friday, November 18, 2011 \\ Subject: Approval Letter
}

Tracking \#: AMEND-3370 ( $\mathrm{H}-22872)$

Title: $\quad$ Preventing Weight Gain \& Metabolic Syndrome Risk in College Adults Using a Tailored, Web-Based Intervention

The following changes on $11 / 18 / 2011$ to the study referenced above were reviewed and approved using expedited review procedures in accordance with 45 CFR 46.110.

This amendment is to collect current attitudes/perceptions of students (other than study participants) during the duration of the study (15 month protocol) for this study as well as environmental factors such as alcohol access (non-participant burden). For example we would like to better understand the students (18-24 year old other than the study participants) concepts of the following: fruit and vegetable consumption (FRUVED questions), mindfulness of food consumption, use of food purchasing as it relates to online ordering, calories consumed while in transport (car calories), green eating awareness, and college environment perceptions (CEPS). These surveys will be done in different locations of the university campus(es) by trained undergraduate nutrition majors and graduate students with laptops for participants to efficiently take the questionnaire(s). If the student volunteers to participate in one or more questionnaires they will compensated with a $\$ 5$ valued incentive for completing a questionnaire. They are not limited to how many they can participate in. (Questions of the questionnairs are attached in the miscellaneous attachments of the protocol). Further we would like to identify alcohol access on and off-campus by researchers determining if screening/identification of minor-age students is occuring (non-participant burden). For the enrolled participant we would like to add one more data point of collection which would be a hip circumference measurement. This would compliment the waist measurement Which is already being gathering to determine waist-to-hip ratio fo the study outcome impact. Also a post evaluation survey for the study participants will be available if the participant would like to volunteer in participating in it after the study (protocol attached).

The following documents have been reviewed and approved:Advertisement 


\begin{abstract}
Attachments - PRT Monitors PRT Ad.pdf Television Advertisement Attachments Email to Professors of GEC courses YEAH Email to Professors. pdf Billboard Consent Form(s) Attachments APPENDIX D Concent Form on YEAH Website.pdf YEAH Website Informed Consent Survey Monkey Informed Consent.pdf WVU Survey Monkey Concent Form for YEAH Miscellaneous Attachments Attachments Alcohol Availability Assessment Protocol WVU.pdf Enviornment Alcohol Outlet Access on and off- campus Car Calorie Survey.pdf Calories consumed during transportation College Environment Perceptions Survey WVU.pdf College Environment Perceptions of Studens Questions food delivery questions.pdf Food Delivery/Online Purchasing Fruit and Vegetable Consumption FRUVED questions.pdf Fruit and Vegetable Consumption FRUVED questions Green Eating Survey WWU.pdf Green Eating Survey Mindfulness of Food Questions WVU.pdf Mindfulness Food Questions Post Evaluation protocol and instruments for WWU.pdf Post Evaluation Survey Miscellaneous Attachments Attachments Blood Pressure Protocols-NRI.pdf Blood Pressure Protocol Cholestech LDX Quick Guide.pdf Lipid Panel Triglycerides and Glucose Machine CLIA Wavier 2010_2012.pdf CLIA Waiver DCA Vantage Operating Instructions.pdf Info of Hemoglobin A1c Machine DCA Vantage technical specifications.pdf Hemoglobin A1c Machine HemoPointH2.pdf Hematocrit and Hemoglobin Machine LDX Quick Reference Guide.pdf Biochemical Finger Stick Protocol Protocol for Spirometry Testing.pdf Spirometery Protocol Tobacco Use Questionnaire.pdf Tobacco Use Paper Pencil Questionnaire YEAH_Multistate_Research_Study_Manual_Version_10[1].pdf YEAH Multisite Research Study Manual Módification Checklist
\end{abstract}

The approved and validated ICF, with the date of expedited approval is valid until the date of continuing review. The ICF is available in the BRAAN system for your use. Please do not use earlier versions.

Thank you.

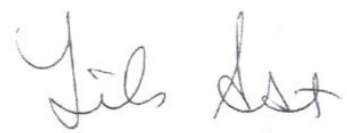

Board Designee: Ast, Lilo

Continue following the regulations below:

1. Unanticipated or serious adverse events/side effects encountered in this research study must be reported to the IRB within five (5) days.

2. Any modifications to the study protocol or informed consent form must be reviewed and approved by the IRB prior to implementation.

3. You may not use a modified informed consent form until it has been approved and validated by the IRB.

Letter Sent By: Ast, Lilo, 11/18/2011 2:40 PM 
Appendix F

\section{Would you like to earn $\$ 75.00$ ?}

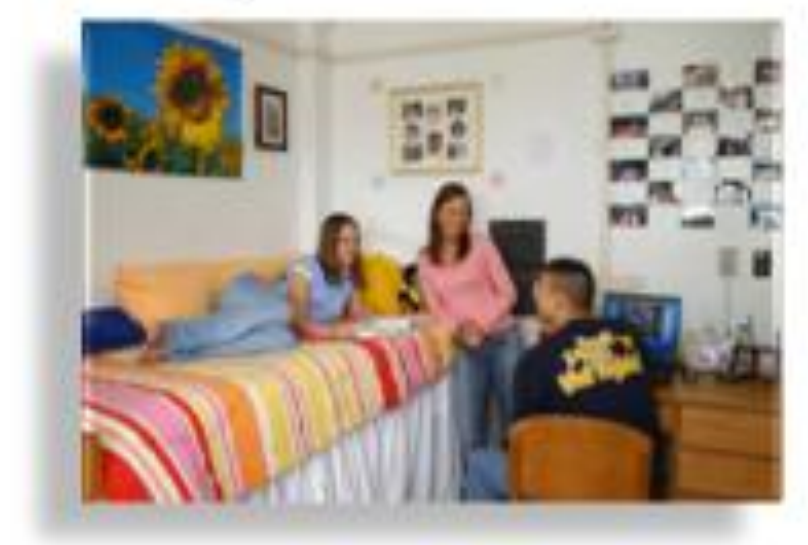

Do you meet the following criteria?

$\sqrt{\text { Fulli-time student at WVU }}$
$\sqrt{18 \text { to } 24 \text { years of age }}$
$\sqrt{\text { Freshman, Sophomore or Junior status }}$

If so, you may be eligible to participate in an online nutrition, physical activity, and stress management study.

Visit http://www. survermonkey.com/5/8LJQYF5

or contact Amanda Dent at

wvcoordinatorguveahproject.com

\footnotetext{
This reseach project is being oenduded by Melissa Odert, Ass istat Fictesser for Hamen Nutrton and Foods in the WvU Devis Colege of Agtcuture, Netura Fessures and Deslon, and hes been approved by the West Viginia Uherstys insitiona Feview Eoard.
}

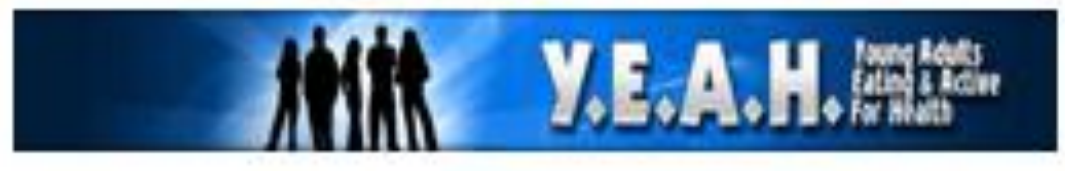




\title{
Would you like to earn $\$ 75.00$ ?
}

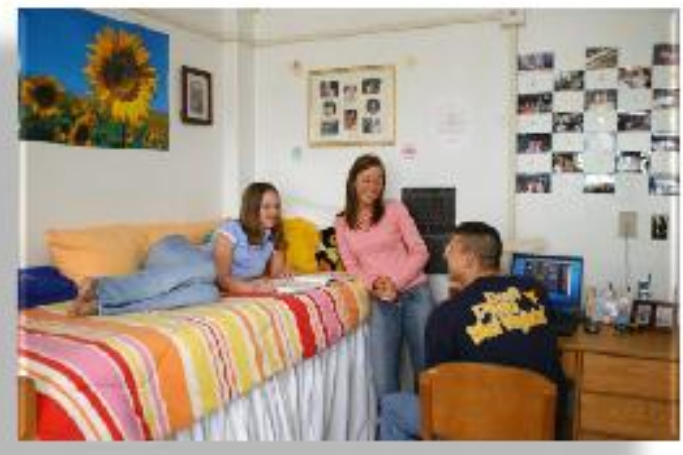

\section{Do you meet the following criteria?}

\author{
$\sqrt{ }$ Full-time student at WVU \\ $\sqrt{ } 18$ to 24 years of age \\ $\checkmark$ Freshman, Sophomore or Junior status
}

If so, you may be eligible to participate in an online nutrition, physical activity, and stress management study.

\author{
Visit http://www.survevmonkev.com/s/8LJQYF5 \\ or contact Amanda Dent at \\ wvcoordinator@yeahproject.com
}

This research project is being conducted by Melissa Olfert, Assistant Professor for Human Nutrition and Foods in the WVU Davis College of Agriculture, Natural Resources and Design, and has been approved by the West Virginia University's Institutional Review Board.

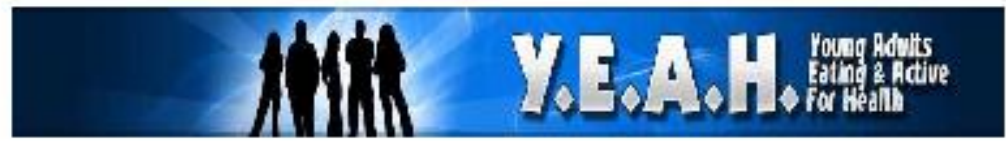




\section{APPENDIX H}

\section{Informed Consent Form for Y.E.A.H.-Young Adults Eating and Active for Health}

Scroll through and read the consent form. If you interested in participating you must select "accept" located at the bottom of the form. If you choose not to participate, select the "decline".

\section{PURPOSE OF STUDY}

You are invited to participate in this project to explore how young adult college students perceive nutrition, exercise and stress management as it relates to weight maintenance. Your participation will help us learn more about factors affecting weight maintenance and test a webbased program focusing on healthy behaviors.

\section{CAN I PARTICIPATE?}

\section{If you are/have:}

$\checkmark$ 18-24 years old

$\checkmark$ a full-time student: first, second, or third year college student

$\checkmark$ a body mass index (BMI) $>18.5$

$\checkmark$ free from life threatening illness or other conditions such as pregnancy or dietand/or activity-related medical restrictions that would prevent participation in an online nutrition and fitness program and/or prevent accurate physical assessments.

$\checkmark$ regular access to a computer with Internet connection

\section{You must not be:}

$\checkmark$ a current nutrition, exercise science and/or health promotion major

$\checkmark$ currently enrolled in a nutrition course

\section{WHAT WILL I BE ASKED TO DO?}

Step 1: You will be asked to complete a survey online. The survey includes questions about dietary intake, physical activity, stress management, and also ask questions such as "Sometimes things just taste so good that I keep on eating even when I am no longer hungry". It takes about 25 minutes to complete.

Step 2: At the end of the survey, you will need to make an appointment to have your weight, height, and waist measured. Assessments will be done in a private room and will take about 20 minutes. For these assessments, you will need to wear shorts and a t-shirt. Waist circumference is done by putting a measuring tape around your waist, at the top of your hip bones. The tape will need to be directly against your skin, not on top of a shirt. The tape will be snug, but will not compress your skin. You may be asked if you desire to volunteer to complete additional assessments.

Step 3: You will then be randomly assigned to intervention or control group. If you are assigned to the intervention group, for 10 weeks you will receive 3 email messages per week and also spend approximately 20-30 minutes a week on the online intervention activities. Then the following 10 months you will receive 4 email messages (nudges) per month. Control group will 
have access to these materials at the end of the study.

Step 4: At about 10-12 weeks from enrollment, you will be asked to complete a second online survey and have your weight, height, and waist measured again. At the time of this measurement you may be given a brief survey about what you liked and did not like about the program. Following this, you may be contacted by email for additional questions evaluating the program.

Step 5: Next year (about 15 months from enrollment), you be asked to complete the final online survey and weight, height, and waist measurements..

\section{WHAT DO I GET OUT OF IT?}

Study findings will be used to further the development of nutrition education materials for your university's students. You will receive $\$ 10$ compensation for your time to complete the first physical assessment, \$25 compensation for your second physical assessment, and $\$ 40$ for your third and final physical assessment for a maximum of $\$ 75$. You must complete Step 1 to participate in Step 2. You must complete Step 2 to participate in Step 3, 4, \& 5.

\section{RISKS}

Except for your time and inconvenience, the risk to you is minimal. Your physical assessments will be taken in a private area to minimize any discomfort you may experience. Some questions may be sensitive in nature, such as "Do you eat more than you usually do when you are under stress?" There may be minimal risk of data being intercepted during the completion and transmission of the online surveys. This risk will be reduced by using an encrypted transmission for online surveys.

\section{VOLUNTARY}

Participation is voluntary. You may refuse to answer any questions that are part of the survey. You may decide not to participate or to discontinue participation at any time. If you leave the study for any reason, you will only be compensated for completed physical assessments. You are encouraged to contact the study coordinator should you decide not to continue your participation in this study.

\section{CONFIDENTIALITY}

The website is password protected for both the participants and researchers. All information that you provide, either online or in person, will be kept on a secured hard drive or locked in file cabinets for 7 years then destroyed. Name and address will be collected and other personal identifiers such as social security number may be requested for compensation. If collected, SSN will not be entered into the website, but will be securely stored on-site in the researcher's office in the department of your University.

The online survey you fill out will be stored in a database on the secured server maintained by ITT, Sioux Falls, South Dakota. When data collection is complete, data will be removed from the server and transferred to disks and maintained at South Dakota State University. Unidentifiable data will be shared with all researchers involved in the project. To secure data and maintain confidentiality, an https encrypted website is being used for this study. Your confidentiality will be maintained to the degree permitted by the technology used. Specifically, no guarantees can be made regarding the interception of data sent via the Internet by any third 
parties. When data are presented for scientific purposes, data will be reported in summary format, and no names will be used.

\section{Questions}

If you have any questions or concerns about what this study involves, please contact the researcher from your state (listed below). If you have concerns regarding your rights as a research participant, please contact the human subjects' representative from your state (listed below). This study has been approved by the Institutional Review Board (IRB) of all participating institutions. The IRB approval date for each institution is listed in the table below.

\begin{tabular}{|c|c|c|}
\hline $\begin{array}{l}\text { State/Date of } \\
\text { Approval }\end{array}$ & Researcher & Human Subjects Representative \\
\hline $\begin{array}{l}\text { Alabama } \\
\text { IRB approved } \\
12-22-2010\end{array}$ & $\begin{array}{l}\text { Dr. Beatrice W. Phillips } \\
\text { ghebwp@tuskegee.edu }\end{array}$ & $\begin{array}{l}\text { Stephen O. Sodeke, PhD } \\
\text { Chair, HPRC } \\
\text { femisodeke@tuskegee.edu }\end{array}$ \\
\hline $\begin{array}{l}\text { Florida } \\
\text { IRB approved } \\
11-23-2010\end{array}$ & $\begin{array}{l}\text { Dr. Karla Shelnutt } \\
\text { kpagan@ufl.edu }\end{array}$ & $\begin{array}{l}\text { UFIRB Office, Box } 112250 \\
\text { University of Florida, Gainesville, FL } \\
32611-2250 \\
352-392-0433\end{array}$ \\
\hline $\begin{array}{l}\text { Indiana } \\
\text { IRB approved } \\
1-07-2011\end{array}$ & $\begin{array}{l}\text { Dr. Onikia Esters } \\
\text { oesters@purdue.edu }\end{array}$ & $\begin{array}{l}\text { Institutional Review Board at Purdue } \\
\text { University } \\
\text { Ernest C. Young Hall, Room } 1032 \\
155 \text { S. Grant St. } \\
\text { West Lafayette, IN 47907-2114 } \\
\text { irb@purdue.edu } \\
765-494-5942\end{array}$ \\
\hline $\begin{array}{l}\text { Kansas } \\
\text { IRB approved } \\
1-11-2011\end{array}$ & $\begin{array}{l}\text { Dr. Tandalayo Kidd } \\
\text { martan@k-state.edu }\end{array}$ & $\begin{array}{l}\text { Dr. Jerry Jaax, Associate Vice Provost } \\
\text { for Research Compliance and University } \\
\text { Veterinarian } \\
203 \text { Fairchild Hall } \\
\text { Kansas State University } \\
\text { Manhattan, KS } 66506 \\
\text { jaax@ksu.edu } \\
\text { (785) 532-3224 }\end{array}$ \\
\hline $\begin{array}{l}\text { Maine } \\
\text { IRB approved } \\
11-29-10\end{array}$ & $\begin{array}{l}\text { Dr. Adrienne White } \\
\text { awhite@maine.edu }\end{array}$ & $\begin{array}{l}\text { Gayle Jones } \\
\text { gayle.jones@umit.maine.edu } \\
\text { 207-581-1498 }\end{array}$ \\
\hline $\begin{array}{l}\text { Michigan } \\
\text { IRB approved } \\
1-4-2011\end{array}$ & $\begin{array}{l}\text { Dr. Sharon Hoerr } \\
\text { hoerrs@msu.edu }\end{array}$ & $\begin{array}{l}\text { Office of Human Research Protections } \\
207 \text { Olds Hall } \\
\text { Michigan State University } \\
\text { East Lansing, Ml 48824-1047 } \\
\text { irb@msu.edu } \\
517-355-2180 \\
517-432-4503 \text { (fax) }\end{array}$ \\
\hline
\end{tabular}




\begin{tabular}{|c|c|c|}
\hline $\begin{array}{l}\text { New Hampshire } \\
\text { IRB approved } \\
01-07-2011\end{array}$ & $\begin{array}{l}\text { Dr. Gale Carey } \\
\text { gale.carey@unh.edu }\end{array}$ & $\begin{array}{l}\text { Julie F. Simpson } \\
\text { Department: Office Of Sponsored } \\
\text { Research } \\
\text { Title: MANGER-RESEARCH } \\
\text { INTEGRITY SERV/AFFIL FACULTY } \\
\text { Address: Serv Bldg \&Fire Rm } 103 \\
\text { Phone: 603-862-2003 } \\
\text { EMail: julie.simpson@unh.edu }\end{array}$ \\
\hline $\begin{array}{l}\text { New Jersey } \\
\text { IRB approved } \\
11-23-2010\end{array}$ & $\begin{array}{l}\text { Dr. Carol Byrd-Bredbenner } \\
\text { bredbenner@aesop.rutgers.edu }\end{array}$ & $\begin{array}{l}\text { Rutgers University Institutional Review } \\
\text { Board for the Protection of Human } \\
\text { Subjects, Office of Research and } \\
\text { Sponsored Programs, } 3 \text { Rutgers Plaza, } \\
\text { New Brunswick, NJ 08901-8559 } \\
\text { humansubjects@orsp.rutgers.edu } \\
\text { 732-932-0150 ext. } 2104\end{array}$ \\
\hline $\begin{array}{l}\text { New York } \\
\text { IRB approved } \\
12-3-2010\end{array}$ & $\begin{array}{l}\text { Dr. Tanya Horacek } \\
\text { thoracek@syr.edu }\end{array}$ & $\begin{array}{l}\text { The Office Research Integrity and } \\
\text { Protections } \\
121 \text { Bowne Hall } \\
\text { Syracuse University } \\
\text { Syracuse, NY } 13244-1200 \\
315-443-3013\end{array}$ \\
\hline $\begin{array}{l}\text { North Carolina } \\
\text { IRB approved } \\
01-05-2011\end{array}$ & $\begin{array}{l}\text { Dr. Sarah Colby } \\
\text { colbys@ecu.edu }\end{array}$ & $\begin{array}{l}\text { Susan L. McCammon } \\
\text { University and Medical Center } \\
\text { Institutional Review Board } \\
600 \text { Moye Blvd } \\
\text { Greenville, NC } 27858 \\
\text { mccammons@ecu.edu } \\
\text { (252) 744-2914 }\end{array}$ \\
\hline $\begin{array}{l}\text { Rhode Island } \\
\text { IRB approved } \\
12-23-10\end{array}$ & $\begin{array}{l}\text { Dr. Geoff Greene } \\
\text { gwg@uri.edu }\end{array}$ & $\begin{array}{l}\text { Office of the Vice Provost for } \\
\text { Graduate Studies, Research and } \\
\text { Outreach } \\
\text { robind@uri.edu } \\
401-874-4328\end{array}$ \\
\hline $\begin{array}{l}\text { South Dakota } \\
\text { IRB approved } \\
09-21-2010\end{array}$ & $\begin{array}{l}\text { Dr. Kendra Kattelmann } \\
\text { kendra.kattelmann@sdstate.edu }\end{array}$ & $\begin{array}{l}\text { SDSU Research Compliance } \\
\text { Coordinator } \\
\text { sdsu.irb@sdstate.edu }\end{array}$ \\
\hline $\begin{array}{l}\text { West Virginia } \\
\text { IRB approved } \\
12-14-10\end{array}$ & $\begin{array}{l}\text { Dr. Melissa Olfert } \\
\text { melissa.olfert@mail.wvu.edu }\end{array}$ & $\begin{array}{l}\text { Affiliation Compliance Administration } \\
\text { Lilo Ast } \\
\text { 304-293-7555 } \\
\text { lilo.ast@mail.wvu.edu }\end{array}$ \\
\hline $\begin{array}{l}\text { Wisconsin } \\
\text { IRB approved } \\
1-10-11\end{array}$ & $\begin{array}{l}\text { Dr. Susan Nitzke } \\
\text { nitzke@nutrisci.wisc.edu }\end{array}$ & $\begin{array}{l}\text { University of Wisconsin, Madison } \\
\text { Education Research Institutional Review } \\
\text { Board } \\
\text { ed-irb@education.wisc.edu } \\
608-262-9710\end{array}$ \\
\hline
\end{tabular}

NOTE: THERE WILL BE TWO BUTTONS ON THE BOTTOM OF THE SCREEN. THEY WILL BE ASKED TO SELECT ONE OF THE BUTTONS. 
I accept participation.

I decline participation. 


\section{APPENDIX I}

\section{Screening Questions}

Thank you for your interest in this study. To find out whether you are eligible to participate, please answer the following questions:

1. Are you between the ages of 18 and 24 ?

() Yes

() No

2. Are you a full-time student?

() Yes

() No

3. Are you a first, second, or third year college student?

() Yes

() No

4. Do you have a life threatening illness or other conditions such as pregnancy or diet- and/or activity-related medical restrictions that would prevent participation in an online nutrition and fitness program and/or prevent accurate physical assessments?

() Yes

() No

5. Do you have regular access to a computer with internet connection?

() Yes

() No

6. Are you a current nutrition, exercise science and/or health promotion major?

() Yes

() No

7. What is your Body Mass Index (BMI)? To determine your BMI, please enter your height and weight into the BMI calculator (NEED ITT TO PUT ONE IN) at the right. After you calculate your $\mathrm{BMI}$, please select whether your BMI is greater or less than 18.5.

() less than 18.5

() greater than or equal to 18.5

8. Please select the university you are attending:

-- Select a University --

9. Are you currently enrolled in a nutrition course?

Yes

No

10. Please select your gender:

() Male

() Female (if female, additional question pops up: Are you pregnant or lactating?)

Check Eligibility (button) 
Additional Questions for Intervention (not Pilot)

Did you participate in the Y.E.A.H. project online study last spring 2010 ?

() Yes

() No 


\section{Appendix $\mathbf{J}$}

\section{Outcome Surveys \\ Screening Questions}

\section{Thank you for your interest in this study. To find out whether you are eligible to participate, please answer the following questions:}

1. Are you between the ages of 18 and 24 ?

() Yes

() No

2. Are you a full-time student?

() Yes

() No

3. Are you a first, second, or third year college student?

() Yes

() No

4. Do you have a life threatening illness or other conditions such as pregnancy or diet- and/or activity-related medical restrictions that would prevent participation in an online nutrition and fitness program and/or prevent accurate physical assessments?

() Yes

() No

5. Do you have regular access to a computer with internet connection?

() Yes

() No

6. Are you a current nutrition, exercise science and/or health promotion major?

() Yes

() No

7. What is your Body Mass Index (BMI)? To determine your BMI, please enter your height and weight into the BMI calculator at the right. After you calculate your BMI, please select whether your BMI is greater or less than 18.5 .

() less than 18.5

() greater than or equal to 18.5

8. Please select the university you are attending:

-- Select a University --

9. Are you currently enrolled in a nutrition course?

Yes

No

10. Did you participate in the Y.E.A.H. project online study last spring $2010 ?$

() Yes

() No 
11. Please select your gender:

() Male

() Female (if female, additional question pops up: Are you pregnant or lactating? () Yes () No

\section{Check Eligibility (button)}

\section{Exercise}

\section{Survey 1 of 13}

Regular exercise is any planned physical activity (e.g., brisk walking, aerobics, jogging, bicycling, swimming, rowing, etc.) performed to increase physical fitness. Such activity should be performed 3 to 5 times per week for 30 minutes per session. Exercise does not have to be painful to be effective but should be done at a level that increases your breathing rate and causes you to break a sweat.

1. Do you exercise regularly according to that definition?

(1) No, and I do NOT intend to in the next 6 months

(2) No, but I intend to in the next 6 months

(3) No, but I intend to in the next 30 days

(4) Yes, I have been for LESS than 6 months

(5) Yes, I have been for MORE than 6 months

\section{Fruit/Vegetable Intake}

When considering the amount of a food eaten, a cup is about the size of a baseball. US Dietary Guidelines define 1 cup of fruits and vegetables as equal to:

1 cup cooked or raw fruits or vegetables

2 cups of lettuce salad

A piece of fruit about the size of a small apple or large banana

$1 / 2$ cup of dried fruit like raisins, or

1 cup (8 ounces) of $100 \%$ fruit juice

2. Do you eat 5 or more cups of fruits and vegetables a day?

(1) No, and I do NOT intend to in the next 6 months

(2) No, but I intend to in the in the next 6 months

(3) No, but I intend to in the next 30 days

(4) Yes, but I have been for LESS than 6 months

(5) Yes and I have been for MORE than 6 months

Stress Management

Stress management includes regular relaxation and physical activity, talking with others and/or making time for social activities.

3. Do you effectively practice stress management in your daily life?

(1) No, and I do NOT intend to in the next 6 months

(2) No, but I intend to in the in the next 6 months

(3) No, but I intend to in the next 30 days

(4) Yes, but I have been for LESS than 6 months

(5) Yes and I have been for MORE than 6 months

\section{Survey 2 of 13}

BRFSS Module 6: Inadequate Sleep (2009)

\section{Source(s):}


Cohen S, Kamarack T, Mermelstein R. A Global Measure of Perceived Stress. Journal of Health and Social Behavior. 1983;24:385-396.

Mikolajczyk R, El Ansari W, Maxwell A. Food consumption frequency and perceived stress and depressive symptoms among students in three European countries. Nutrition Journal.

2009;8:31.

Note: Perceived stress was measured with Cohen's Perceived Stress Scale (PSS -14 items), which assesses the extent to which a respondent considers life situations to be stressful. The questions measure how unpredictable, uncontrollable, and overloaded respondents find their lives, using a 5-point Likert scale response format (' $0=$ Never', ' 4 = Very Often'). Scores for individual participants were obtained by summing their responses to all 14 items.

The next sets of questions are about how you perceive stress.

In the last month, how often have you...

1 ...been upset because of something that happened unexpectedly?
(1) Never
(2) Almost never
(3) Sometimes
(4) Fairly often
(5) Very often
(6) Choose not to answer

2...felt that you were unable to control the important things in your life?
(1) Never
(2) Almost never
(3) Sometimes
(4) Fairly often
(5) Very often
(6) Choose not to answer

3...felt nervous and stressed?
(1) Never
(2) Almost never
(3) Sometimes
(4) Fairly often
(5) Very often
(6) Choose not to answer

4... dealt successfully with irritating life hassles?
(1) Never
(2) Almost never
(3) Sometimes
(4) Fairly often
(5) Very often
(6) Choose not to answer 
5 ...felt that you were effectively coping with important changes that were occurring in your life?
(1) Never
(2) Almost never
(3) Sometimes
(4) Fairly often
(5) Very often
(6) Choose not to answer

6 ...felt confident about your ability to handle your personal problems?
(1) Never
(2) Almost never
(3) Sometimes
(4) Fairly often
(5) Very often
(6) Choose not to answer

7 ...felt that things were going your way?
(1) Never
(2) Almost never
(3) Sometimes
(4) Fairly often
(5) Very often
(6) Choose not to answer

8...found that you could not cope with all the things that you had to do?
(1) Never
(2) Almost never
(3) Sometimes
(4) Fairly often
(5) Very often
(6) Choose not to answer

9... been able to control irritations in your life?
(1) Never
(2) Almost never
(3) Sometimes
(4) Fairly often
(5) Very often
(6) Choose not to answer

10 ...felt that you were on top of things?
(1) Never
(2) Almost never
(3) Sometimes
(4) Fairly often
(5) Very often
(6) Choose not to answer

$11 . .$. been angered because of things that happen that were outside of your control?

(1) Never 
(2) Almost never

(3) Sometimes

(4) Fairly often

(5) Very often

(6) Choose not to answer

12...found yourself thinking about things that you have to accomplish?
(1) Never
(2) Almost never
(3) Sometimes
(4) Fairly often
(5) Very often
(6) Choose not to answer

13... been able to control the way you spend your time?
(1) Never
(2) Almost never
(3) Sometimes
(4) Fairly often
(5) Very often
(6) Choose not to answer

14....felt difficulties were piling up so high that you could not overcome them?
(1) Never
(2) Almost never
(3) Sometimes
(4) Fairly often
(5) Very often
(6) Choose not to answer

This question is about your sleep patterns.

BRFSS Module 5: Inadequate Sleep

15. On average, how many hours of sleep do you get in a 24-hour period? Think about the time you actually spend sleeping or napping, not just the amount of sleep you think you should get.

** (If you choose not to answer, please type CNA in the box)

** (If do not know, please type DNK in the box)

\section{Survey 3 of 13}

\section{Sue Schembre's Weight Related Behavior Questionnaire (WREQ)}

Source: Schembre S, Greene G, Melanson K. Development and validation of a weight-related eating questionnaire. Eating Behaviors. 2009;10:199-124.

Note: WREQ scale scores are calculated as the average of the summed item raw scores by the following criteria:

Not at all = 1; Slightly = 2; More or Less = 3; Pretty Well = 4; Completely = 5

Routine Restraint $=($ Item $1+$ Item $3+$ Item 7$) / 3$ 
Compensatory Restraint $=($ Item $10+$ Item $12+$ Item 16)/3

Susceptibility to External Cues $=($ Item $5+$ Item $8+$ Item $9+$ Item $11+$ Item 13)/5

Emotional Eating $=($ Item $2+$ Item $4+$ Item $6+$ Item $14+$ Item 15)/5

\section{Please choose the response that best describes you.}

1. I purposefully hold back at meals in order not to gain weight.
(1) Not at all
(2) Slightly
(3) More or less
(4) Pretty well
(5) Completely
(6) Choose not to answer

2. I tend to eat more when I am anxious, worried, or tense.
(1) Not at all
(2) Slightly
(3) More or less
(4) Pretty well
(5) Completely
(6) Choose not to answer

3. I count calories as a conscious means of controlling my weight.
(1) Not at all
(2) Slightly
(3) More or less
(4) Pretty well
(5) Completely
(6) Choose not to answer

4. When I feel lonely I console myself by eating.
(1) Not at all
(2) Slightly
(3) More or less
(4) Pretty well
(5) Completely
(6) Choose not to answer

5. I tend to eat more food than usual when I have more available places that serve or sell food.
(1) Not at all
(2) Slightly
(3) More or less
(4) Pretty well
(5) Completely
(6) Choose not to answer

6. I tend to eat when I am disappointed or feel let down.
(1) Not at all
(2) Slightly
(3) More or less
(4) Pretty well 
(5) Completely

(6) Choose not to answer

7. I often refuse foods or drinks offered because I am concerned about my weight.
(1) Not at all
(2) Slightly
(3) More or less
(4) Pretty well
(5) Completely
(6) Choose not to answer

8. If I see others eating, I have a strong desire to eat too.
(1) Not at all
(2) Slightly
(3) More or less
(4) Pretty well
(5) Completely
(6) Choose not to answer

9. Some foods taste so good I eat more even when I am no longer hungry.
(1) Not at all
(2) Slightly
(3) More or less
(4) Pretty well
(5) Completely
(6) Choose not to answer

10. When I have eaten too much during the day, I will often eat less than usual the following day.
(1) Not at all
(2) Slightly
(3) More or less
(4) Pretty well
(5) Completely
(6) Choose not to answer

11. I often eat so quickly I don't notice l'm full until l've eaten too much.
(1) Not at all
(2) Slightly
(3) More or less
(4) Pretty well
(5) Completely
(6) Choose not to answer

12. If I eat more than usual during a meal, I try to make up for it at another meal.
(1) Not at all
(2) Slightly
(3) More or less
(4) Pretty well
(5) Completely
(6) Choose not to answer 
13. When I'm offered delicious food, it's hard to resist eating it even if I've just eaten.

(1) Not at all

(2) Slightly

(3) More or less

(4) Pretty well

(5) Completely

(6) Choose not to answer

14. I eat more when I'm having relationship problems.
(1) Not at all
(2) Slightly
(3) More or less
(4) Pretty well
(5) Completely
(6) Choose not to answer

15. When I'm under a lot of stress, I eat more than I usually do.
(1) Not at all
(2) Slightly
(3) More or less
(4) Pretty well
(5) Completely
(6) Choose not to answer

16. When I know l'll be eating a big meal during the day, I try to make up for it by eating less before or after that meal.
(1) Not at all
(2) Slightly
(3) More or less
(4) Pretty well
(5) Completely
(6) Choose not to answer

Survey 4 of 13

Source: Strong K, Parks S, Anderson E, Winett R, Davy B. Weight Gain Prevention: Identifying Theory-Based Targets for Health Behavior Change in Young Adults. Journal of American Dietetic Association 2008;108:1708-1715.

Note: Scores are calculated by the following: Never = 1; Seldom = 2; Occasionally = 3; Often = 4; Repeatedly $=5$

Indicate below how often in the past 3 months you have done the following:

1. Remind myself that planning quick and simple meals is important.
(1) Never
(2) Seldom
(3) Occasionally
(4) Often
(5) Always
(6) Choose not to answer 
2. Tell myself that healthy meals do not require a lot of work.
(1) Never
(2) Seldom
(3) Occasionally
(4) Often
(5) Always
(6) Choose not to answer

3. Remind myself to eat in moderation.
(1) Never
(2) Seldom
(3) Occasionally
(4) Often
(5) Always
(6) Choose not to answer

4. Tell myself to allow room for an occasional treat food or dessert for just plain enjoyment.
(1) Never
(2) Seldom
(3) Occasionally
(4) Often
(5) Always
(6) Choose not to answer

5. Remind myself to think about my beverage choices.
(1) Never
(2) Seldom
(3) Occasionally
(4) Often
(5) Always
(6) Choose not to answer

6. Tell myself that fruits and vegetables should be included in every meal.
(1) Never
(2) Seldom
(3) Occasionally
(4) Often
(5) Always
(6) Choose not to answer

Indicate how often during the past 3 months you did the following:

7. Planned quick, easy, and healthy snacks.
(1) Never
(2) Seldom
(3) Occasionally
(4) Often
(5) Always
(6) Choose not to answer 
8. Select beverages with my health in mind.
(1) Never
(2) Seldom
(3) Occasionally
(4) Often
(5) Always
(6) Choose not to answer

9. Purposely added vegetables to my meals and snacks.
(1) Never
(2) Seldom
(3) Occasionally
(4) Often
(5) Always
(6) Choose not to answer

10. Was flexible and sensible with my food choices.
(1) Never
(2) Seldom
(3) Occasionally
(4) Often
(5) Always
(6) Choose not to answer

11. Would you say that your diet is...

1) Somewhat or Very Unhealthy

2) Somewhat Healthy

3) Very Healthy

4) Choose not to answer

Survey 5 of 13

Source: http://riskfactor.cancer.gov/diet/screeners/fat/percent_energy.pdf

Thinking about your eating habits over the past 12 months. About how often did you eat or drink each of the following foods? Remember breakfast, lunch, dinner, snacks, and eating out. Click on only one bubble for each food.

1. Cold cereal

(1) Never

(2) Less than once per month

(3) 1-3 times per month

(4) 1-2 times per week

(5) 3-4 times per week

(6) 5-6 times per week

(7) 1 time per day

(8) 2 or more times per day

(9) Choose not to answer

2. Skim milk, on cereal or to drink

(1) Never

(2) Less than once per month 
(3) 1-3 times per month

(4) 1-2 times per week

(5) 3-4 times per week

(6) 5-6 times per week

(7) 1 time per day

(8) 2 or more times per day

(9) Choose not to answer

3. Eggs, fried or scrambled in margarine, butter, or oil

(1) Never

(2) Less than once per month

(3) 1-3 times per month

(4) 1-2 times per week

(5) 3-4 times per week

(6) 5-6 times per week

(7) 1 time per day

(8) 2 or more times per day

(9) Choose not to answer

4. Sausage or bacon, regular-fat

(1) Never

(2) Less than once per month

(3) 1-3 times per month

(4) 1-2 times per week

(5) 3-4 times per week

(6) 5-6 times per week

(7) 1 time per day

(8) 2 or more times per day

(9) Choose not to answer

5. Margarine or butter on bread, rolls, pancakes

(1) Never

(2) Less than once per month

(3) 1-3 times per month

(4) 1-2 times per week

(5) 3-4 times per week

(6) 5-6 times per week

(7) 1 time per day

(8) 2 or more times per day

(9) Choose not to answer

6) Orange juice or grapefruit juice

(1) Never

(2) Less than once per month

(3) 1-3 times per month

(4) 1-2 times per week

(5) 3-4 times per week

(6) 5-6 times per week

(7) 1 time per day

(8) 2 or more times per day

(9) Choose not to answer 
7. Fruit (not juices)
(1) Never
(2) Less than once per month
(3) 1-3 times per month
(4) 1-2 times per week
(5) 3-4 times per week
(6) 5-6 times per week
(7) 1 time per day
(8) 2 or more times per day
(9) Choose not to answer

8. Beef or pork hot dogs, regular-fat
(1) Never
(2) Less than once per month
(3) 1-3 times per month
(4) 1-2 times per week
(5) 3-4 times per week
(6) 5-6 times per week
(7) 1 time per day
(8) 2 or more times per day
(9) Choose not to answer

9. Cheese or cheese spread, regular-fat

(1) Never

(2) Less than once per month

(3) 1-3 times per month

(4) 1-2 times per week

(5) 3-4 times per week

(6) 5-6 times per week

(7) 1 time per day

(8) 2 or more times per day

(9) Choose not to answer

10. French fries, home fries, or hash brown potatoes

(1) Never

(2) Less than once per month

(3) 1-3 times per month

(4) 1-2 times per week

(5) 3-4 times per week

(6) 5-6 times per week

(7) 1 time per day

(8) 2 or more times per day

(9) Choose not to answer

11. Margarine or butter on vegetables, including potatoes
(1) Never
(2) Less than once per month
(3) 1-3 times per month
(4) 1-2 times per week
(5) 3-4 times per week 
(6) 5-6 times per week

(7) 1 time per day

(8) 2 or more times per day

(9) Choose not to answer

12. Mayonnaise, regular-fat

(1) Never

(2) Less than once per month

(3) 1-3 times per month

(4) 1-2 times per week

(5) 3-4 times per week

(6) 5-6 times per week

(7) 1 time per day

(8) 2 or more times per day

(9) Choose not to answer

13. Salad dressings, regular-fat

(1) Never

(2) Less than once per month

(3) 1-3 times per month

(4) 1-2 times per week

(5) 3-4 times per week

(6) 5-6 times per week

(7) 1 time per day

(8) 2 or more times per day

(9) Choose not to answer

14. Rice

(1) Never

(2) Less than once per month

(3) 1-3 times per month

(4) 1-2 times per week

(5) 3-4 times per week

(6) 5-6 times per week

(7) 1 time per day

(8) 2 or more times per day

(9) Choose not to answer

15. Margarine, butter, or oil on rice or pasta

(1) Never

(2) Less than once per month

(3) 1-3 times per month

(4) 1-2 times per week

(5) 3-4 times per week

(6) 5-6 times per week

(7) 1 time per day

(8) 2 or more times per day

(9) Choose not to answer

16. Over the past 12 months, when you prepared foods with margarine or ate margarine, how often did you use a reduced-fat margarine? 
(1) Didn't Use Margarine

(2) Almost Never

(3) About $1 / 4$ of the time

(4) About $1 / 2$ of the time

(5) About $3 / 4$ of the time

(6) Almost always or always

(7) Choose not to answer

17. Overall, when you think about the foods you ate over the past 12 months, would you say your diet was high, medium, or low in fat?
(1) High
(2) Medium
(3) Low
(4) Choose not to answer

\section{Survey 6 of 13 \\ $\mathrm{NCl}$ Fruit and Vegetable Screener}

Source: http://riskfactor.cancer.gov/diet/screeners/fruitveg/allday.pdf

Think about what you usually ate last month. Please think about all the fruits and vegetables that you ate last month. Include those that were:

- Raw and cooked,

- Eaten as snacks and at meals

- Eaten at home and away from home (restaurants, friends, take-out), and

- Eaten alone and mixed with other foods.

Report how many times per month, week, or day you ate each food, and if you ate it, how much you usually had.

If you mark "never" for a question, follow the "Go to" instruction.

Choose the best answer for each question. Mark only one response for each question.

1. Over the last month, how many times per month, week, or day did you drink $100 \%$ juice such as orange, apple, grape, or grapefruit juice? Do not count fruit drinks like Kool-Aid, lemonade, $\mathrm{Hi}-\mathrm{C}$, cranberry juice drink, Tang, and Twister. Include juice you drank at all mealtimes and between meals.

(1) Never (go to question 3)

(2) 1-3 times last month

(3) 1-2 times per week

(4) 3-4 times per week

(5) 5-6 times per week

(6) 1 time per day

(7) 2 times per day

(8) 3 times per day

(9) 4 times per day

(10) 5 or more times per day

(11) Choose not to answer

2. Each time you drank $100 \%$ juice, how much did you usually drink?

(1) Did not drink $100 \%$ juice

(2) Less than $3 / 4$ cup (less than 6 ounces)

(3 $3 / 4$ to $1 \frac{1}{4}$ cup (6 to 10 ounces) 
(4) $1 \frac{1}{4}$ to 2 cups (10 to 16 ounces)

(5) More than 2 cups (more than 16 ounces)

(6) Choose not to answer

3. Over the last month, how many times per month, week, or day did you eat fruit? Count any kind of fruit-fresh, canned, and frozen. Do not count juices. Include fruit you ate at all mealtimes and for snacks.

(1) Never (go to question 5)

(2) 1-3 times last month

(3) 1-2 times per week

(4) 3-4 times per week

(5) 5-6 times per week

(6) 1 time per day

(7) 2 times per day

(8) 3 times per day

(9) 4 times per day

(10) 5 or more times per day

(11) Choose not to answer

4. Each time you ate fruit, how much did you usually eat?

(1) Did not eat fruit

(2) Less than 1 medium fruit (less than $1 / 2$ cup)

(3) 1 medium fruit (about $1 / 2$ cup)

(4) 2 medium fruits (about 1 cup)

(5) More than 2 medium fruits (more than 1 cup)

(6) Choose not to answer

5. Over the last month, how often did you eat lettuce salad (with or without other vegetables)?

(1) Never (go to question 7)

(2) 1-3 times last month

(3) 1-2 times per week

(4) 3-4 times per week

(5) 5-6 times per week

(6) 1 time per day

(7) 2 times per day

(8) 3 times per day

(9) 4 times per day

(10) 5 or more times per day

(11) Choose not to answer

6. Each time you ate lettuce salad, how much did you usually eat?

(1) Did not eat lettuce salad

(2) About $1 / 2$ cup

(3) About 1 cup

(4) About 2 cups

(5) More than 2 cups

(6) Choose not to answer

7. Over the last month, how often did you eat French fries or fried potatoes?

(1) Never (go to question 9)

(2) 1-3 times last month 
(3) 1-2 times per week

(4) 3-4 times per week

(5) 5-6 times per week

(6) 1 time per day

(7) 2 times per day

(8) 3 times per day

(9) 4 times per day

(10) 5 or more times per day

(11) Choose not to answer

8. Each time you ate French fries or fried potatoes, how much did you usually eat?

(1) Did not eat French fries or fried potatoes

(2) Small order or less (About 1 cup or less)

(3) Medium order (About1 $1 \frac{1}{2}$ cups)

(4) Large order (About 2 cups)

(5) Super-Size order or more (About 3 cups or more)

(6) Choose not to answer

9. Over the last month, how often did you eat other white potatoes? Count baked, boiled, and mashed potatoes, potato salad, and white potatoes that were not fried.

(1) Never (go to question 11)

(2) 1-3 times last month

(3) 1-2 times per week

(4) 3-4 times per week

(5) 5-6 times per week

(6) 1 time per day

(7) 2 times per day

(8) 3 times per day

(9) 4 times per day

(10) 5 or more times per day

(11) Choose not to answer

10. Each time you ate these potatoes, how much did you usually eat?

(1) Not eat these types of potatoes

(2) 1 small potato or less (1/2 cup or less)

(3) 1 medium potato (1/2 to 1 cup)

(4) 1 large potato (1 to $1 \frac{1}{2}$ cups)

(5) 2 medium potatoes or more ( $1 \frac{1}{2}$ cups or more)

(6) Choose not to answer

11. Over the last month, how often did you eat cooked dried beans? Count baked beans, bean soup, refried beans, pork and beans and other bean dishes.

(1) Never (go to question 13)

(2) 1-3 times last month

(3) 1-2 times per week

(4) 3-4 times per week

(5) 5-6 times per week

(6) 1 time per day

(7) 2 times per day

(8) 3 times per day 
(9) 4 times per day

(10) 5 or more times per day

(11) Choose not to answer

12. Each time you ate these beans, how much did you usually eat?

(1) Did not eat cooked dried beans

(2) Less than $1 / 2$ cup

(3) $1 / 2$ to 1 cup

(4) 1 to $1 \frac{1}{2}$ cups

(5) More than $1 \frac{1}{2}$ cups

(6) Choose not to answer

13) Over the last month, how often did you eat other vegetables?

DO NOT COUNT:

- Lettuce salads

- White potatoes

- Cooked dried beans

- Vegetables in mixtures, such as in sandwiches, omelets, casseroles, Mexican dishes, stews, stir-fry, soups, etc.

- Rice

COUNT: All other vegetables—raw, cooked, canned, and frozen

(1) Never (go to question 15)

(2) 1-3 times last month

(3) 1-2 times per week

(4) 3-4 times per week

(5) 5-6 times per week

(6) 1 time per day

(7) 2 times per day

(8) 3 times per day

(9) 4 times per day

(10) 5 or more times per day

(11) Choose not to answer

14. Each of these times that you ate other vegetables, how much did you usually eat?

(1) Did not eat these vegetables

(2) Less than $1 / 2$ cup

(3) $1 / 2$ to 1 cup

(4) 1 to 2 cups

(5) More than 2 cups

(6) Choose not to answer

15. Over the last month, how often did you eat tomato sauce? Include tomato sauce on pasta or macaroni, rice, pizza and other dishes.

(1) Never (go to question 17)

(2) 1-3 times last month

(3) 1-2 times per week

(4) 3-4 times per week 
(5) 5-6 times per week

(6) 1 time per day

(7) 2 times per day

(8) 3 times per day

(9) 4 times per day

(10) 5 or more times per day

(11) Choose not to answer

16. Each time you ate tomato sauce, how much did you usually eat?

(1) Did not eat tomato sauce

(2) About $1 / 4$ cup

(3) About $1 / 2$ cup

(4) About 1 cup

(5) More than 1 cup

(6) Choose not to answer

17. Over the last month, how often did you eat vegetable soups? Include tomato soup, gazpacho, beef with vegetable soup, minestrone soup, and other soups made with vegetables.

(1) Never (go to question 19)

(2) 1-3 times last month

(3) 1-2 times per week

(4) 3-4 times per week

(5) 5-6 times per week

(6) 1 time per day

(7) 2 times per day

(8) 3 times per day

(9) 4 times per day

(10) 5 or more times per day

(11) Choose not to answer

18. Each time you ate vegetable soup, how much did you usually eat?

(1) Did not eat vegetable soup

(2) Less than 1 cup

(3) 1 to 2 cups

(4) 2 to 3 cups

(5) More than 3 cups

(6) Choose not to answer

19. Over the last month, how often did you eat mixtures that included vegetables? Count such foods as sandwiches, casseroles, stews, stir-fry, omelets, and tacos.

(1) Never

(2) 1-3 times last month

(3) 1-2 times per week

(4) 3-4 times per week

(5) 5-6 times per week

(6) 1 time per day

(7) 2 times per day

(8) 3 times per day

(9) 4 times per day

(10) 5 or more times per day

(11) Choose not to answer 
20. Including snacks, how many cups of fruit and $100 \%$ fruit juice do you usually eat each day?

(1) Less than $1 / 2$ cup

(2) $1 / 2$ cup

(3) 1 cup

(4) $1 \frac{1}{2}$ cups

(5) 2 cups

(6) $2 \frac{1}{2}$ cups

(7) 3 cups

(8) $31 / 2$ cups

(9) 4 cups

(10) $4 \frac{1}{2}$ cups

(11) 5 cups

(12) $5 \frac{1}{2}$ cups

(13) 6 cups or more

(14) Choose not to answer

21. Including snacks, how many cups of vegetables do you usually eat each day?

(1) Less than $1 / 2$ cup

(2) $1 / 2$ cup

(3) 1 cup

(4) $1 \frac{1}{2}$ cups

(5) 2 cups

(6) $2 \frac{1}{2}$ cups

(7) 3 cups

(8) $3 \frac{1}{2}$ cups

(9) 4 cups

(10) $4 \frac{1}{2}$ cups

(11) 5 cups

(12) $5 \frac{1}{2}$ cups

(13) 6 cups or more

(14) Choose not to answer

The next 2 questions are about grains.

22. How many servings of grains do you eat on average per day?

From Healthy Eating Index

NOTE: Any food made from wheat, rice, oats, cornmeal, barley or another cereal grain is a grain product. Bread, pasta, oatmeal, breakfast cerals, tortillas and grits are examples of grain products.

Examples: 1 serving = 1 slice of bread; 1 cup of ready-to-eat cereal; $1 / 2$ cup cooked rice or pasta

1) Less than one

2) 1

3) 2

4) 3

5) 4 
6) 5

7) 6 or more

8) Choose not to answer

23. How many servings of whole grains do you eat on average per day?

NOTE: All grains begin as whole grains; however, if after milling they keep all the parts of the original grain in their original proportions they are still considered a whole grain. Whole grains should be the first ingredient listed on the label.

Examples: 1 serving = 1 slice whole wheat bread; 5-6 whole grain crackers; $1 / 2$ cup cooked brown rice; $1 / 2$ cup oatmeal

1) Less than one

2) 1

3) 2

4) 3

5) 4

6) 5

7) 6 or more

8) Choose not to answer

\section{Survey 7 of 13}

Source: West et al. Obesity 2006 14:1825

1. On average, how often in the past month did you consume a non-diet, sugar-sweetened soft drink (pop)? (For example, Coke, Sprite, Dr. Pepper, Pepsi, Mountain Dew, Orange Crush, Mr. Pibb, 7-Up, Fanta, root beer)

(1) Never or less than one per month

(2) One to four per month

(3) Two to six per week

(4) One per day

(5) Two per day

(6) Three per day

(7) Four per day or more

(8) Choose not to answer

2. If you consumed any non-diet, sugar-sweetened soft drinks last month, what was the typical serving size you consumed?

(1) I have not had a non-diet sugared soft drink in the last month

(2) 12-ounce can

(3) Restaurant glass or cup

(4) 20-ounce bottle

(5) 2-liter bottle

(6) Choose not to answer

3. On average, how often in the past month did you consume fruit drinks or other sugar sweetened beverages? (For example, Hawaiian Punch, Hi-C, Kool-Aid, Ocean Spray cranberry juice cocktail, Snapple, Sunny Delight, Country Time Lemonade, Sobe, Arizona Ice Tea, sugar sweetened tea, etc.) 
(1) Never or less than one per month

(2) One to four per month

(3) Two to six per week

(4) One per day

(5) Two per day

(6) Three per day

(7) Four per day or more

(8) Choose not to answer

4. If you consumed any fruit drinks last month, what was the typical serving size you consumed?

(1) I have not had a fruit drink in the last month

(2) 11.5-ounce can or less

(3) 20-ounce bottle

(4) 64-ounce bottle

(5) Choose not to answer

Note: The following energy drink and coffee drink items were designed by Mallory Koenings, Susan Nitzke, Beatrice Phillips.

5. On average, how often in the past month did you consume non-diet (NOT sugar-free) energy drinks (For example, RockStar, Red Bull, Monster, Full Throttle)?

(1) Never or less than one per month

(2) One to four per month

(3) Two to six per week

(4) One per day

(5) Two per day

(6) Three per day

(7) Four per day or more

(8) Choose not to answer

6. If you consumed any non-diet energy drinks last month, what was the typical serving size you consumed?

(1) I have not had a non-diet energy drink in the last month

(2) 2-6 oz. (energy shot)

(3) Between 6 and 16 oz.

(4) More than $16 \mathrm{oz}$.

(5) Choose not to answer

7. On average, how often in the past month did you consume sugar-sweetened specialty coffee drinks (For example, Frappuccino, flavored latté/cappuccino)?
(1) Never or less than one per month
(2) One to four per month
(3) Two to six per week
(4) One per day
(5) Two per day
(6) Three per day
(7) Four per day or more
(8) Choose not to answer 
8. If you consumed any sugar-sweetened specialty coffee drinks last month, what was the typical serving size you consumed?

(1) I have not had a sugar-sweetened specialty coffee last month

(2) 12 oz. or less

(3) More than $12 \mathrm{oz}$.

(4) Choose not to answer

Survey 8 of 13

International Physical Activity Questionnaire (IPAQ)

Source: http://www.projectwebhealth.com/lesson/survey.php?sid=76

How Active Are You?

We are interested in finding out about the kinds of physical activities that people do as part of their everyday lives. The questions will ask you about the time you spent being physically active in the last 7 days. Please answer each question even if you do not consider yourself to be an active person. Please think about the activities you do at work, as part of your house and yard work, to get from place to place, and in your spare time for recreation, exercise or sport.

Think about all the vigorous activities that you did in the last 7 days. Vigorous physical activities refer to activities that take hard physical effort and make you breathe much harder than normal or make your heart beat much harder than normal. Think only about those vigorous physical activities that you did for at least $\mathbf{1 0}$ minutes at a time, such as running, aerobics, heavy yard work, or anything else that causes large increases in breathing or heart rate.

1. During the last 7 days, on how many days did you do vigorous physical activities like heavy lifting, digging, aerobics, or fast bicycling?
(1) 0 days (Skip to question 3)
(2) 1 day
(3) 2 days
(4) 3 days
(5) 4 days
(6) 5 days
(7) 6 days
(8) 7 days
(9) Choose not to answer

2) How much time did you usually spend doing vigorous physical activities on one of those days?

(1) Did not do vigorous physical activities

(2) 10 minutes

(3) 20 minutes

(4) 30 minutes

(5) 40 minutes

(6) 50 minutes

(7) 60 minutes

(8) 70 minutes ( $1 \mathrm{hr} 10 \mathrm{~min})$

(9) 80 minutes (1 hr $20 \mathrm{~min})$

(10) 90 minutes (1 hr $30 \mathrm{~min})$ 
(11) 100 minutes (1 hr $40 \mathrm{~min}$ )

(12) 110 minutes (1 hr $50 \mathrm{~min}$ )

(13) 120 minutes (2 hrs)

(14) 130 minutes (2 hrs $10 \mathrm{~min}$ )

(15) 140 minutes (2 hrs $20 \mathrm{~min}$ )

(16) 150 minutes (2 hrs $30 \mathrm{~min}$ )

(17) 160 minutes (2 hrs $40 \mathrm{~min}$ )

(18) 170 minutes (2 hrs 50 min)

(19) $180+$ minutes (3 hrs or more)

(20) Don't know/not sure

(21) Choose not to answer

Think about all the moderate activities that you did in the last 7 days. Moderate activities refer to activities that take moderate physical effort and make you breathe somewhat harder than normal or make your heart beat somewhat harder than normal. Think only about those physical activities that you did for at least 10 minutes at a time, such as brisk walking, bicycling, vacuuming, gardening, or anything else that causes some increase in breathing or heart rate.

3. During the last 7 days, on how many days did you do moderate physical activities like carrying light loads, bicycling at a regular pace, or doubles tennis? Do not include walking.

(1) 0 days (Skip to question 5)

(2) 1 day

(3) 2 days

(4) 3 days

(5) 4 days

(6) 5 days

(7) 6 days

(8) 7 days

(9) Choose not to answer

4. How much time did you usually spend doing moderate physical activities on one of those days?

(1) Do not do moderate physical activities

(2) 10 minutes

(3) 20 minutes

(4) 30 minutes

(5) 40 minutes

(6) 50 minutes

(7) 60 minutes

(8) 70 minutes ( $1 \mathrm{hr} 10 \mathrm{~min})$

(9) 80 minutes (1 hr $20 \mathrm{~min})$

(10) 90 minutes (1 hr $30 \mathrm{~min})$

(11) 100 minutes ( $1 \mathrm{hr} 40 \mathrm{~min}$ )

(12) 110 minutes ( $1 \mathrm{hr} 50 \mathrm{~min}$ )

(13) 120 minutes (2 hrs)

(14) 130 minutes (2 hrs $10 \mathrm{~min}$ )

(15) 140 minutes (2 hrs $20 \mathrm{~min}$ )

(16) 150 minutes (2 hrs $30 \mathrm{~min}$ )

(17) 160 minutes (2 hrs $40 \mathrm{~min}$ )

(18) 170 minutes (2 hrs $50 \mathrm{~min}$ ) 
(19) $180+$ minutes (3 hrs or more)

(20) Don't know/not sure

(21) Choose not to answer

Think about the time you spent walking in the last 7 days. This includes at work and at home, walking to travel from place to place, and any other walking that you might do solely for recreation, sport, exercise or leisure.

5. During the last 7 days, on how many days did you walk for at least 10 minutes at a time?

(1) 0 days (Skip to question 7)

(2) 1 day

(3) 2 days

(4) 3 days

(5) 4 days

(6) 5 days

(7) 6 days

(8) 7 days

(9) Choose not to answer

6. How much time did you usually spend walking on one of those days?

(1) Did not walk

(2) 10 minutes

(3) 20 minutes

(4) 30 minutes

(5) 40 minutes

(6) 50 minutes

(7) 60 minutes

(8) 70 minutes ( $1 \mathrm{hr} 10 \mathrm{~min})$

(9) 80 minutes (1 hr $20 \mathrm{~min})$

(10) 90 minutes (1 hr $30 \mathrm{~min}$ )

(11) 100 minutes (1 hr $40 \mathrm{~min})$

(12) 110 minutes ( $1 \mathrm{hr} 50 \mathrm{~min}$ )

(13) 120 minutes (2 hrs)

(14) 130 minutes (2 hrs $10 \mathrm{~min})$

(15) 140 minutes (2 hrs $20 \mathrm{~min}$ )

(16) 150 minutes (2 hrs $30 \mathrm{~min}$ )

(17) 160 minutes (2 hrs $40 \mathrm{~min}$ )

(18) 170 minutes (2 hrs $50 \mathrm{~min}$ )

(19) $180+$ minutes (3 hrs or more)

(20) Don't know/not sure

(21) Choose not to answer

This question is about the time you spent sitting on weekdays during the last 7 days. Include time spent at work, at home, while doing course work and during leisure time. This may include time spent sitting at a desk, visiting friends, reading or sitting or lying down to watch television.

7. During the last 7 days, how much time did you spend sitting on a week day?

(1) 10 minutes

(2) 20 minutes 
(3) 30 minutes

(4) 40 minutes

(5) 50 minutes

(6) 60 minutes

(7) 70 minutes ( $1 \mathrm{hr} 10 \mathrm{~min})$

(8) 80 minutes (1 hr $20 \mathrm{~min})$

(9) 90 minutes (1 hr $30 \mathrm{~min}$ )

(10) 100 minutes (1 hr $40 \mathrm{~min}$ )

(11) 110 minutes (1 hr 50 min)

(12) 120 minutes (2 hrs)

(13) 130 minutes (2 hrs $10 \mathrm{~min}$ )

(14) 140 minutes (2 hrs $20 \mathrm{~min}$ )

(15) 150 minutes (2 hrs $30 \mathrm{~min}$ )

(16) 160 minutes (2 hrs $40 \mathrm{~min}$ )

(17) 170 minutes (2 hrs 50 min)

(18) $180+$ minutes (3 hrs or more)

(19) Don't know/not sure

(20) Choose not to answer

Think about the time you spent doing any physical activities specifically designed to strengthen your muscles such as lifting weights, push-ups or sit-ups. Include all such activities even if you have reported them before.

8. During the last 7 days, how many days did you do any physical activities designed to strengthen muscles such as lifting weights, push-ups or sit-ups?
(1) 0 days (Skip to question 68)
(2) 1 day
(3) 2 days
(4) 3 days
(5) 4 days
(6) 5 days
(7) 6 days
(8) 7 days
(9) Choose not to answer

9. How much time did you usually spend doing strength training activities on one of those days?

(1) Did not do strength activities

(2) 10 minutes

(3) 20 minutes

(4) 30 minutes

(5) 40 minutes

(6) 50 minutes

(7) 60 minutes

(8) 70 minutes ( $1 \mathrm{hr} 10 \mathrm{~min})$

(9) 80 minutes (1 hr $20 \mathrm{~min}$ )

(10) 90 minutes (1 hr $30 \mathrm{~min}$ )

(11) 100 minutes ( $1 \mathrm{hr} 40 \mathrm{~min}$ )

(12) 110 minutes ( $1 \mathrm{hr} 50 \mathrm{~min}$ )

(13) 120 minutes (2 hrs)

(14) 130 minutes (2 hrs $10 \mathrm{~min}$ )

(15) 140 minutes (2 hrs $20 \mathrm{~min}$ ) 
(16) 150 minutes (2 hrs $30 \mathrm{~min}$ )

(17) 160 minutes (2 hrs $40 \mathrm{~min}$ )

(18) 170 minutes (2 hrs 50 min)

(19) $180+$ minutes (3 hrs or more)

(20) Don't know/not sure

(21) Choose not to answer

\section{Survey 9 of 13 \\ Sue Schembre's Physical Activity Behavior Questionnaire (PABQ)}

Note: PABQ scale scores are calculated as the average of the summed item raw scores by the following criteria: Not at all=1;

Slightly=2; More or Less=3; Pretty Well=4; Completely=5.

Outcome expectations=sum of raw scores (Item 1+ltem 2+ltem 9+ltem 13+ltem 14)/5

Self-Regulation=sum of raw scores (Item 3+ltem 4+ltem $5+$ +ltem $6+$ Item 8 )/5

Personal Barriers=sum of raw scores (Item 7+ltem 10+Item 11+ltem 12+Item 15)/5

(Personal communication: January 22, 2010)

Please choose the response that best describes you.

All answers are: Describes me: not at all, slightly, more or less, pretty well, and completely.

1. I find being physically active gives me a lot of energy.
(1) Not at all
(2) Slightly
(3) More or less
(4) Pretty well
(5) Completely
(6) Choose not to answer

2. I feel good physically after I've exercised.
(1) Not at all
(2) Slightly
(3) More or less
(4) Pretty well
(5) Completely
(6) Choose not to answer

3. I schedule all events in my life around my exercise routine.
(1) Not at all
(2) Slightly
(3) More or less
(4) Pretty well
(5) Completely
(6) Choose not to answer

4. I schedule exercise at specific times of the week in order to maintain a routine.
(1) Not at all
(2) Slightly
(3) More or less
(4) Pretty well
(5) Completely 
(6) Choose not to answer

5. I set goals for myself in order to keep physically active.
(1) Not at all
(2) Slightly
(3) More or less
(4) Pretty well
(5) Completely
(6) Choose not to answer

6. I make commitments to exercise and stick to them.
(1) Not at all
(2) Slightly
(3) More or less
(4) Pretty well
(5) Completely
(6) Choose not to answer

7. I'm just too lazy to exercise regularly.
(1) Not at all
(2) Slightly
(3) More or less
(4) Pretty well
(5) Completely
(6) Choose not to answer

8. I make back up plans to be sure I get enough exercise.
(1) Not at all
(2) Slightly
(3) More or less
(4) Pretty well
(5) Completely
(6) Choose not to answer

9. Being physically active gives me a strong sense of accomplishment.
(1) Not at all
(2) Slightly
(3) More or less
(4) Pretty well
(5) Completely
(6) Choose not to answer

10. I have too many things to do during the day and can never find time to exercise.
(1) Not at all
(2) Slightly
(3) More or less
(4) Pretty well
(5) Completely
(6) Choose not to answer

11. My lack of motivation stops me from being physically active. 

(1) Not at all
(2) Slightly
(3) More or less
(4) Pretty well
(5) Completely
(6) Choose not to answer

12. When I am exercising, I often feel as though I would rather be doing something else.
(1) Not at all
(2) Slightly
(3) More or less
(4) Pretty well
(5) Completely
(6) Choose not to answer

13. Being physically active improves my mood.
(1) Not at all
(2) Slightly
(3) More or less
(4) Pretty well
(5) Completely
(6) Choose not to answer

14. I consider being physically active an effective way of relieving stress.
(1) Not at all
(2) Slightly
(3) More or less
(4) Pretty well
(5) Completely
(6) Choose not to answer

15. I don't exercise as regularly when I get depressed or upset about something.
(1) Not at all
(2) Slightly
(3) More or less
(4) Pretty well
(5) Completely
(6) Choose not to answer

\section{Survey 10 of 13}

\section{Source(s):}

Renner B, Knoll N, Schwarzer R. Age and body weight make difference in optimistic health beliefs and nutrition behaviors. International Journal of Behavioral Medicine. 2000;7:143-159.

Schwarzer R, Fuchs R. Changing risk behaviors and adopting health behaviors: The role of selfefficacy beliefs: In A. Bandura (Ed.), Self-efficacy in Changing Societies. New York: Cambridge University Press; 1995. 
The Health-Specific Nutrition Self-Efficacy instrument assesses the self-efficacy construct from the Social Cognitive Theory.

Note: A score for each item is determined by assigning a score of 1, 2, 3, or 4 to the answer choices very uncertain, rather uncertain, rather certain, and very certain respectively. Scores for each item are summed to determine a total score.

I am certain that, if I wanted to, I could control myself to...

1 ...reduce my alcohol consumption.

(1) Very uncertain

(2) Rather uncertain

(3) Rather certain

(4) Very certain

(5) Choose not to answer

2...not to drink any alcohol at all.

(1) Very uncertain

(2) Rather uncertain

(3) Rather certain

(4) Very certain

(5) Choose not to answer

3...drink only at special occasions.

(1) Very uncertain

(2) Rather uncertain

(3) Rather certain

(4) Very certain

(5) Choose not to answer

The next few questions ask about alcohol. One drink or alcoholic beverage is defined as a 12ounce beer, a 4-ounce glass of wine, a shot of liquor, or a mixed drink.

American College Health Association; National College Health Assessment

Note: These questions are coded as a 2-digit number such as 01,02, etc. through 99.

(If you choose not to answer, please type CNA in the box)

4. The last time you "partied"/socialized, how many hours did you drink alcohol? (If you did not drink alcohol, please enter 00. If less than 10, enter 01, 02, 03, etc.) State your best estimate.

() Choose not to answer

5. The last time you "partied"/socialized, how many drinks of alcohol did you have? (If you did not drink alcohol, please enter 00. If less than 10, enter 01, 02, 03, etc.) State your best estimate.

() Choose not to answer

6. In the last two weeks, how many times have you had five or more drinks of alcohol at a sitting? State your best estimate. 
() Choose not to answer

() N/A, don't drink

() None

() 1 time

() 2 times

() 3 times

() 4 times

() 5 times

() 6 times

() 7 times

() 8 times

() 9 times

() 10 or more times

7. How many drinks of alcohol do you think the typical student at your school had the last time he/she "partied"/socialized? (If you think the typical student at your school does not drink alcohol, please enter 00. If less than 10, enter 01, 02, 03, etc.)

() Choose not to answer

During the last 12 months, when you "partied"/socialized, how often did you... (Please mark the appropriate column for each row)

8...Alternate non-alcoholic with alcoholic beverages?

(1) Not applicable/ Do not drink

(2) Always

(3) Usually

(4) Sometimes

(5) Rarely

(6) Never

(7) Choose not to answer

9...Determine, in advance, not to exceed a set number of drinks?

(1) Not applicable/ Do not drink

(2) Always

(3) Usually

(4) Sometimes

(5) Rarely

(6) Never

(7) Choose not to answer

10...Choose not to drink alcohol?

(1) Not applicable/ Do not drink

(2) Always

(3) Usually

(4) Sometimes

(5) Rarely

(6) Never

(7) Choose not to answer 
11...Use a designated driver?
(1) Not applicable/ Do not drink
(2) Always
(3) Usually
(4) Sometimes
(5) Rarely
(6) Never
(7) Choose not to answer

12...Eat before and/or during drinking?
(1) Not applicable/ Do not drink
(2) Always
(3) Usually
(4) Sometimes
(5) Rarely
(6) Never
(7) Choose not to answer

13... Have a friend let you know when you've had enough?
(1) Not applicable/ Do not drink
(2) Always
(3) Usually
(4) Sometimes
(5) Rarely
(6) Never
(7) Choose not to answer

14 ...Keep track of how many drinks you were having?
(1) Not applicable/ Do not drink
(2) Always
(3) Usually
(4) Sometimes
(5) Rarely
(6) Never
(7) Choose not to answer

15...Pace your drinks to 1 or fewer per hour?
(1) Not applicable/ Do not drink
(2) Always
(3) Usually
(4) Sometimes
(5) Rarely
(6) Never
(7) Choose not to answer

16...Avoid drinking games?
(1) Not applicable/ Do not drink
(2) Always
(3) Usually
(4) Sometimes 
(5) Rarely

(6) Never

(7) Choose not to answer

$17 .$. Stay with the same group of friends the entire time you were drinking?
(1) Not applicable/ Do not drink
(2) Always
(3) Usually
(4) Sometimes
(5) Rarely
(6) Never
(7) Choose not to answer

18 ...Stick with only one kind of alcohol when drinking?
(1) Not applicable/ Do not drink
(2) Always
(3) Usually
(4) Sometimes
(5) Rarely
(6) Never
(7) Choose not to answer

\section{Survey 11 of 13}

Source: Zullig KJ, Huebner ES, Patton JM, Murray KA. The brief multidimensional students' life satisfaction scale- college version. Am J Behav. 2009; 33(5): 483-493

These questions are about satisfaction with different areas of your life. Please choose the best answer for each.

1. I would describe my satisfaction with my family life as:
(1) Terrible
(2) Unhappy
(3) Mostly dissatisfied
(4) Mixed (about equally satisfied and dissatisfied)
(5) Mostly satisfied
(6) Pleased
(7) Delighted
(8) Choose not to answer

2. I would describe my satisfaction with my friendships as:
(1) Terrible
(2) Unhappy
(3) Mostly dissatisfied
(4) Mixed (about equally satisfied and dissatisfied)
(5) Mostly satisfied
(6) Pleased
(7) Delighted
(8) Choose not to answer

3, I would describe my satisfaction with my school experience as: 

(1) Terrible
(2) Unhappy
(3) Mostly dissatisfied
(4) Mixed (about equally satisfied and dissatisfied)
(5) Mostly satisfied
(6) Pleased
(7) Delighted
(8) Choose not to answer

4. I would describe my satisfaction with myself as:
(1) Terrible
(2) Unhappy
(3) Mostly dissatisfied
(4) Mixed (about equally satisfied and dissatisfied)
(5) Mostly satisfied
(6) Pleased
(7) Delighted
(8) Choose not to answer

5. I would describe my satisfaction with where I live as:
(1) Terrible
(2) Unhappy
(3) Mostly dissatisfied
(4) Mixed (about equally satisfied and dissatisfied)
(5) Mostly satisfied
(6) Pleased
(7) Delighted
(8) Choose not to answer

6. I would describe my satisfaction with my relationships as:
(1) Terrible
(2) Unhappy
(3) Mostly dissatisfied
(4) Mixed (about equally satisfied and dissatisfied)
(5) Mostly satisfied
(6) Pleased
(7) Delighted
(8) Choose not to answer

7. I would describe my satisfaction with my physical appearance as:
(1) Terrible
(2) Unhappy
(3) Mostly dissatisfied
(4) Mixed (about equally satisfied and dissatisfied)
(5) Mostly satisfied
(6) Pleased
(7) Delighted
(8) Choose not to answer

8. I would describe my satisfaction with my job as:

(1) Terrible 
(2) Unhappy

(3) Mostly dissatisfied

(4) Mixed (about equally satisfied and dissatisfied)

(5) Mostly satisfied

(6) Pleased

(7) Delighted

(8) Choose not to answer

9. I would describe my satisfaction with my overall life as:
(1) Terrible
(2) Unhappy
(3) Mostly dissatisfied
(4) Mixed (about equally satisfied and dissatisfied)
(5) Mostly satisfied
(6) Pleased
(7) Delighted
(8) Choose not to answer

BRFSS Section 21: Emotional Support and Life Satisfaction

10. How often do you get the social and emotional support you need?
(1) Always
(2) Usually
(3) Sometimes
(4) Rarely
(5) Never
(6) Don't know/ Not Sure
(7) Choose not to answer

\section{Survey 12 of 13}

These next two questions are about tobacco use. If you have never used tobacco, please mark never used.

1. Within the last 30 days, on how many days did you use cigarettes, pipe tobacco, or cigars?
(1) Never used
(2) Have used, but not in the last 30 days
(3) 1-2 days
(4) 3-5 days
(5) $6-9$ days
(6) $10-19$ days
(7) 20-29 days
(8) Used daily
(9) Choose not to answer

2. Within the last 30 days, on how many days did you use smokeless tobacco (i.e. chew)?
(1) Never used
(2) Have used, but not in the last 30 days
(3) $1-2$ days
(4) 3-5 days
(5) 6-9 days
(6) 10-19 days 
(7) 20-29 days

(8) Used daily

(9) Choose not to answer

\section{Survey 13 of 13}

Source: Lucia L Kaiser, Marilyn S Townsend, Hugo R Melgar-Quiñonez, Mary L Fujii, and Patricia B Crawford. Choice of instrument influences relations between food insecurity and obesity in Latino women. Am J Clin Nutr 2004;80:1372- 8.

1. How old are you?

(1) Less than 18 years old

(2) 18

(3) 19

(4) 20

(5) 21

(6) 22

(7) 23

(8) 24

(9) More than 24 years old

(10) Choose not to answer

2. What is your gender?
(1) Male
(2) Female
(3) Choose not to answer

3. Are you Hispanic or Latino?
(1) Yes
(2) No
(3) Don't know / Not sure
(4) Choose not to answer

4. Which one or more of the following would you say is your race?
(1) White
(2) Black or African American
(3) Asian
(4) Native Hawaiian or Other Pacific Islander
(5) American Indian or Alaska Native
(6) Other [specify]

5. What is your year in school?
(1) Freshman
(2) Sophomore
(3) Junior
(4) Senior
(5) Graduate
(6) Choose not to answer

6. Where do you live?

(1) Campus residence hall 
(2) Sorority or fraternity

(3) Other university/college housing

(4) Off campus housing

(5) Parent or guardian's home

(6) Other, specify

7. Where is the university you attend?
(1) Alabama
(2) Florida
(3) Maine
(4) Kansas
(5) Indiana
(6) Michigan
(7) New Hampshire
(8) New Jersey
(9) New York
(10) North Carolina
(11) Rhode Island
(12) South Dakota
(13) Wisconsin
(14) West Virginia
(15) Choose not to answer

8. How would you define your current relationship status?

(1) Single

(2) In a committed relationship

(3) Choose not to answer

9. What is your height?

(If you choose not to answer, please type CNA in the box) Feet Inches

10. What is your weight (in pounds)?

(If you choose not to answer, please type CNA in the box)

11. How much do you want to weigh (in pounds)?

(If you choose not to answer, please type CNA in the box)

12. How would you describe your weight?
(1) Very Underweight
(2) Slightly Underweight
(3) About the Right Weight
(4) Slightly Overweight
(5) Very Overweight
(6) Choose not to answer 
13. Are you trying to do any of the following about your weight?

(1) I am not trying to do anything

(2) Stay the same weight

(3) Lose weight

(4) Gain weight

(5) Choose not to answer

14. Do you participate in...? (Check all that apply)

(1) Intercollegiate sports team (varsity)

(2) Club sports team

(3) Intramurals

(4) None

15. How many hours a week do you work for pay during the school year?

(1) I do not work

(2) 1 to 9 hours

(3) 10 to 19 hours

(4) 20 to 29 hours

(5) 30 to 39 hours

(6) 40 hours

(7) More than 40 hours

(8) Choose not to answer

16. Are you an international student?

(1) Yes

(2) No

(3) Choose not to answer

Food Delivery Questions - Added for 15 month ONLY

The following questions are about food delivery on your campus.

17. Where you live during this school semester, how often is food provided as part of your rental contract?
(1) 7 days/week
(2) 5-6 days/week
(3) 3-4 days/week
(4) 1-2 days/week
(5) 0 days/week 5
(6) Choose not to answer

18. What do you usually do on the days food is not provided where you live?

(1) This does not apply to me; food is provided 7 days/week as part of my housing.

(2) I cook for myself.

(3) I eat out or get take-out food.

(4) I order delivery.

(5) I go to my parents', other relatives', or friends' homes for meals.

(6) I get meals where I work.

(7) I look for opportunities to find free food, like food that is offered at meetings or other events.

(8) Choose not to answer 8 
19. Over the last month, how often have you had food delivered to your residence?

(1) Never

(2) 1-3 times last month

(3) 1-2 times per week

(4) 3-4 times per week

(5) 5-6 times per week

(6) 1 time per day

(7) 2 times per day

(8) 3 or more times per day

(9) Choose not to answer

20. When you order food delivery, how often do you use a collective website like campusfood.com?
(1) Never
(2) Almost Never
(3) Sometimes
(4) Fairly Often
(5) Very Often
(6) Choose not to answer 


\section{Appendix K}

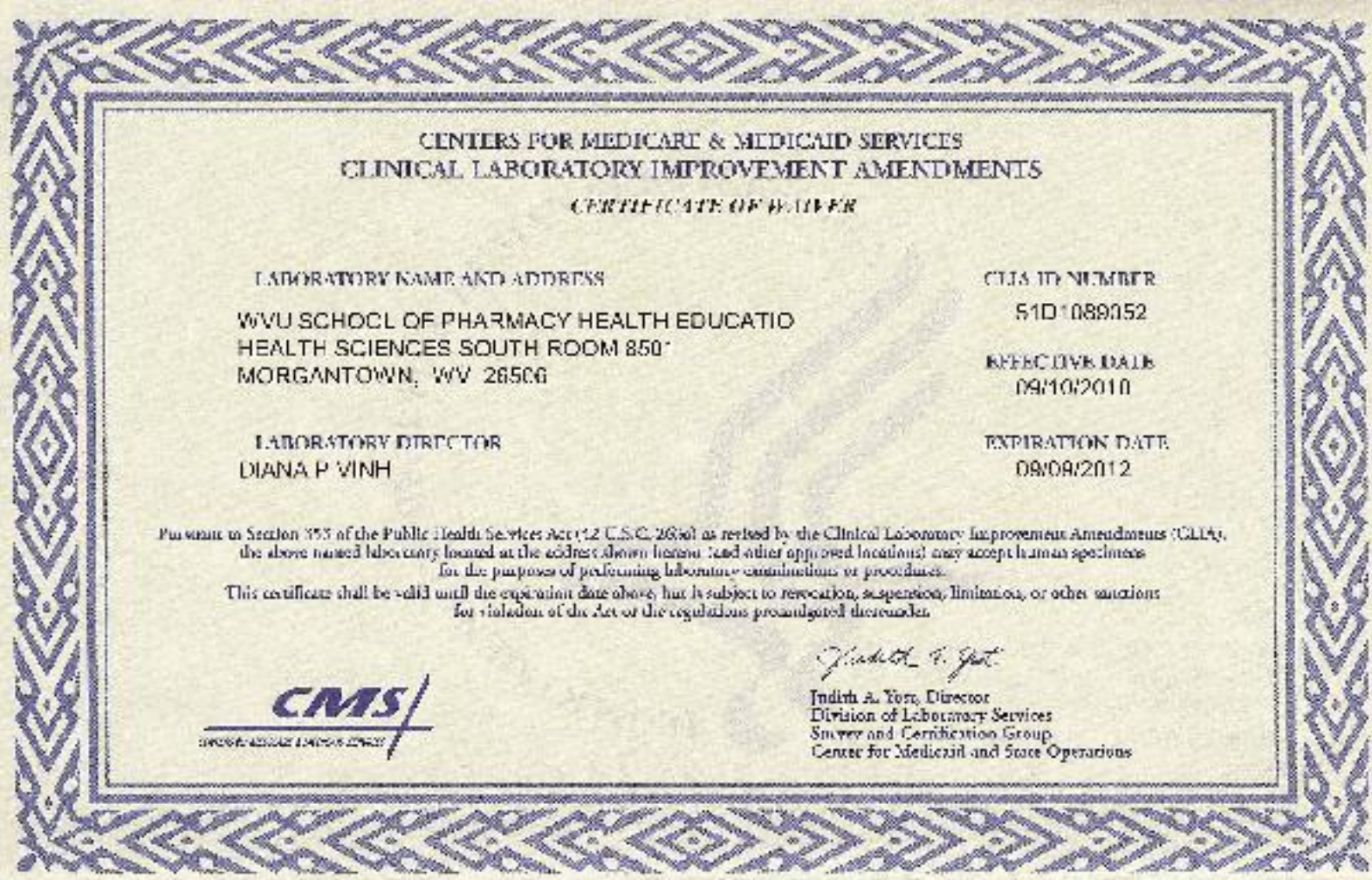

sit onder

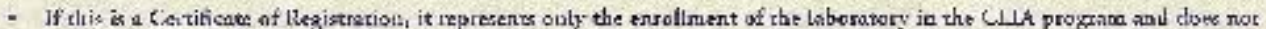

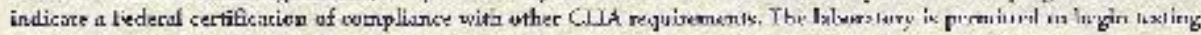

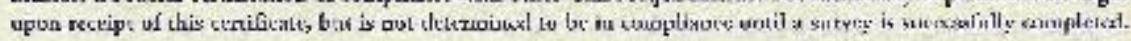

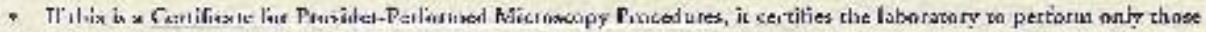

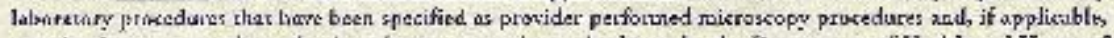

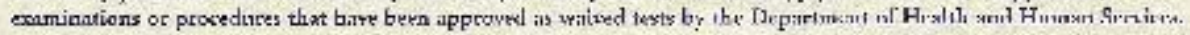

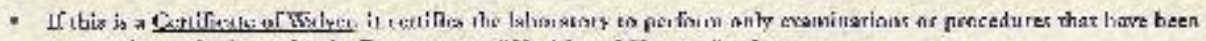

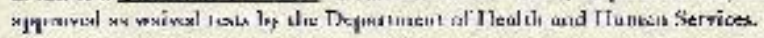
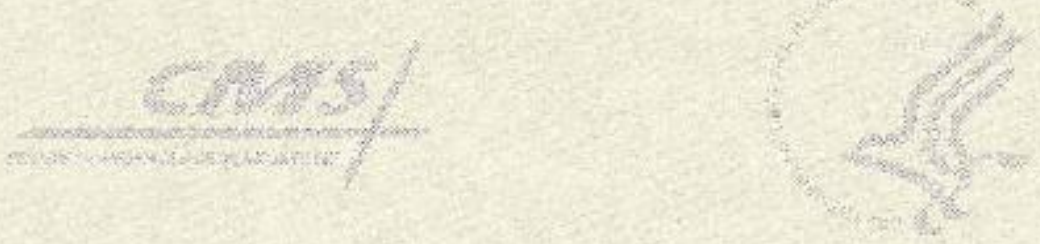

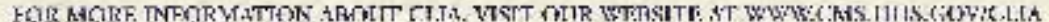

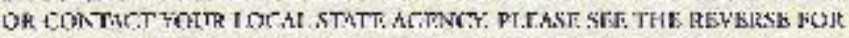

YMIR STATE AGENCT'S ADIJUESS AND PHUNE NUMBELR.

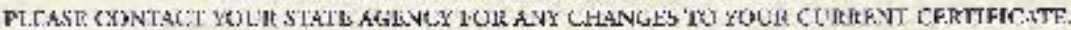




\section{Appendix L}

\section{Tobacco Use and Exposure Questionnaire}

\section{*1. INFORMED CONSENT}

West Virginia University

Davis College of Agriculture, Natural Resources \& Design

Division of Animal \& Nutritional Sciences

Human Nutrition

You have been invited to take part in a research project described below. The researcher will explain the project to you in detail upon request. You should feel free to ask questions either in person or by e-mail at melissa.olfert@mail.wvu.edu. If you have quesitons later, Professor Melissa Olfert, the person mainly responsible for this study, 304-293-1918, will discuss them with you.

PURPOSE OF STUDY:

You are invited to participate in this survey to help identify frequency of tobacco use, environmental and social influences on tobacco use as well as environmental exposure.

\section{CAN I PARTICIPATE?}

You must be:

- 18 to 24 years old

- A full-time undergraduate student

You must not be:

- A current nutrition, excercise physiology and/or health promotion major

\section{WHAT WILL I BE ASKED TO DO?}

You will be asked to complete an online survey. It takes about 7-10 minutes to complete.

\section{WHAT DO I GET OUT OF IT?}

You will receive a $\$ 5$ bill or giftcard.

\section{RISKS}

Except for your time and incovenience, the risk to you is minimal. There may be minimal risk of data being intercepted during the completion and transmission of the online surveys. This risk will be reduced by using an encrypted transmission for online surveys. 


\section{Tobacco Use and Exposure Questionnaire}

\section{VOLUNTARY}

Participation is voluntary. You may refuse to answer any questions that are part of the survey by selecting "Choose not to answer". You may decide not to participate or to stop participation at any time. You are encouraged to contact the study coordinator should you decide not to continue your participation in this study.

\section{CONFIDENTIALITY}

The project's research records may be reviewed by the departments at West Virginia University responsible for regulatory and research oversight.

All information that you provide, either online or in person, will be kept on a secured hard drive or locked in file cabinets for $\mathbf{5}$ years and then destroyed. All contact information will be securely stored on-site in the researcher's office in the Department of Animal \& Nutritional Sciences (G016 Agricultural Sciences Bldg.) Morgantown, WV.

The online survey you will fill out will be stored in a database on the secured server. To secure data and maintain confidentiality, an https encrypted website is being used for this study. Your confidentiality will be maintained to the degree permitted by the technology used. Specifically, no guarantees can be made regarding the interception of data sent via the Internet by any third parties.

When data are presented for scientific purposes, data will be reported in summary format, and no names will be used.

This study has been approved by the Institutional Review Board (IRB) at West Virginia University on 11/18/2011.

Thank you for your time and interest in the study!

I choose to participate

I do not choose to participate

\section{Cigarettes}




\section{Tobacco Use and Exposure Questionnaire}

* 11. Have you used smokeless tobacco products (i.e. chew, spit, dip, snuff) in the past 7 days?

$\square$ Yes

No

*12. List the number of smokeless tobacco products (chew, spit, dip, snuff) used in the past 7 days.

* 13. Have you used smokeless tobacco products (i.e. chew, spit, dip, snuff) in the past 30 days?

$\square$ Yes

$\square$ No

*14. List the number of smokeless tobacco products (chew, spit, dip, snuff) used in the past 30 days.

*15. If NO to all previous questions concerning smokeless tobacco products, did you quit in the past 6 months?

$\square$ Yes

$\square$ No

\section{Hooka or Waterpipe}

* 16. Have you used a hooka or waterpipe in the past 24 hours?

$\square$ Yes

No

* 17. List the number of times a hooka or waterpipe was used in the past 24 hours.

* 18. Have you used a hooka or waterpipe in the past 7 days?

$\square$ Yes

No

* 19. List the number of times a hooka or waterpipe was used in the past 7 days. 


\section{Tobacco Use and Exposure Questionnaire}

* 20. Have you used a hooka or waterpipe in the past $\mathbf{3 0}$ days?

$\square$ Yes

No

*21. List the number of times a hooka or water pipe was used in the past $\mathbf{3 0}$ days.

*22. If NO to all previous questions concerning a hooka or waterpipe, did you quit in the past 6 months?

$\square$ Yes

No

\section{Cigar}

*23. Have you used a cigar in the past 24 hours?

$\square$ Yes

No

*24. List the number of cigars used in the past $\mathbf{2 4}$ hours.

*25. Have you used a cigar in the past 7 days?

$\square$ Yes

$\square$ No

*26. List the number of cigars used in the past 7 days.

*27. Have you used a cigar in the past 30 days?

$\square$ Yes

$\square$ No

*28. List the number of cigars used in the past $\mathbf{3 0}$ days.

*29. If NO to all previous questions concerning cigars, did you quit in the past 6 months? $\square$ Yes 
Tobacco Use and Exposure Questionnaire

Environmental and Social Influences on Tobacco Use

*30. How many people who in live your home or dorm (not counting yourself) smoke inside your home? (Includes pipes and cigars).

*31. About how many cigarettes or cigars per day are smoked inside your home or dorm?

No cigarettes

$1-4$ cigarettes

5-9 cigarettes

10-19 cigarettes

20 or more cigarettes

* 32. Which statement best describes the rules about smoking at your work or school?

smoking is not allowed

smoking is allowed in some places

Smoking is allowed anywhere inside my work or school

Smoking is allowed only outside

I don't have a job or attend school

*33. Which statement best describes the rules about smokeless tobacco use at your work or school?

Oral tobacco use is not allowed

Oral tobacco use is allowed in some places

Oral tobacco use is allowed anywhere inside at my work or school

Oral tobacco use is allowed only outside at my work or school

*34. At work or school or on-campus, how much of the time are you exposed to tobacco smoke (close enough to smell the smoke)?

None

Less than 1 hour per day of exposure

1-4 hours per day of exposure

More than 4 hours of exposure 


\section{Tobacco Use and Exposure Questionnaire}

*35. At work or school or on-campus, when you smell the smoke, how many people are usually smoking in the same area as you (close enough to smell the smoke)?

$$
\begin{aligned}
& 1 \text { or } 2 \text { smokers } \\
& 3 \text { or more } \\
& \text { No one smokes at work or at school or on-campus }
\end{aligned}
$$

* 36. Which statement best describes the rules about smoking at your home or dorm?

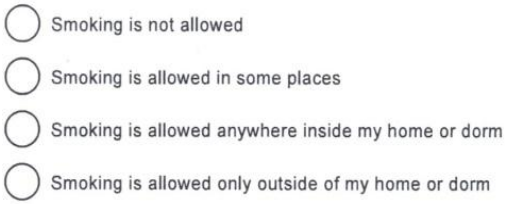

* 37. Which statement best describes the rules about smokeless tobacco use at your home or dorm?
Smokeless tobacco is not allowed
Smokeless tobacco is allowed in some places
Smokeless tobacco is allowed anywhere in my home or dorm
Smokeless tobacco is allowed only outside my home or dorm

*38. Does anyone smoke in your car?

I don't have a car

Yes

No

* 39. About how often are you exposed to tobacco smoke in social settings outside of work or your own home?
Seldom
Once a week
Several times a week
Daily 


\section{Tobacco Use and Exposure Questionnaire}

* 40. Indicate the average amount of time you are exposed to the smoke outside of your work or home?

None
Less than 1 hour per day of exposure
$1-4$ hours per day of exposure
More than 4 hours of exposure

*41. Do any of your family members use smokeless tobacco? (Check all that apply)

$\square$ Spouse/Significant other

$\square$ Parents

$\square$ Brothers or sisters

$\square$ Children

$\square$ Other (specify)

None of my family members use smokeless tobacco

42. If yes, please specify how many family members use smokeless tobacco (i.e. significant other - 1, brother - 2). 


\section{Appendix M}

Name:

ID Number:

\section{Five Facet Mindfulness Questionnaire}

\section{Reference:}

Baer, R. A., Smith, G. T., Hopkins, J., Krietemeyer, J., \& Toney, L. (2006). Using self- report assessment methods to explore facets of mindfulness. Assessment, 13, 27-45.

\section{Description:}

This instrument is based on a factor analytic study of five independently developed mindfulness questionnaires. The analysis yielded five factors that appear to represent elements of mindfulness as it is currently conceptualized. The five facets are observing, describing, acting with awareness, non-judging of inner experience, and non-reactivity to inner experience. More information is available in:

Please rate each of the following statements using the scale provided. Write the number in the blank that best describes your own opinion of what is generally true for you.

(1) never or very rarely (2) rarely true (3) sometimes (4) often true (5) always true

1. When I'm walking, I deliberately notice the sensations of my body moving.

2. I'm good at finding words to describe my feelings.

3. I criticize myself for having irrational or inappropriate emotions.

4. I perceive my feelings and emotions without having to react to them.

5. When I do things, my mind wanders off and I'm easily distracted.

6. When I take a shower or bath, I stay alert to the sensations of water on my body.

7. I can easily put my beliefs, opinions, and expectations into words.

8. I don't pay attention to what l'm doing because I'm daydreaming, worrying, or otherwise distracted.

9. I watch my feelings without getting lost in them.

10. I tell myself I shouldn't be feeling the way l'm feeling.

11. I notice how foods and drinks affect my thoughts, bodily sensations, and emotions.

12. It's hard for me to find the words to describe what I'm thinking.

13. I am easily distracted.

14. I believe some of my thoughts are abnormal or bad and I shouldn't think that way.

15. I pay attention to sensations, such as the wind in my hair or sun on my face.

16. I have trouble thinking of the right words to express how I feel about things

17. I make judgments about whether my thoughts are good or bad.

18. I find it difficult to stay focused on what's happening in the present.

19. When I have distressing thoughts or images, I "step back" and am aware of the

thought or image without getting taken

over it.

20. I pay attention to sounds, such as clocks ticking, birds chirping, or cars passing.

21. In difficult situations, I can pause without immediately reacting.

22. When I have a sensation in my body, it's difficult for me to describe it because I can't find the right words.

23. It seems I am "running on automatic" without much awareness of what I'm doing.

24. When I have distressing thoughts or images, I feel calm soon after. 
25. I tell myself that I shouldn't be thinking the way I'm thinking.

26. I notice the smells and aromas of things.

27. Even when I'm feeling terribly upset, I can find a way to put it into words.

28. I rush through activities without being really attentive to them.

reacting.

29. When I have distressing thoughts or images I am able just to notice them without

30. I think some of my emotions are bad or inappropriate and I shouldn't feel them.

31. I notice visual elements in art or nature, such as colors, shapes, textures, or patterns

of light and shadow.

32. My natural tendency is to put my experiences into words.

33. When I have distressing thoughts or images, I just notice them and let them go.

34. I do jobs or tasks automatically without being aware of what I'm doing.

35. When I have distressing thoughts or images, I judge myself as good or bad,

depending what the thought/image is about.

36. I pay attention to how my emotions affect my thoughts and behavior.

37. I can usually describe how I feel at the moment in considerable detail.

38. I find myself doing things without paying attention.

39. I disapprove of myself when I have irrational ideas.

\section{Scoring Information:}

Observe items:

$1,6,11,15,20,26,31,36$

Describe items:

2, 7, 12R, 16R, 22R, 27, 32, 37
Act with Awareness items:

5R, 8R, 13R, 18R, 23R, 28R, 34R, 38R

Nonjudge items:

3R, 10R, 14R, 17R, 25R, 30R, 35R, 39R

Nonreact items:

4, 9, 19, 21, 24, 29, 33

\section{Appendix N}




\section{YEAH Follow-Up Evaluation - Intervention - paper and pencil}

3. Rate the degree to which the following motivated you to make a change to improve your health:

Interaction with study personne

Monetary Incentive

Completing the online surveys at baseline

Completing the online surveys at 3 months

Feedback on my weight at baseline

Feedback on my weight at 3 months

Feedback on my waist circumference at baseline

Feedback on my waist circumference at 3 months

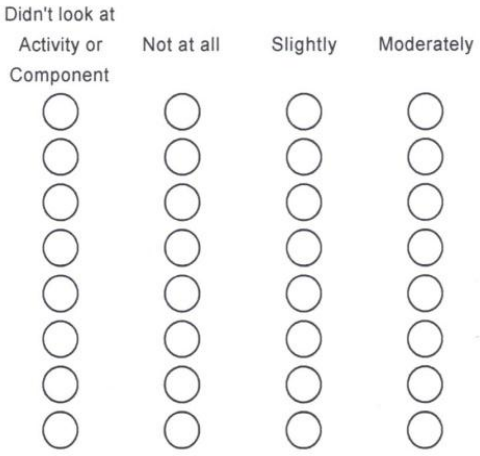

Mostly Very Much

4. State and rate the degree (Not at all, Slightly, Moderately, Mostly, Very Much) to which any other things that were not listed above motivated you to make a change to improve your health:

2

3.

3.

1. Have you enrolled in any nutrition or exercise science courses since you enrolled in the study?

Yes

No

2. If yes, which discipline?

Nutrition

Exercise Science

Both 


\section{YEAH Follow-Up Evaluation - Intervention - paper and pencil}

3. Do you feel the Y.E.A.H Project's online program influenced your decision to enroll in these classes?
$\bigcirc$ res
№

4. What was your overall opinion of the study?
Excellent
Good
Satisfactory
Needs Improvement

5. Please indicate ways for making improvements to the study:

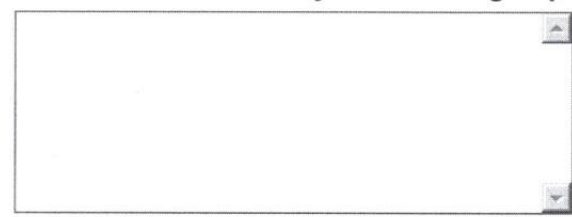

Thank you very much for taking this survey! 


\section{YEAH Follow-Up Evaluation - Control paper and pencil}

* 1 . Where is the university you attend?
Alabama
Michigan
Rhode Island
Florida
New Hampshire
South Dakota
Maine
New Jersey
Wisconsin
Kansas
New York
West Virginia
Indiana
North Carolina

* 2. Please enter your name in the space below. Your name will be removed and replaced with a YEAH ID number before data analysis.

2.

1. Have you gone in to view the profile page on the YEAH website?
Yes
No

2. Rate the degree to which the following motivated you to make a change to improve your health:

Interaction with study personnel

Monetary Incentive

Feedback on my weight at baseline

Feedback on my weight at 3 months

Feedback on my waist circumference at baseline

Feedback on my waist circumference at 3 months

Completing the online surveys at baseline

Completing the online surveys at 3 months

Didn't look at
Activity or
Component Not at all




\section{YEAH Follow-Up Evaluation - Control paper and pencil}

3. State and rate the degree (Not at all, Slightly, Moderately, Mostly, Very Much) to which any other things that were not listed motivated you to make a change to improve your health:

1.

2.

3 .

4

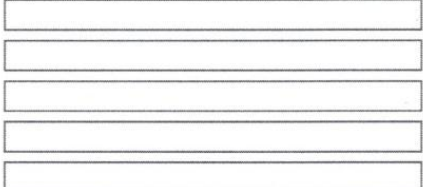

4. As part of YEAH, some participants were asked to view activities. Please indicate below if you viewed any of the activities and to what extent.

I did not view this activity at

I viewed this activity moderately

I viewed this entire activity

Stress Management

Activities

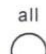

I viewed this activity slightly

0

Eating Activities

Physical Activity Activities

3.

1. Have you enrolled in any nutrition or exercise science courses since you enrolled in the study?

Yes

No

2. If yes, which discipline?

Nutrition

Exercise Science

Both

3. Do you feel the Y.E.A.H Project's online program influenced your decision to enroll in these classes?

Yes

No 


\section{YEAH Follow-Up Evaluation - Control paper and pencil}

4. What was your overall opinion of the study?
Excellent
Good
Satisfactory
Needs Improvement

5. Please indicate ways for making improvements to the study:

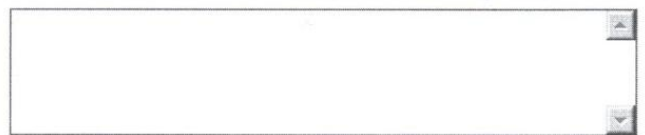

Thank you very much for taking this survey! 


\section{Appendix 0}

\section{NRI Vending Machine Usage Survey}

\section{General Instructions}

-Answer each question as best you can.

-Estimate if you are not sure.

-A guess is better than leaving a blank.

-Put an $\mathrm{X}$ in the box next to your answer.

-If you make any changes, cross out the incorrect answer and put an X in the box next to the correct answer. Also draw

a circle around the correct answer.

1. ID \#

2. How many times per week do you buy snack foods and/or beverages from the vending machines on campus? (If you use the machine less than once per week, skip to question

19.

If you use the machine 1-2 times or more per week, please continue answering questions below).

Less than once per week

$1-2$ times per week

3-4 times per week

5-6 times per week

7 or more times per week 
NRI Vending Machine Usage Survey

2. What You Look For In Vending Machines

When making a choice at a vending machine, how important is:

3. Trying a snack and/or beverage l've never had before:

very unimportant $\bigcirc$ Unimportant $\bigcirc_{\text {unimportant }}$ Neither important or $\bigcirc$ Important

4. Snack and/or beverage taste:

Very unimportant $\bigcirc$ Unimportant $\bigcirc_{\text {unimportant }}$ Neither important or $\bigcirc$ Important

5. Snack and/or beverage price:

$\bigcirc$ Very unimportant $\bigcirc$ Unimportant $\bigcirc_{\text {unimportant }}$ Neither important or $\bigcirc$ Important $\quad$ very important

6. Number of calories in a snack and/or beverage:

$\bigcirc$ Very unimportant $\bigcirc$ Unimportant $\bigcirc_{\text {unimportant }}$ Neither important or $\bigcirc$ Important

7. Amount of fat in a snack and/or beverage:

$\bigcirc$ Very unimportant $\bigcirc$ Unimportant $\bigcirc_{\text {unimportant }}$ Neither important or $\bigcirc$ Important $O$ Very important

8. Amount of carbohydrates in a snack and/or beverage:

Very unimportant $\bigcirc$ Unimportant $\bigcirc_{\text {unimportant }}$ Neither important or $\bigcirc$ important

9. Amount of protein in a snack and/or beverage:

$\bigcirc$ very unimportant $\bigcirc$ Unimportant $\bigcirc_{\text {unimportant }}$ Neither important or $\bigcirc$ Important very important

10. How "healthy" a snack and/or beverage is:

Very unimportant $\bigcirc$ Unimportant $\bigcirc_{\text {Unimportant }}$ Neimportant or $\bigcirc$ Important $\bigcirc$ very important

11. Watching my weight:

Very unimportant $\bigcirc$ Unimportant $\bigcirc_{\text {unimportant }}$ Neither important or $\bigcirc$ Important

12. Value for my money:

Very unimportant $\bigcirc$ Unimportant $\bigcirc$ Neither important or $\bigcirc$ important $\quad$ very important 
NRI Vending Machine Usage Survey

13. Buying my "usual" snack and/or beverage:

very unimportant

Unimportant

$\bigcirc_{\text {unimportant }}$ Neither important or $\bigcirc$ Important

very important

14. How hungry and/or thirsty I am:

$\bigcirc$ very unimportant $\bigcirc$ Unimportant $\bigcirc_{\text {unimportant }}$ Neither important or $\bigcirc$ Important 
NRI Vending Machine Usage Survey

3. Additional Vending Usage Questions

15. I would like healthy options in the snack food and beverage vending machines on campus.

$\bigcirc$ strongly disagree $\bigcirc$ Disagree $\quad \bigcirc_{\text {disagree }}$ Neither agree nor $\bigcirc$ Agree $\quad \bigcirc$ strongly agree

16. If there were a variety of healthy snack food and beverage choices, I would use the snack food and beverage vending machines more often than I do currently.
strongly disagree
Disagree
Neither agree nor
Agree
strongly agree

17. On average, how much do you spend per week on items from vending machines on campus?

\$0-\$2.00

\$2.01-\$4.00

\$4.01-56.00

More than $\$ 6.00$ 


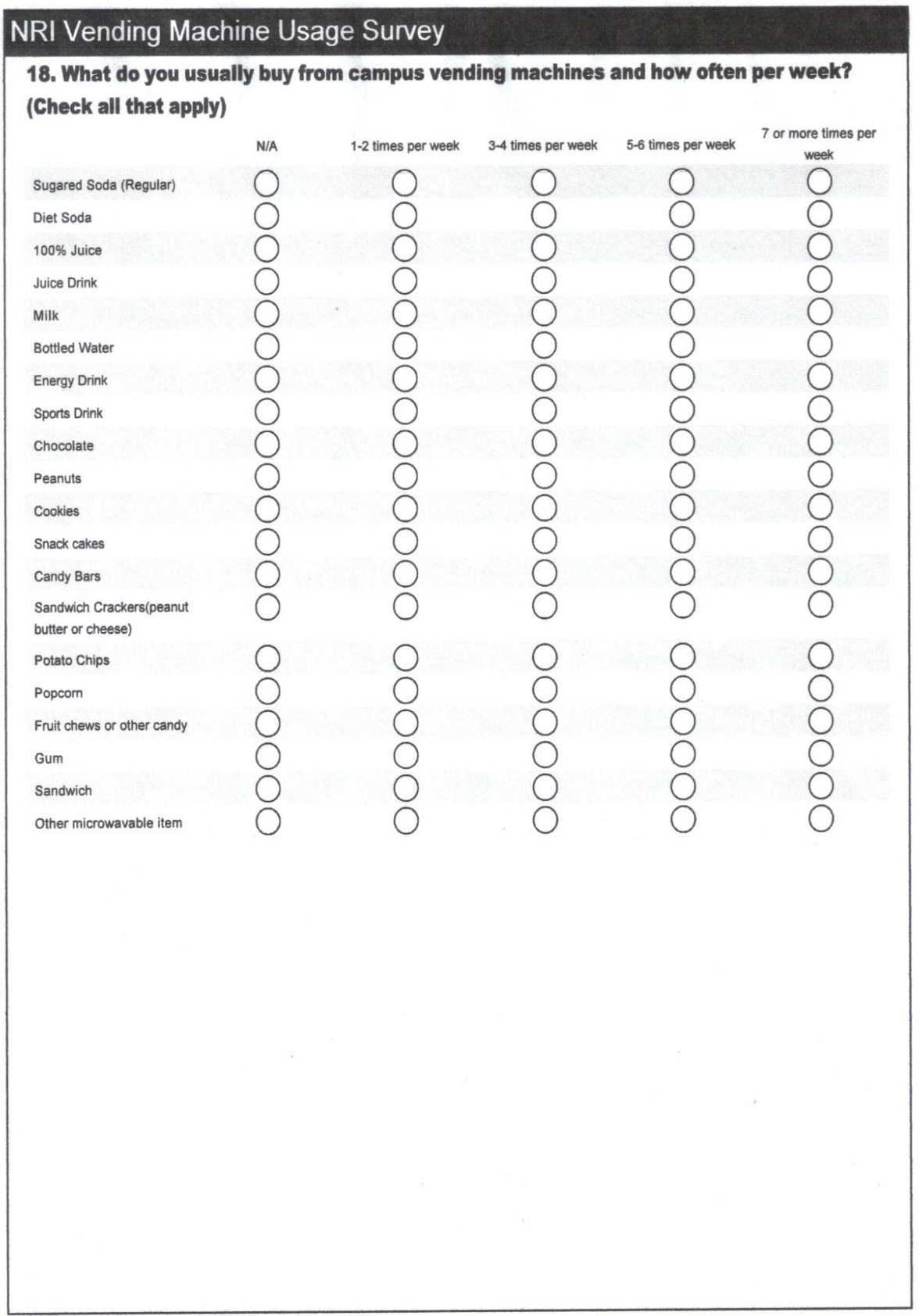




\section{NRI Vending Machine Usage Survey}

4. Campus Food

19. Where do you usually get your food when you are on campus? (Check all that apply)

$\square$ Bring from home

$\square$ Buy from Union food courts and eat on campus

$\square$ Eat away from campus

$\square$ Buy from campus vending machines

Don't eat anything on campus 


\section{Appendix P}

\section{Green Eating Survey}

\section{Green Eating Survey}

You have been invited to take part in a research project described below. The researcher will explain the project to you in detail upon request. The person mainly responsible for this study is Professor Melissa Olfert. Her contact information is as follows:

Email: melissa.olfert@mail.wvu.edu

Phone: 304-293-1918

Please feel free to ask questions either in person or by e-mail. If you have more questions later, Professor Melissa Olfert will discuss them with you. You must be at least 18 years old to be in this research study.

Description of the project:

You have been asked to take part in a study that will ask questions about your eating patterns during transportation so that we can understand more about these behaviors.

What will be done:

If you decide to take part in this study here is what will happen: You will fill out a survey, which should take about 5 minutes. If you fill in the contact information at the end of the survey you will receive class credit for your participation.

Risks or discomfort:

The questions being asked should not pose any discomfort. If any question poses discomfort, simply refrain from answering that question. (or simply do not answer/skip that question)

Benefits of this study:

The results of this study will help us to learn more about the relationships between dietary practices and transportation in order to develop programs to improve health.

Confidentiality:

Your participation in this survey is anonymous unless you wish to receive extra credit. Even then your survey results will remain confidential. If you wish to receive extra credit you must provide the course information, your email address and your WWU Student ID when prompted at the end of the survey. This information will be removed from your responses before data analysis and destroyed after class credit has been provided.

You should understand that any form of communication over the Internet does carry a minimal loss of confidentiality. None of the information will identify you by name. At the end of the study, the database will be removed from the Survey Monkey site. The unidentifiable data will be stored on a password-protected computer.

Decision to quit at any time:

The decision to take part in this study is up to you. You do not have to participate. If you decide to take part in the study you may quit at any time. Whatever you decide will not affect your status as a student or your grade in this class. You will, however, only receive extra credit if you complete the survey. If you wish to withdraw from the study after submitting your survey, simply inform Professor Melissa Olfert at 304-293-1918 or melissa.olfert@mail.wvu.edu of your decision before class credit has been provided and the link between student ID and survey responses has been destroyed.

Rights and Complaints:

If you are not satisfied with the way this study is performed, or have any questions about your rights as a research subject, you may discuss your complaints with Professor Melissa Olfert (304-293-1918 or melissa.olfert@mail.wvu.edu). In addition, if you have any questions of your rights as a research participant you may contact the West Virginia University Institutional Review Board.

2. Green Eating Survey 


\section{Green Eating Survey}

1. The survey you are being asked to complete is part of an instrument development process. We are trying to see if any questions are confusing or difficult. We will not be looking at individual answers and will not be using your answers for research.

I agree to participate

O I prefer not to

\section{Green Fating}

2. Green eating includes:

- Eating locally grown, organic, vegetarian, and minimally processed foods.

- Consuming foods and beverages that are fair trade certified.

- If applicable, selecting meats, poultry and dairy that do not contain hormones or antibiotics.

Based on the definition of green eating, which of the following best describes you now:

I do not regularly practice green eating and do not intend to start within the next 6 months

I am thinking about practicing green eating within the next 6 months

I am planning on practicing green eating within the next 30 days

I regularly practice green eating and have been doing so for less than 6 months

I regularly practice green eating and have been doing so for 6 months or more

\section{Behavior}




\section{Green Eating Survey}

3. Please answer the following questions:

Locally grown foods are grown within 100 miles (anywhere in $\mathrm{Rl}$ and
nearby $\mathrm{MA}$ or $\mathrm{CT}$ ). Based on this, how often do you eat locally grown
foods?
How often do you shop at farmer's markets during the warmer months?
How often do you grow your own produce during the warmer months?
Minimally processed foods are items that are closest to their natural form.
Bor example a tomato is minimally processed compared to ketchup.
foods?
A vegetarian or plant based meal does not contain meat, fish, or poultry.
Based on this definition, how often do you consume vegetarian meals?
How often do you choose foods labeled USDA organic?
How often do you buy single serving items like single serving beverages
or snacks?
How often do you use reusable shopping bags for shopping?
How often do you select meats, poultry, and dairy products that are raised
without antibiotics or hormones?
How often do you select fair trade certified foods or beverages?

4. Have you ever hear of or seen the Marine Stewardship Council (MSC) eco-label fish and seafood label?

Yes

No

5. How often do you purchase meat, poultry, and dairy products that are certified humane?

Never

Rarely

Sometimes

often

Almost always

Not sure

6. Have you noticed green seal labeled paper and cleaning products?

Yes
No 


\section{Green Eating Survey}

7. Thinking about how many times you purchase food please answer the following:

On average, how many times do you go to a grocery store?
On average, in the warmer months, how many times do you go to a
farmer's market or farm stand?
On average, how many times do you eat at restaurants that buy locally
produced food?
On average, how many times do you eat a vegetarian meals?
On average, how often do you buy foods that are certified USDA organic?
On average, how often do you buy foods in bulk?

8. Thinking about where you eat, do you live on campus?

Yes

No

9. Do you mainly eat in the dining halls?

Yes

No

5.

10. If no, what are you main sources of food consumption?

$\square$ food prepared at home
$\square$ fast food restaurants
$\square$ food from convenience stores
$\square$ takeout food

11. How sure are you that you know where your food comes from when eating at these places?

Not at all sure

Somewhat sure

Sure

very sure 


\section{Green Eating Survey}

12. On a scale of $1-5$ with 1 being not at all likely and 5 being extremely likely, how likely would you be to:

Eat mainly locally produced foods?
Eat foods labeled USDA organic, fair trade certified, certified
sustainable seafood, or certified humane raised and handled?
Grow your own food for consumption?
Eat minimally processed foods?
Eat a vegetarian diet?

13. How would you judge yourself overall regarding environmental issues and food consumption?
Would you be someone who does not consider environmental issues at all?

Not at all

Very much

14. How significant would you rate environmental aspects when you make buying decisions for food you buy every day?

Not at all significant

Somewhat significant

Very significant

Not sure

\section{Motivations Behind Food and Beverage Choices}

15. Thinking about your motivation behind choosing food and beverages:

I select a particular food or drink based on cost.

I select a particular food or drink based on its nutritional value or health benefits.

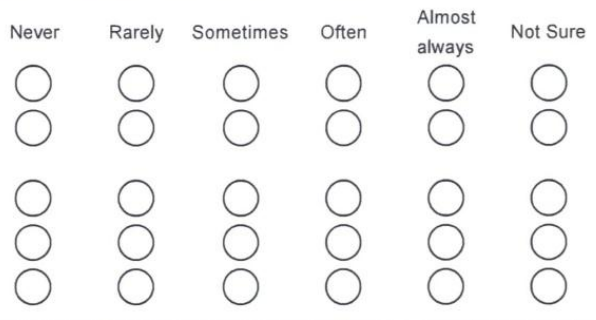

7. Pros and Cons of Green Eating 


\section{Green Eating Survey}

16. Here are some advantages and disadvantages of green eating. We don't want to ask whether you agree or disagree with each statement. Instead we want to ask, HOW IMPORTANT each statement TO ME and MY decision about whether or not to eat green.

For each of the following statements, how important is it for me that...?

nd the health of

Eating green can be a hassle

Eating green is not practical in my life right now

Eating green is one way to improve my own health and the health of the planet

Worrying about small farmers is not worth the time

Eating foods labeled fair trade will help the ethical treatment of the food producers

As climate change proceeds, my food choices won't make a difference anyhow

Green eating is worth the extra effort

Overfishing is not a problem

Growing my own food can save me money

My food purchases will not affect the treatment of workers

Growing my own food is not practical where I live

Growing my own food can be a way to relieve stress

Eating green can be too expensive

Buying local is not practical from where I live

By eating green, I can help protect the planet

Eating green would be too difficult

Page 6 


\section{Green Eating Survey}

17. For each of the following statements, how important is it for me that...?

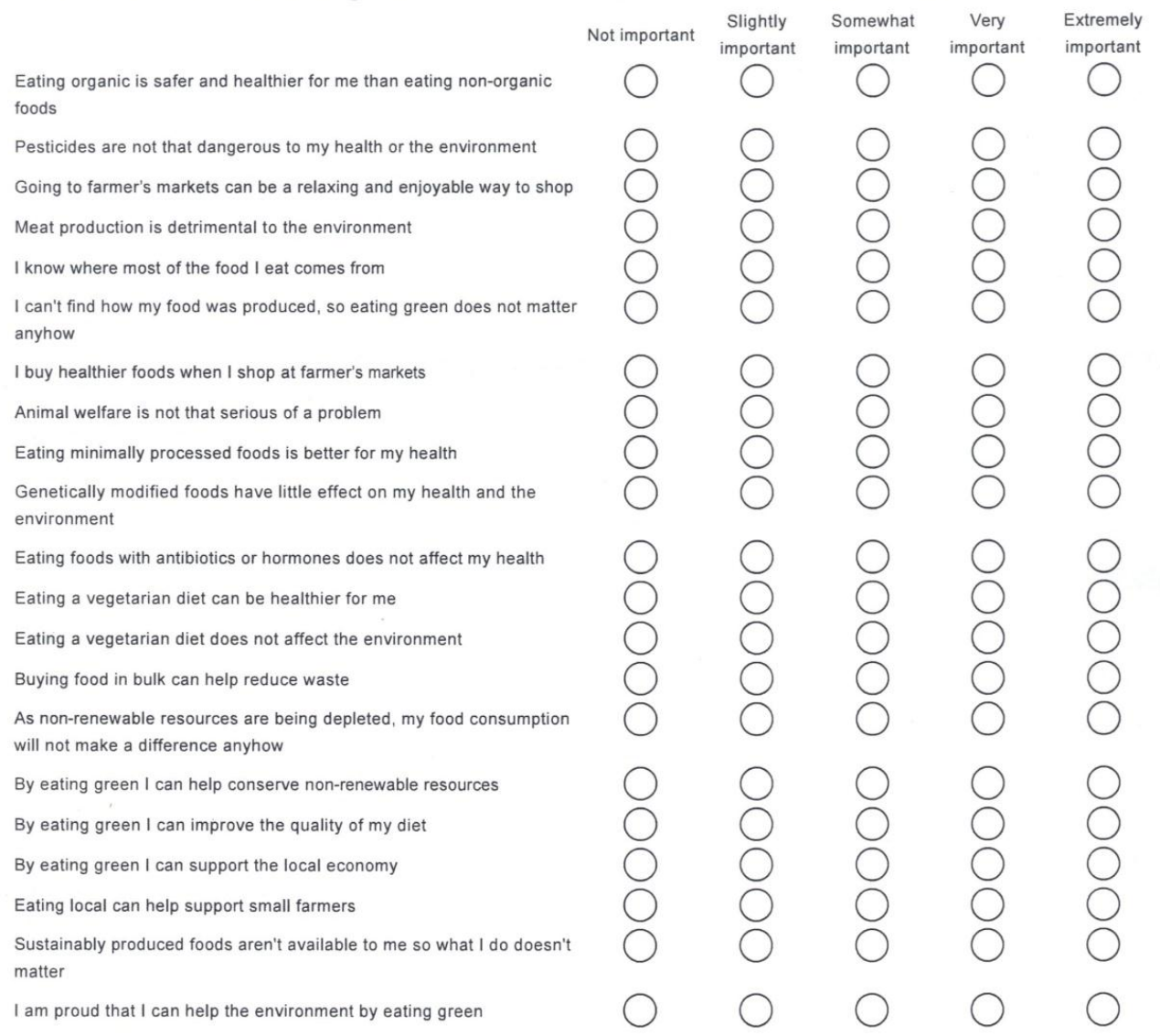

18. Are there other advantages to green eating that you can think of?

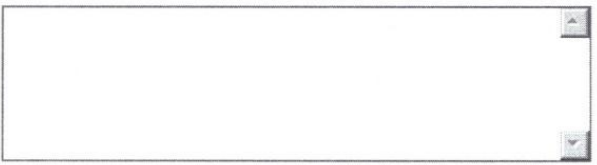

19. Are there other disadvantages to green eating that you can think of? 


\section{Green Eating Survey}

\section{Confidence in Green Eating}

20. Here are some situations that can make green eating more challenging. Green eating means eating locally grown, organic, vegetarian, minimally processed and minimally packaged foods; selecting meats, poultry and dairy that do not contain hormones or antibiotics; and consuming foods and beverages that are fair trade certified. Please rate HOW CONFIDENT you are for each statement below:

How confident or sure are you that you would eat green even when...?

I am busy

I am at school during the semester

When I am at home

It is inconvenien

I think my friends and/or family want me to

When I go out to eat

When I eat in the dining halls

During the winter months

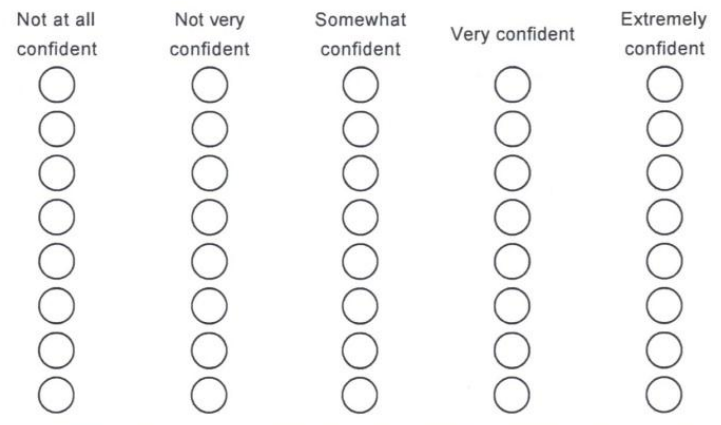

\section{Other}

21. What is your age (in years?

22. What is your gender?

23. Are you Hispanic or Latino? 


\section{Green Eating Survey}

24. Which one or more of the following would you say is your race?

$\square$ White

$\square$ Black or African American

$\square$ Asian

$\square$ Hispanic / Latino

Native Hawaiian or Other Pacific Islander

American Indian or Alaska Native

Other

\section{What is your year in school?}

26. What is your current major?

$\square$ Agricultural Sciences
$\square$ Biological Sciences
$\square$ Business Administration
$\square$ Education
$\square$ Exercise Science/Kinesiology
$\square$ Fine Arts
$\square$ Humanities
$\square$ Nutrition
$\square$ Social Sciences
$\square$ Undeclared
$\square$ Other

\section{Where do you live?}

\section{$\square$}

28. How would you define your current relationship status?

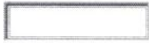

\section{How many children do you have?}

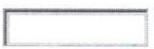

30. What is your...

current weight (in pounds)?

desired weight (in pounds)?

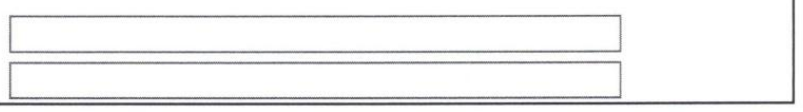

Page 9 
Green Eating Survey

31. How do you describe your weight?

32. Are you trying to do any of the following about your weight?

33. Are you a vegan?

34. Are you a vegetarian?

$\square$ 


\section{Appendix Q}

\section{Car Calories Survey}

\section{*1. INFORMED CONSENT}

West Virginia University

Davis College of Agriculture, Natural Resources \& Design

Division of Animal \& Nutritional Sciences

Human Nutrition

You have been invited to take part in a research project described below. The researcher will explain the project to you in detail upon request. You should feel free to ask questions either in person or by e-mail at melissa.olfert@mail.wvu.edu. If you have quesitons later, Professor Melissa Olfert, the person mainly responsible for this study, 304-293-1918, will discuss them with you.

\section{PURPOSE OF STUDY:}

You are invited to participate in this survey to help identify how often people consume calories while traveling. By car calories, we mean any food or drink consumed while inside a motor vehicle, whether moving or still.

\section{CAN I PARTICIPATE?}

You must be:

- 18 to 24 years old

- A full-time undergraduate student

You must not be:

- A current nutrition, excercise physiology and/or health promotion major

\section{WHAT WILL I BE ASKED TO DO?}

You will be asked to complete an online survey. It takes about 5-7 minutes to complete.

\section{WHAT DO I GET OUT OF IT?}

You will receive a $\$ 5$ bill or giftcard.

\section{RISKS}

Except for your time and incovenience, the risk to you is minimal. There may be minimal risk of data being intercepted during the completion and transmission of the online 


\section{Car Calories Survey}

surveys. This risk will be reduced by using an encrypted transmission for online surveys.

\section{VOLUNTARY}

Participation is voluntary. You may refuse to answer any questions that are part of the survey by selecting "Choose not to answer". You may decide not to participate or to stop participation at any time. You are encouraged to contact the study coordinator should you decide not to continue your participation in this study.

\section{CONFIDENTIALITY}

The project's research records may be reviewed by the departments at West Virginia University responsible for regulatory and research oversight.

All information that you provide, either online or in person, will be kept on a secured hard drive or locked in file cabinets for $\mathbf{5}$ years and then destroyed. All contact information will be securely stored on-site in the researcher's office in the Department of Animal \& Nutritional Sciences (G016 Agricultural Sciences Bldg.) Morgantown, WV.

The online survey you will fill out will be stored in a database on the secured server. To secure data and maintain confidentiality, an https encrypted website is being used for this study. Your confidentiality will be maintained to the degree permitted by the technology used. Specifically, no guarantees can be made regarding the interception of data sent via the Internet by any third parties.

When data are presented for scientific purposes, data will be reported in summary format, and no names will be used.

This study has been approved by the Institutional Review Board (IRB) at West Virginia University on 11/18/2011.

Thank you for your time and interest in the study!

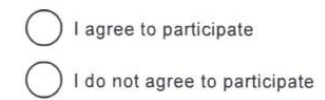

In the last week, how many times did you eat or drink (not including water or other non-caloric drinks, such as diet soda, tea/coffee without sugar, milk or creamer) in your car/personal vehicle or other public transport? 


\section{Car Calories Survey}

*2. Car/truck/van/SUV

O

$1-3$

$4-6$

1-10

$11-14$

$15-19$

$20+$

*3. Other Public Transport

0

1-3

4-6

$7-10$

11-14

15-19

$20+$

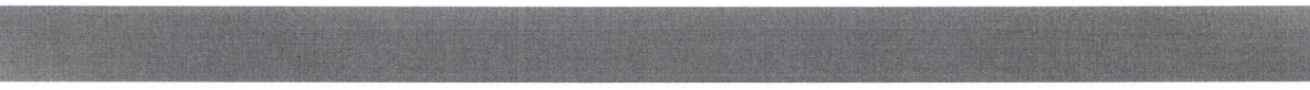

If answering 0 to both of the above questions (Go to question 22).

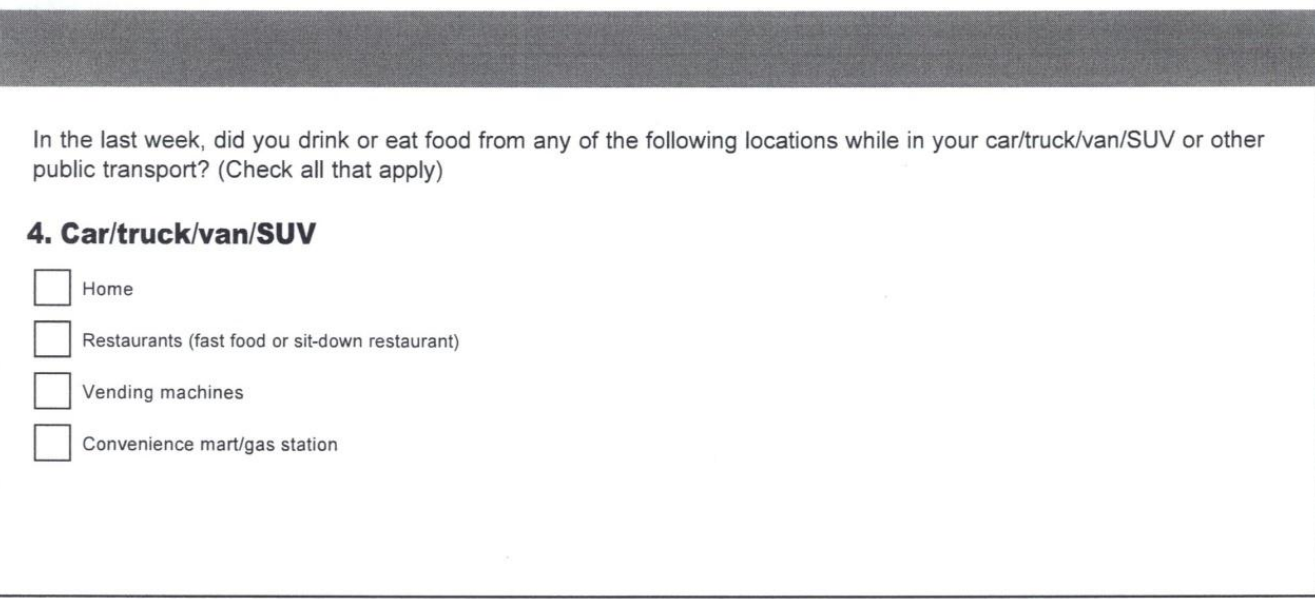

Page 3 


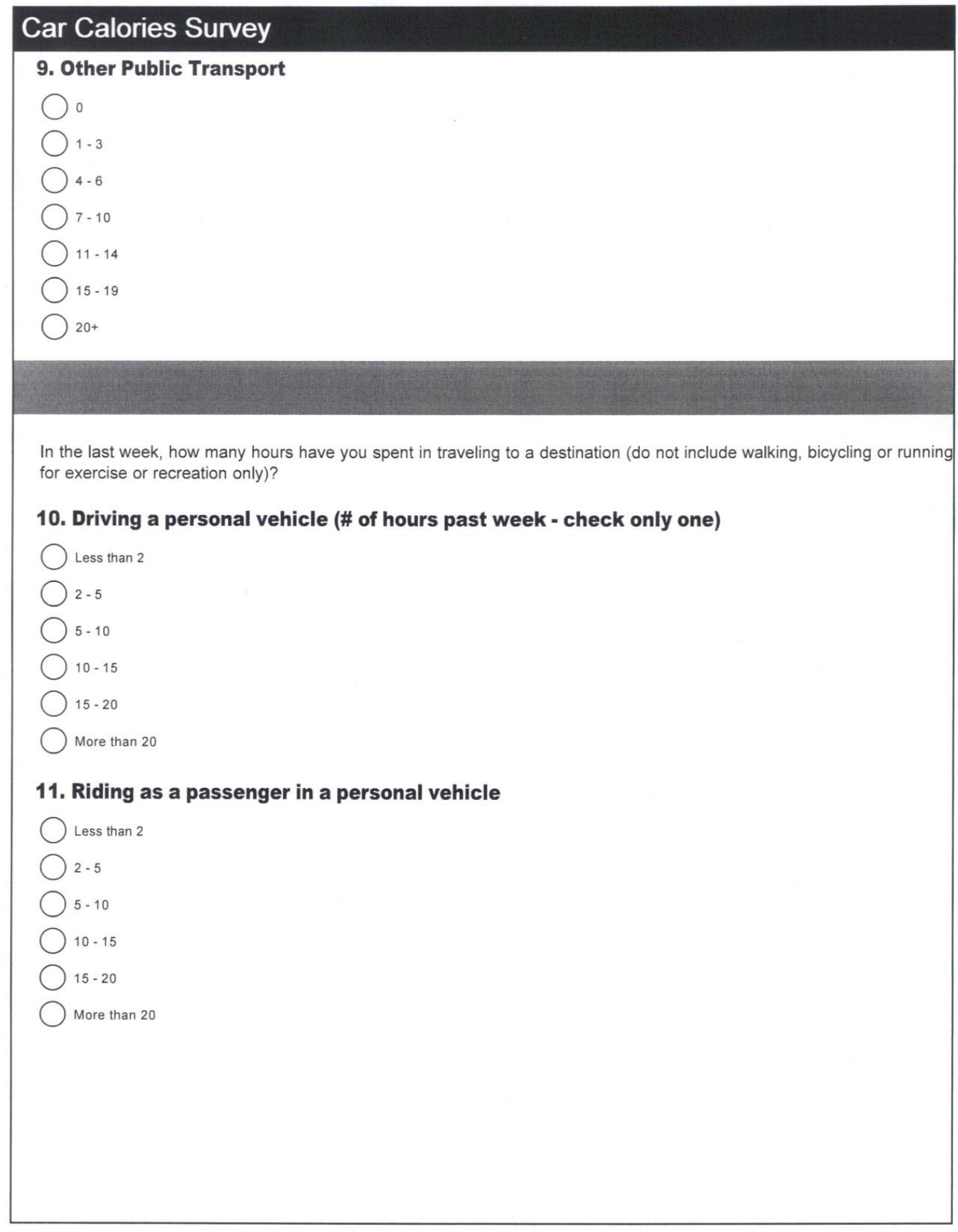

Page 5 


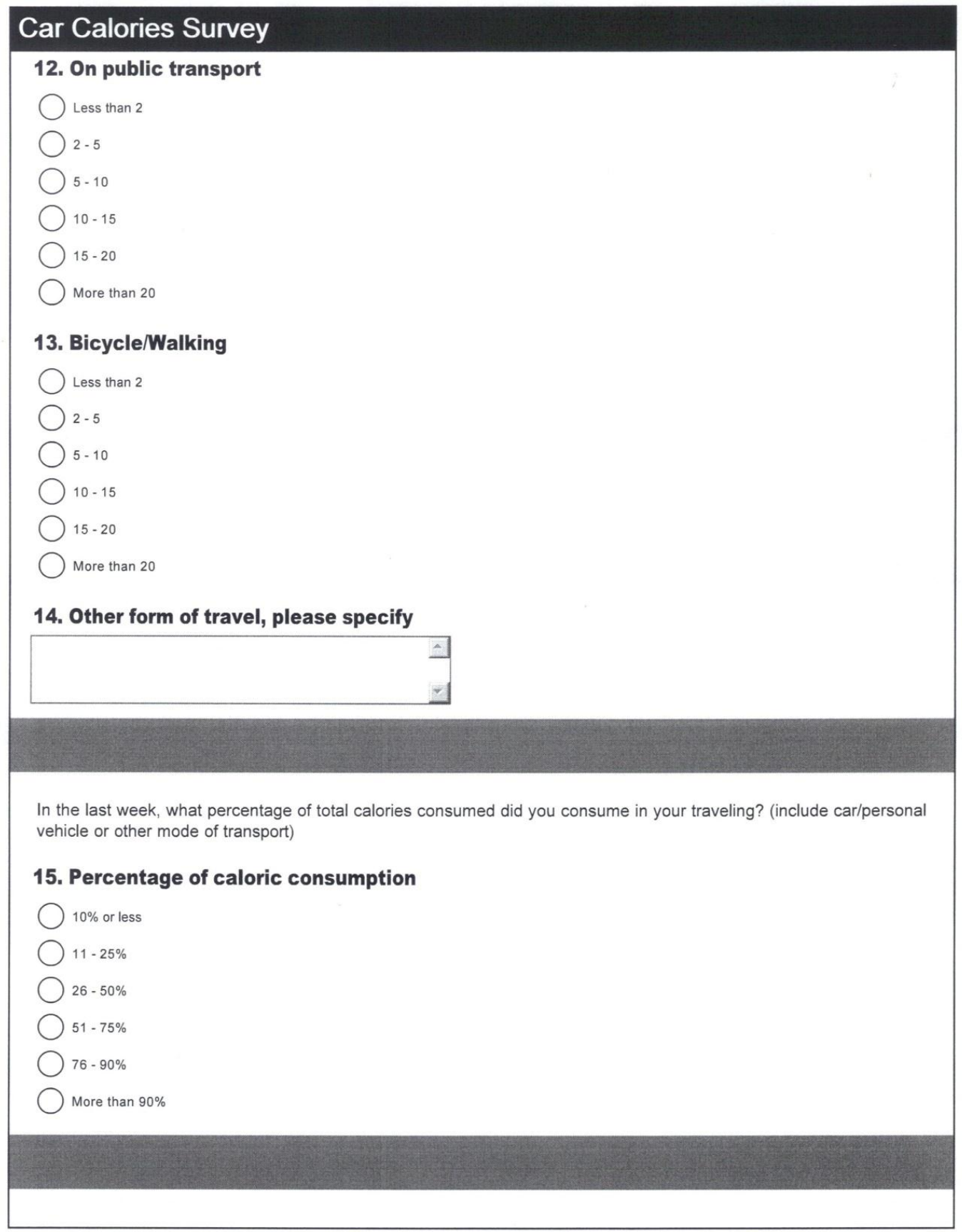

Page 6 


\section{Car Calories Survey}

5. Other, please specify

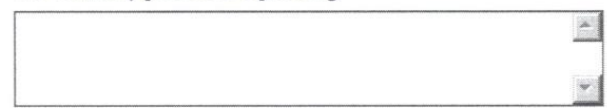

6. Other Public Transport

$\square$ Home

Restaurants (fast food or sit-down restaurant)

Vending machines

Convenience mart/gas station

\section{Other locations, please specify}

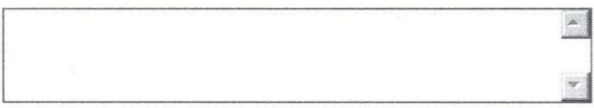

In the last week, how many 12-ounce caloric beverages or "full sugar beverages" did you drink while in your car or other mode of transportation? (one can is 12 ounces; 2 liter bottle is five (5) 12 ounce servings) (Full sugar beverages include soda, juice, sweet tea, lemonade, juice drinks, sports drinks, power drinks, milk, flavored milk, yogurt drinks, etc.)

\section{Car/truck/van/SUV (\# of 12 oz sugar drinks/past week - check only one)}
0
$1-3$
$4-6$
7-10
11-14
15-19
$20+$ 


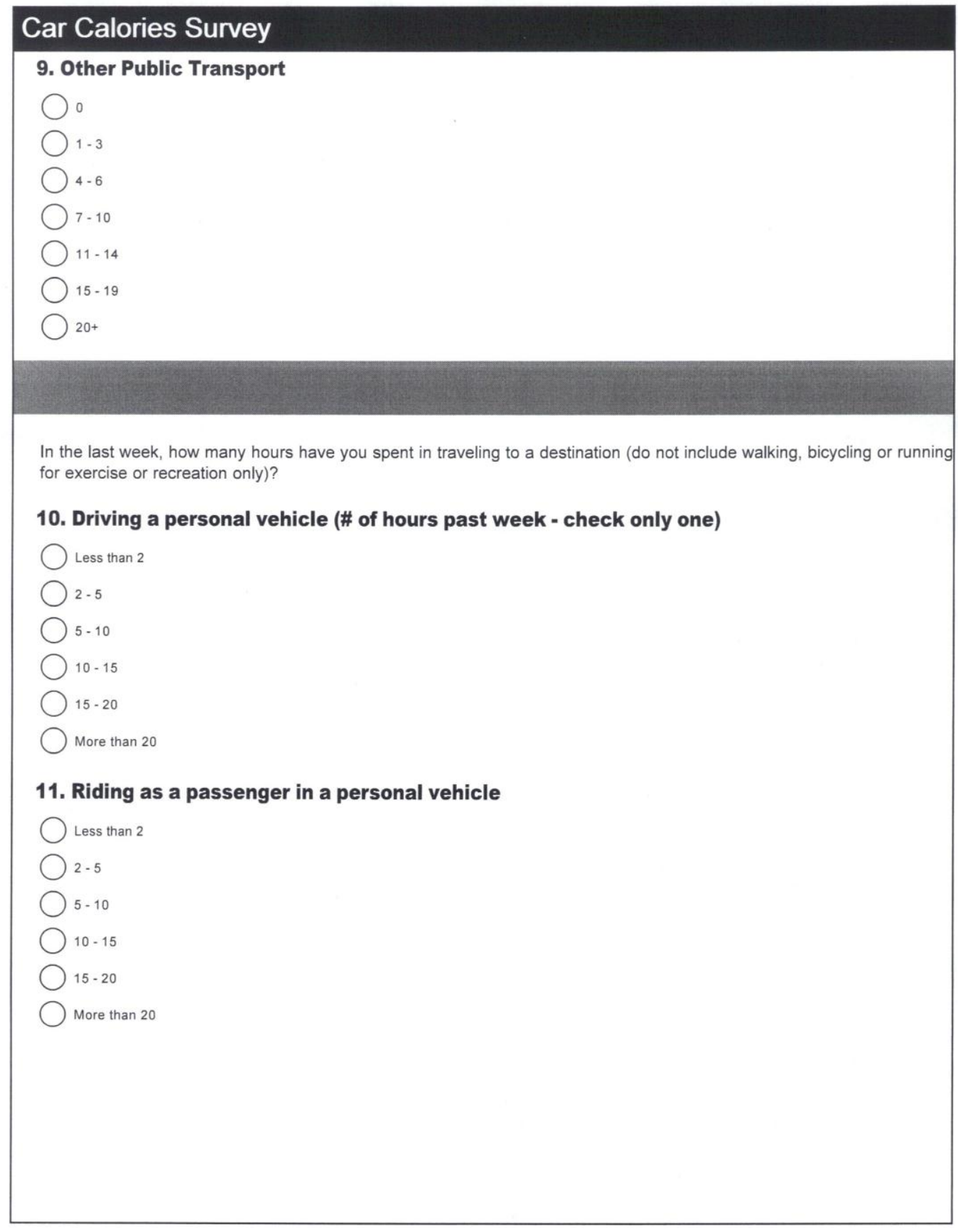

Page 5 


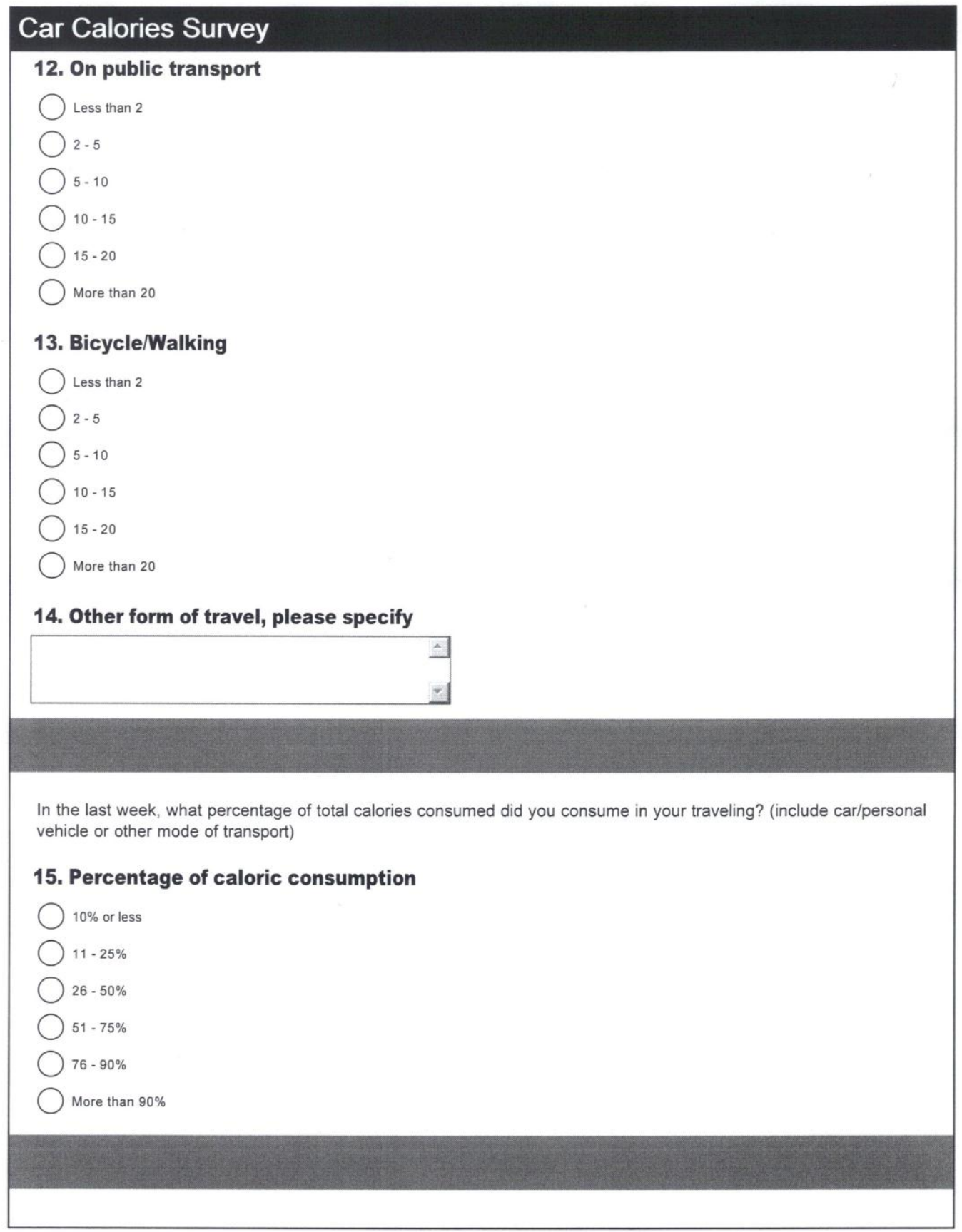

Page 6 


\section{Car Calories Survey}

In the last 24 hours, what percentage of calories did you consume in your traveling (include car/personal vehicle or other transport)?

\section{Percentage of caloric consumption}

$10 \%$ or less

○ $11-25 \%$

$26-50 \%$

○1 $51.75 \%$

○ $76-90 \%$

More than $90 \%$

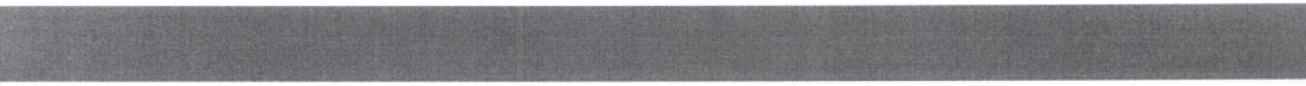

Questions 16 - 21 pertain only to your car or personal vehicle (DO NOT include public or other transport travel)

17. If there were other people with you in your car or personal vehicle, were you

More likely to eat

Less likely to eat

No effect

18. If there were children with you in your car or personal vehicle, were you

More likely to eat

Less likely to eat

No effect

19. In the last week, what were you typically doing while you ate in your car or personal vehicle? (Check all that apply)
$\square$ Driving
Passenger
Parked while eating

20. Other, please specify

-




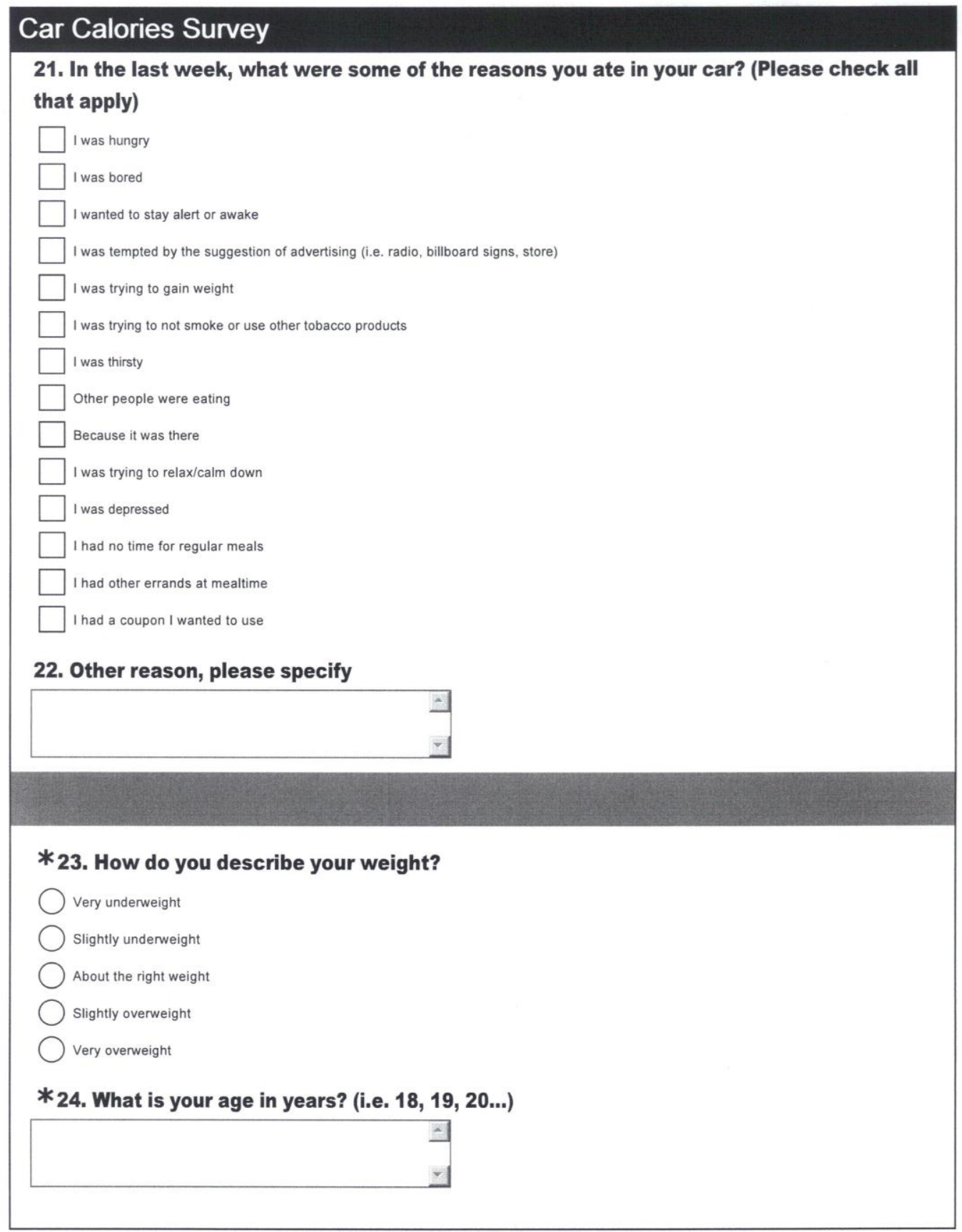




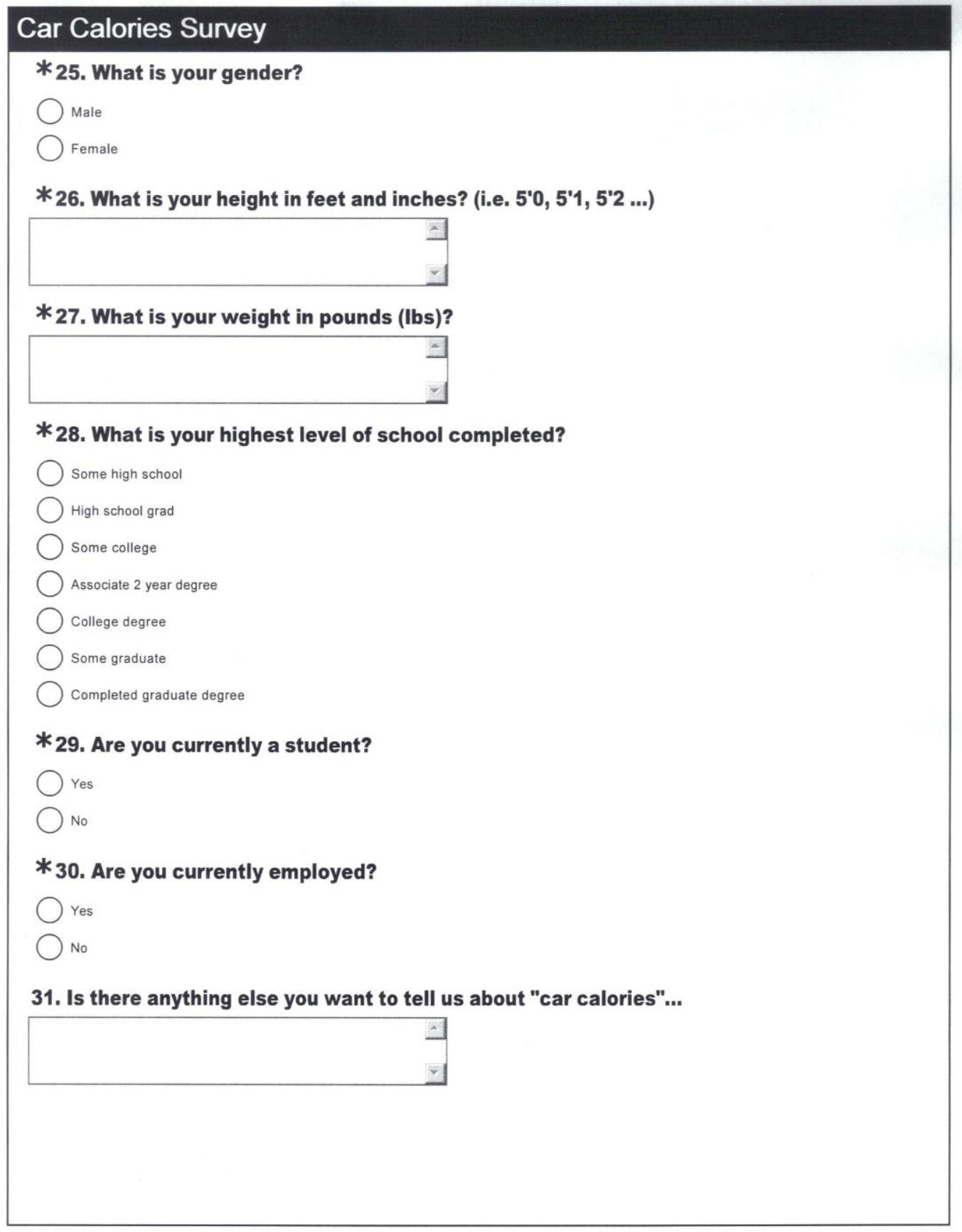

